Drug Metabolism Reviews

\title{
The importance of drug metabolites synthesis: the case-study of cardiotoxic anticancer drugs
}

\section{Ivanna Hrynchak, Emília Sousa, Madalena Pinto \& Vera Marisa Costa}

To cite this article: Ivanna Hrynchak, Emília Sousa, Madalena Pinto \& Vera Marisa Costa (2017): The importance of drug metabolites synthesis: the case-study of cardiotoxic anticancer drugs, Drug Metabolism Reviews, DOI: 10.1080/03602532.2017.1316285

To link to this article: http://dx.doi.org/10.1080/03602532.2017.1316285

Accepted author version posted online: 10 Apr 2017.

Submit your article to this journal $\asymp$

View related articles $\asymp$

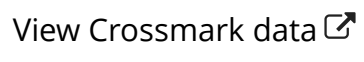




\section{The importance of drug metabolites synthesis: the case-study of cardiotoxic anticancer drugs}

Ivanna Hrynchak $^{1}$, Emília Sousa $^{1,2 *}$, Madalena Pinto $^{1,2}$, Vera Marisa Costa $^{3}$

1 Laboratório de Química Orgânica e Farmacêutica, Departamento de Ciências Químicas, Faculdade de Farmácia, Universidade do Porto, Rua Jorge Viterbo Ferreira 228, 4050-313, Porto, Portugal.

2 CIIMAR - Centro Interdisciplinar de Investigação Marinha e Ambiental, Avenida General Norton de Matos, S/N, 4450-208 Matosinhos, Portugal.

3 UCIBIO, REQUIMTE (Rede de Química e Tecnologia), Laboratório de Toxicologia, Departamento de Ciências Biológicas, Faculdade de Farmácia, Universidade do Porto *corresponding author, e-mail: esousa@ff.up.pt 


\title{
The importance of drug metabolites synthesis: the case-study of cardiotoxic anticancer drugs
}

\begin{abstract}
Anticancer drugs are presently guarantying more survivors as a result of more powerful drugs or combinations of drugs used in therapy. Thus, it has become more crucial to study and overcome the side effects of these therapies. Cardiotoxicity is one of the most relevant side effect on the long-term cancer survivors, because of its high social and economic impact. Drug metabolism can result in active metabolites or toxic metabolites that can lead to important side effects. The metabolites of anticancer drugs are possible culprits of cardiotoxicity; however, the cardiotoxicity of many of the metabolites in several drug classes was not yet suitably studied so far. On the other hand, the use of prodrugs that are bioactivated through metabolism can be a good alternative to obtain more cardio safe drugs. In this review, the methods to obtain and study metabolites are summarized and their application to the study of a group of anticancer drugs with acknowledged cardiotoxicity is highlighted. In this group of drugs, doxorubicin (DOX, 1), mitoxantrone (MTX, 2), cyclophosphamide (CTX, 3), and 5-fluorouracil (5FU, 4) are included, as well as the tyrosine kinase inhibitors, such as imatinib (5), sunitinib (6), and sorafenib (7). Only with the synthesis and purification of considerable amounts of the metabolites can reliable studies be performed, either in vitro or in vivo that allow accurate conclusions regarding the cardiotoxicity of anticancer drug metabolites and then pharmacological prevention or treatment of the cardiac side effects can be done.
\end{abstract}

Keywords: Anticancer drugs; Cardiotoxicity; In vitro models; Metabolites; Metabolites synthesis. 


\section{List of Abbreviations:}

ALDH - Aldehyde dehydrogenase

CAP - Capecitabine

CML - Chronic myelogenous leukaemia

CTX - Cyclophosphamide

CYP - Cytochrome

Cyd deaminase - Cytidine deaminase

DPD - Dihydropyrimidine dehydrogenase

dThdPhase - Thymidine phosphorylase

DOX - Doxorubicin

DOXol - Doxorubicinol

5-dFCyd - 5-deoxy-5-fluorocytidine

5-dFUrd - 5-deoxy-5-fluorouridine

FBAL $-\alpha$-Fluoro- $\beta$-alanine

FLT3 - Fams-like tyrosine kinase-3

FDA - Food and Drug Administration

FUPA - $\alpha$-Fluoro- $\beta$-ureidopropionic acid

5-FU - 5-Fluoruracil

5-FdUMP - Fluorodeoxyuridine monophosphate

5-FUTP - Fluouridine triphosphate

5-FdUTP - Fluorodeoxyuridine triphosphate

5-FUMP - 5'-Fluorouridine-5' -monophosphate

5-FUDP - 5-Fluorouridine-5' -diphosphate

5-FdUDP - 5-Fluoro-2'-deoxyuridine-5'-diphosphate

5-FUH2 - 5,6-Dihydro-5-fluorouracil

GST - Glutathione S-transferase

$\mathrm{h}$ - hours

JNK - Jun $N$-terminal kinase

MTX - Mitoxantrone

NADPH - Nicotinamide adenine dinucleotide phosphate

NAT - N-acetyl transferase

PDGFR - Platelet-derived growth factor receptors

RARG - Retinoic acid receptor gamma

ST - Sulphotransferases

TKIs - Tyrosine kinase inhibitors

TOP - Topoisomerase 
VEGFRs - Vascular endothelial growth factor receptors

\section{Introduction}

During the drug development process, a selected drug candidate is thoroughly evaluated regarding the information of its metabolic pathway and pharmacokinetics. This information is required by regulatory agencies to better assess the safety of a drug candidate before it can be approved (Lin and Lu, 1997). Over time in the drug development process, many regulatory guidelines have chosen to incorporate metabolites on their safety evaluation guidelines (Baillie et al., 2002) mainly because of putative active/toxic metabolites formation. In fact, many drugs can give rise to one or more metabolites with biological activity (Lin and $\mathrm{Lu}, 1997)$. It should be noted that to the pharmaceutical researchers and regulatory agencies, the patient's safety is of paramount concern, especially if metabolites are suspected to be reactive and toxic (Luffer-Atlas, 2008).

Concerning toxicity, the early information on human metabolism of a new drug is essential to foresee the potential clinical drug-drug interactions and to select the appropriate animal species where those drugs are to be tested in pre-clinical studies. Regulatory agencies require human risk assessment to show that the systemic exposure of an unchanged drug and its major metabolites do not exceed the safety margin. Ideally, the metabolite profile of a drug obtained in vitro should generally mimic the in vivo metabolite pattern; however, in vitro models have limitations. Therefore, the comparison between animal and human metabolism should be performed in the early stage of the drug development process (Lin and Lu, 1997).

Different enzymes catalyse different steps of the metabolic pathways and these enzymes catalyse the biotransformation of xenobiotics, including drugs used in the clinical practice. Drug metabolism is usually divided in two phases: phase I or functionalization reactions and phase II or conjugation reactions. Phase I metabolism includes oxidation, reduction, hydrolysis, and hydration reactions. The cytochrome (CYP) P450 system has a major role in the phase I reactions. The functionalization step usually transforms a drug into a more soluble and easier to eliminate drug. The phase II reactions or conjugation reactions include glucuronidation, sulfation, amino acid conjugation, acetylation, methylation, or glutathione conjugation and they usually facilitate elimination (Gibson and Skett, 2001).

As stated, the drug metabolism/biotransformation can lead to pharmacological activation or inactivation (Scheme 1). When metabolism results in the pharmacological 
activation with formation of pharmacologically active metabolites, a process of bioactivation occurs. Fura et al. defined an active metabolite, as "a pharmacologically active metabolic product with activity against the same pharmacological target as the parent molecule". This concept of active metabolite differs from the definition of reactive metabolites that correspond to chemically reactive intermediates formed during metabolism. These reactive intermediaries, when bound to biomolecules via covalent bonds, may elicit toxicity. Parameters, such as the contribution to the total pharmacological activity of a given dose of the parent compound, its intrinsic activity, and the relative concentration at the action site, measure the importance of a particular active metabolite (Fura et al., 2004). Regarding the pharmacokinetic data, the mechanisms of distribution and clearance of active metabolites are often differ from the parent drug. Therefore, to predict the therapeutic outcome and explain the toxicity of specific drugs, it is important to understand the kinetics of the formation of an active metabolite (Lin and $\mathrm{Lu}, 1997)$.

Metabolites can be synthesized and tested in appropriate models if they are suspected to elicit a pharmacological or toxicological effect. Some novel drugs have been discovered during metabolite characterization of drug candidates, namely in the case of paliperidone, the active metabolite of the antipsychotic risperidone, and desvenlafaxine, the active metabolite of the antidepressant venlafaxine, among others (Obach, 2013). In fact, some of these new compounds may be better drug candidates in terms of safety and effectiveness than their parent compounds since they may have characteristics such as better extent of delivery, disposition kinetics, clearance, lower interindividual variability, and/or less potential for accumulation (Liu and Jia, 2007, Obach, 2013).

Another biotransformation process important in the drug discovery process is associated with the prodrug design. A prodrug can be defined as a pharmacologically inactive drug that turns into a pharmacologically active form, after in vivo administration. This transformation can occur either by metabolism or by spontaneous chemical breakdown (Rautio et al., 2008). Targeted prodrug approach is one of the new trends in the treatment of cancer. An ideal prodrug is a drug that increases the bioavailability, eliminates undesirable side effects and enhances the half-life of drugs. Prodrugs of anticancer agents are usually designed to be organ-specific and tumour-specific targeting. An alternative strategy used to achieve the activation site is the use of enzyme immunoconjugates towards antigens expressed on tumours cells and therefore the drug can target the tumour site more precisely (Rooseboom et al., 2004). 
The aim of this review is to highlight the importance of the metabolites of various anticancer drugs including conventional chemotherapy agents such as doxorubicin (DOX, 1), mitoxantrone (MTX, 2), cyclophosphamide (CTX, 3), 5-fluorouracil (5-FU, 4), imatinib (5), sunitinib (6) and sorafenib (7), since they can be directly involved in the cardiotoxicity of these anticancer drugs (Figure 1). In vitro and in vivo studies are performed to discover the metabolite pattern of a given drug. However, the use of conventional in vitro and in vivo studies may not be sufficient to fully explore all compounds for a full chemical and biological characterization of the metabolic profile of a given drug, so one has to resort to other methods. Those methods may include classical semi-synthesis, total synthesis or biomimetic approaches with metabolic enzymes. Herein, studies related with the biological characterization and the syntheses of anticancer metabolites (1-7) are detailed. To improve their pharmacokinetic and pharmacodynamic features, other derivatives such as prodrugs have been studied; therefore, this information is also gathered in this case-study to highlight the potential benefits of the prodrug design of anticancer drugs.

\section{Scheme 1}

Figure 1

\section{In vitro and in vivo methods to study metabolism}

In vitro and animal in vivo studies are performed in the pre-clinical stage to assess the toxicity of a drug and the metabolite profile before the drug goes into human clinical trials. This thorough evaluation is done in order to avoid failures and serious toxicity later on in the drug development process (Gunaratna, 2000). Early in vivo investigations should assess the main metabolic routes (Industry, 2006) and the pharmacokinetic parameters of the most prominent compounds selected from in vitro studies (Gunaratna, 2000).

In vitro studies are suited to determine the potential drug-drug interactions in clinical trials. Food and Drug Administration (FDA) guidelines suggest first the use of in vitro studies to assess the effect of the drug on the metabolic pathways. If the results indicate possible drug-drug interactions, in vivo assays will follow. The main goal of the pre-clinical studies is to predict the in vivo outcome in humans. However, despite of the improvement of in vitro assays, the general consensus is that in vitro models are too simplistic to completely replace in 
vivo studies (Gunaratna, 2000). We can usually assume that potential clinical risks of the parent drug and its metabolites have been adequately investigated during nonclinical studies when the metabolite profiling of a parent drug is similar qualitatively and quantitatively across species, based on the data obtained from in vitro and in vivo metabolism studies (Liu and Jia, 2007).

The in vitro studies during pre-clinical screening are often low-throughput systems. It is now possible to better predict the potential drug-drug interactions before clinical trials since there is a greater availability of human tissues and recombinant enzymes. In vitro metabolic studies have two major goals: identifying the major metabolic pathways of the drug and its metabolites, and exploring the effect of the test drug on the metabolism of other drugs. In addition, these studies may help to determine that a particular drug is not a substrate for certain metabolic pathways. The data obtained allows reducing or even eliminates the need to study the possible inhibitory effects of that drug on other drugs metabolized by that particular pathway. The first in vitro metabolic system used to study drug metabolism involves hepatic enzymes or tissue preparations (Gunaratna, 2000) because liver is the main organ responsible for the biotransformation of xenobiotics. Even so, other organs are also involved in drug biotransformation (Asha and Vidyavathi, 2010), but they will not be reported here for systematic purposes. The metabolites formed in the liver can, through blood distribution, reach most of the organs, namely the heart, where they can exert their effects. In vitro studies can give information about the metabolite's stability, profile and identification; they will allow interspecies comparisons, toxicology species selection, CYP induction/inhibition and drug/drug interaction studies, CYP isoform identifications and phase II enzyme studies (Gunaratna, 2000). Several in vitro human liver models have been developed, including: supersomes, cytosol, cell lines, transgenic cell lines, microsomes, isolated hepatocytes, tissue slices, S9 fractions, and isolated perfused liver (Table 1). All of these models, with the exception of primary hepatocytes, cell lines, liver slices, and isolated perfused liver require exogenous cofactors to attain the maximum enzymatic activity (Asha and Vidyavathi, 2010). The following table 1 summarizes most of the in vitro models used in metabolism studies.

\section{Table 1}

As stated, as part of the drug development process, pharmaceutical companies are required by regulatory agencies to study the metabolism of a given drug candidate. It is a part of the preclinical absorption-distribution-metabolism-excretion-toxicity (ADMET) studies, 
which are usually performed in vivo using animal models like rat, mice, dog, and monkey (Industry, 2006). The pharmacokinetic evaluation after multiple dosing can also be evaluated to identify potential auto induction. Moreover, even when two drugs share a common metabolic pathway, it may not lead to clinically significant pharmacokinetic interactions when co-administered to a patient. Whether the two co-administered drugs will interact in humans will depend on various factors, including the relative affinities of each drug for the binding site on the metabolizing enzyme as well as the effective free drug concentration available locally for binding. However, a small pharmacokinetic interaction can result in significant pharmacodynamic adverse effects, especially for drugs with narrow therapeutic index (Bjornsson et al., 2003).

In vivo drug metabolism studies to assess distribution and disposition of major metabolites and the human unique metabolites are usually done by evaluating the metabolite profiling in blood, selected tissues, urine, and bile. In many cases, metabolites can be easily found in other biological matrices than blood, such as excreta (Liu and Jia, 2007). FDA guidance defines major metabolites as those identified in human plasma that account for more than $10 \%$ of the drug related material (administered dose or systemic exposure, whichever is lower) (Industry, 2005).

The evaluation of urine, faeces, and expired air (if the drug and its metabolites are expected to be exhaled) from treated animals should use appropriate qualitative and quantitative methods. In metabolites detected in animals as well as in humans, adequacy of systemic exposure should be assessed by the evaluation of area under the curve (AUC), in plasma or serum. The AUC includes both the plasma concentration of the drug candidate and the residence time in vivo (Liu and Jia, 2007).

Pharmacovigilance studies in the later phase of the clinical drug development are valuable as a complement to test efficacy/safety. For some drugs, differences in drug safety and efficacy may be caused by genetic polymorphisms in drug metabolizing enzymes, drug transporters, or drug receptors. It is known that five CYP P450 enzymes - CYP1A2, 2C9, 2C19, 2D6, and 3A4 - are responsible for metabolizing most commercially available drugs. The CYP3A4 enzyme accounts for the biotransformation of $50 \%$ of these drugs. CYP2C9, CYP2C19, and CYP2D6 enzymes account for approximately another $40 \%$ of drug metabolism by CYP P450s and they exhibit high levels of genetic polymorphism (Bjornsson et al., 2003). Cyclophosphamide (CTX, 3) is the anticancer drug addressed in this review that has the greater bulk of data regarding genetic polymorphisms of metabolic enzymes. CTX (3) is a prodrug, thus to exert its antitumour activity, it requires to be metabolic activated by 
hepatic CYP P450 enzymes to form the active alkylating species (Moore, 1991). Moreover, CTX (3) is also metabolized by glutathione S-transferase (GST) and aldehyde dehydrogenase (ALDH) enzymes. Several studies have been performed to determine if genetic polymorphisms of these enzymes may affect the pharmacokinetics of CTX (3) and thereby its toxicity and therapeutic efficacy (Yule et al., 2004, Petros et al., 2005, Ekhart et al., 2008, Jamieson et al., 2014, Veal et al., 2016). The polymorphisms on CYP isoenzymes have extensively researched, mainly CYP2B6, CYP2C19, and CYP3A4. However, contradictory results have been published; some authors state that those polymorphisms can impact the therapy response rate and cancer recurrence (Yule et al., 2004, Petros et al., 2005, Nakajima et al., 2007), while other studies (Ekhart et al., 2008, Jamieson et al., 2014, Veal et al., 2016) observed that pharmacogenetic factors had only a minor or no influence in the treatment response and in future cancer recurrence.

The polymorphism of the metabolic enzymes involved in 5-FU (4) catabolism is also relevant to its effects. Eighty-five percent to $90 \%$ of the intravenous administered 5-FU (4) is rapidly catabolized by hepatic dihydropyrimidine dehydrogenase (DPD). DPD is the initial and ratelimiting enzyme in the pathway that catabolizes the pyrimidines and its polymorphism is related with 5-FU (4) adverse effects or clinical response. There is a strong association between DPD gene polymorphism that leads to a partial DPD activity deficiency and fluoropyrimidine-related toxicity in cancer patients (Gross et al., 2008). Concerning DOX (1) or MTX (2), the polymorphisms of the efflux transporter proteins are more broadly researched and scarce data exist regarding the enzymes involved in their metabolism. Aldoketoreductases are involved in the metabolism of DOX (1) and some genotypes were associated with higher haematological toxicity, longer progression-free survival and overall survival after DOX (1)-based therapy (Voon et al., 2013). Regarding the targeted therapy drugs mentioned herein, the existing data is occasional and new studies need to be perform to better elucidate the influence of genetic polymorphisms of the metabolic enzymes on their toxic effects and also on their clinical efficacy. Data on imatinib (5) generally rules out biotransformation as having a relevant interest to the interindividual variability of drug efficacy, resistance or toxicity (Rochat, 2005, Gardner et al., 2006, Seong et al., 2013). Nevertheless, information on imatinib (5), shows that polymorphism of CYP3A5*3 was been associated with lower resistance to treatment in Malaysian chronic myeloid leukaemia patients (Maddin et al., 2016). Studies on sorafenib (7) show that polymorphisms on uridine glucuronosyl transferases (UGT), namely of UGT1A1 and UGT1A9, lead to abnormally high area under the curve in treated-patients (Peer et al., 2012). 
Although the liver is the most important drug metabolizing organ, the gut is also very important in the biotransformation of the drugs. Moreover, for orally administered drugs, the enzymes in the gut wall provide an important and highly sensitive site for drug interactions and drug biotransformation. The main intestinal biotransformation enzymes responsible for phase I reactions include CYP, esterases, epoxide hydrolase and alcohol dehydrogenase, and for phase II reactions glucosyltransferases, sulfotransferases (ST), N-acetyl-transferases (NAT), and GST (Liu and Jia, 2007).

\section{Anticancer drugs and metabolites}

Chemotherapy-induced cardiotoxicity is a major limitation to the effective use of several anticancer drugs. These include both conventional chemotherapy and targeted therapy agents, with anthracyclines being the most extensively studied group. Anthracyclines and their metabolites cause a progressive heart failure and, consequently can result in cardiac death (Maharsy, 2015). The next section describes cytotoxic drugs used to treat cancer, DOX (1), MTX (2), CTX (3), and 5-FU (4) and their metabolites, since in the published data those metabolites may have an important role in the induced-cardiotoxicity of these drugs.

\section{Conventional cytotoxic drugs}

The chemotherapeutic agents used to treat cancer in children and adults can cause a wide spectrum of short- and long-term cardiotoxic effects. Those effects can result, at the worst case scenario on cardiac transplantation or death (Raj et al., 2014). In particular, anthracyclines like DOX (1), the most widely prescribed chemotherapeutic in children, (Smith et al., 2010, Lipshultz et al., 2013) MTX (2), CTX (3), 5-FU (4), and taxanes show superior antitumour activity in many solid or hematologic malignancies (Menna et al., 2012). However, anthracyclines induce off-target cardiotoxicity that may progress to dilated cardiomyopathy and systolic heart failure (Lipshultz et al., 2013, Salvatorelli et al., 2015). The cardiomyopathy risk is anthracycline cumulative dose-dependent. Cumulative dose of $400-450 \mathrm{mg}$ of $\mathrm{DOX} / \mathrm{m}^{2}$ or superior can be cause a direct cardiotoxic insult that eventually can progress toward symptomatic cardiac events (Menna et al., 2012). Even so, cardiotoxicity has been detected in lower life time cumulative doses (Menna et al., 2012, Raj et al., 2014). 
DOX (1) is able of DNA intercalation and topoisomerase 2 (Top2) inhibition. As a result, RNA and DNA polymerases activity is impaired and, consequently, they cause DNA strand scission and interfere with cell replication leading to cell death (Raj et al., 2014).

Anthracyclines-induced cardiomyopathy by generation of excess reactive oxygen species (ROS) is the most widely accepted hypothesis to explain their cardiotoxicity. ROS are formed by electron exchange between the anthracycline quinone moiety and oxygen molecules and other cellular electron donors. In addition, anthracyclines can also generate ROS through the formation of complexes with iron and then undergo redox cycling (Menna $e t$ al., 2012, Raj et al., 2014, Vejpongsa and Yeh, 2014). In fact, the classical notion regarding DOX (1)-induced cardiotoxicity is that its redox cycling with quinone formation and cardiac oxidative stress (Costa et al., 2013, Sawyer 2013) promotion are responsible for its cardiotoxicity. Recently, it was found that human induced pluripotent stem cell-derived cardiomyocytes (hiPSC-CMs) of patients that showed DOX (1)-induced cardiotoxicity had substantially lower levels of basal metabolism and mitochondrial content, along with decreased cell viability, impaired calcium handling, decreased antioxidant activity, and increased ROS production. Therefore, those cells are possible biomarkers to the future cardiotoxicity induced by DOX (1) (Burridge et al., 2016). Moreover, exciting new facts regarding DOX (1)-induced cardiotoxicity have been recently published (Zhang et al., 2012, Aminkeng et al., 2015). There are two cellular Top2 enzymes: Top2 $\alpha$ and Top2 $\beta$, and DOX (1) inhibits both. Top2 $\alpha$ is overexpressed in tumour cells while adult mammalian cardiomyocytes express Top2 $\beta$. Zhang et al. (2012) showed that cardiomyocyte-specific deletion of Top2 $\beta$ protects mice of DOX (1)-induced progressive heart failure. The authors suggested that DOX (1) inhibition of Top2 $\beta$ activity impairs mitochondrial biogenesis and leads to oxidative stress. Moreover, a genetic variant of Retinoic Acid Receptor Gamma $(R A R G)$ has been associated in humans with increased cardiotoxicity after anthracycline regiments in children subjected to anthracycline treatments. RARG was found to repress Top $2 b$ expression (Aminkeng et al., 2015), thus further corroborating Top2 $\beta$ involvement in the cardiotoxicity promoted by anthracyclines. 


\section{Doxorubicin (DOX)}

DOX (1) (former generic name, adriamycin), the most commonly used anthracycline, has been used since the late 1960s to treat solid and hematologic malignancies. DOX (1) is used in the treatment of breast cancer, lymphomas, myelogenous or lymphoblastic acute leukaemia's, and osteosarcoma (Maharsy, 2015). DOX (1) displays extensive tissue uptake, high volume of distribution, and reasonable plasma protein binding; it is administered intravenously and it is highly metabolized, and is excreted via bile (50\%) and urine (5-12\%). In bile, about $30 \%$ is excreted in form of conjugates, although their structures were not yet elucidated (Crombag et al., 2016).

Doxorubicinol (DOXol, 8) (Scheme 2) is formed from DOX (1) by a two-electron reduction of the side chain at $\mathrm{C}-13$ carbonyl group of DOX (1) by nicotinamide adenine dinucleotide phosphate (NADPH)-dependent cytoplasmic aldo/ketoses or carbonyl reductases (Menna et al., 2012, Reis-Mendes et al., 2016b). DOXol (8), an alcohol metabolite of DOX (1), has been implicated in the cardiotoxicity observed in DOX (1)-treated patients, largely due to the inhibition of $\mathrm{Na}^{+} / \mathrm{K}^{+}$channels present in the cardiac sarcolemma. DOXol (8) also inhibits the calcium pump of the heart and skeletal muscle and the proton pump of cardiac mitochondria (Boucek Jr et al., 1987, Olson et al., 1988). DOXol (8) is less effective in killing cancer cells but it is more potent than its parent compound in impairing the myocardial cell (Menna et al., 2012, Reis-Mendes et al., 2016b). When DOX (1) is administered, the concentration of DOXol (8) gradually prevails over that of DOX (1) concentration over time, making DOXol (8) the most toxic species at the time when late stage cardiomyopathy is developed (Menna et al., 2012). Inhibition of the aldo/keto reductases that catalyse the reduction results in more DOX (1) to kill cancer cells and less DOXol (8) to compromise cardiac function (Olson et al., 1988); however, cardiotoxicity still persists when DOXol (8) formation is compromised.

Other metabolites can be formed after DOX administration (Scheme 2) like 7hydroxydoxorubicin aglycone (9) by a hydrolytic cleavage and 7-deoxydoxorubicinol aglycone (10) and 7-deoxydoxorubicin aglycone (11) by a reductive cleavage of the glycosidic ring at C-7. Aglycones may be demethylated and conjugated via the sulfate or the glucuronide pathways. Sulfonated (demethyldeoxydoxorubicinol aglycone 4-O-sulfate, 12) and glucuronidated (demethyldeoxydoxorubicinol aglycone 4-O- $\beta$-glucuronide, 13) metabolites have been identified as urinary metabolites, but this biotransformation route seems to be limited to humans (Takanashi and Bachur, 1976, Reis-Mendes et al., 2016b). 


\section{Scheme 2}

A study showed that the aglycones $\mathbf{9 , 1 1}$, and $\mathbf{1 4}$ can be reliably detected and can also significantly contribute to the (cardiac) toxicity of DOX (1) (Joerger et al., 2005). In fact, aglycones are shown to be powerful mitochondrial toxins therefore largely affecting the heart (Reis-Mendes et al., 2016b).

In vitro models to study the metabolism of doxorubicin. Several in vitro models can be used to characterize DOX (1) metabolism. DOX (1) was converted into the corresponding alcohol, DOXol (8), after incubation of the supernatant of rat liver homogenate with DOX (1). Also, the reductive glycosidic cleavage was quite significant when rat liver microsomes were incubated with DOX (1) resulting in the formation of 7-deoxydoxorubicinol aglycone (10) and 7-deoxydoxorubicin aglycone (11) (Weenen et al., 1984).

In a study of 2011, Sharka and colleagues studied the metabolism of anthracyclines in human liver microsomes and demonstrated that for concentrations above $100 \mu \mathrm{M}$, the reduction of DOX (1) to DOXol (8) is not the major metabolic pathway. This is due to the high activity of microsomal hydrolases that leads to increased concentrations of 7 hydroxydoxorubicin aglycone (9) and its reduced metabolite 7-hydroxydoxorubicinol aglycone (14). The microsomal fraction was also responsible for the reduction of the hydrolysed DOX (1) to its 7-deoxydoxorubicin aglycone (11) (Skarka et al., 2011). These reactions may contribute to the resistance of tumour cells against DOX (1) treatment since these metabolites possess a lower cytotoxic ability (Licata et al., 2000).

The metabolism in human cytosol fractions, with high levels of cardiac carbonyl reductases, generates substantial amounts of 7-deoxydoxorubicin aglycone (11) (a product reflecting the reductive cleavage of the glycosidic bond). Moreover, when increasing the concentration of cytosolic proteins the yield of this metabolite also increases. This increase was not accompanied by the formation of the corresponding alcohol metabolite, 7deoxydoxorubicinol aglycone (10), thus suggesting that 7-deoxydoxorubicin aglycone (11) was not a good substrate for cardiac carbonyl reductases. In human cardiac cytosol fractions, DOX (1) is converted to the secondary alcohol metabolite (DOXol, 8) and to a broad panel of 7-hydroxy- or 7-deoxyaglycones: 7-deoxydoxorubicin aglycone (11), 7-hydroxydoxorubicin aglycone (9), and 7-hydroxydoxorubicinol aglycone (14). These metabolites have the 
chemical prerequisites to cause cardiotoxicity and the cardiotoxic potential of these metabolites is influenced by changes in the properties of the anthracycline molecule: deglycosidation decreases the polarity of the anthracycline allowing their faster displacement across in biological membranes. Also, the conversion of DOX (1) to DOXol (8) makes the anthracycline molecule slightly more polar, which favours its retention inside the cardiomyocytes (Licata et al., 2000).

Minotti et al. performed experiments in cytosolic fractions of human myocardium obtained during bypass surgery (Minotti et al., 1995, Minotti et al., 2000). This model provides an ethically acceptable system for predicting the formation metabolites in the human heart (Minotti et al., 2000) and avoids potential pitfalls, since studies in laboratory animals are heavily influenced by species related differences in drug metabolism (Licata et al., 2000). The formation of DOXol (8) was obtained in iron-depleted cytosolic fractions of human myocardium enriched with NADPH and incubated with DOX (1). It was also demonstrated that 7-hydroxydoxorubicin aglycone (9) is not a good substrate for carbonyl reduction (Minotti et al., 2000).

Mitoxantrone (MTX)

MTX (2) is a synthetic anthraquinone that belongs to the synthetic anthracenediones family (Ehninger et al., 1990). It is an antineoplastic agent with antiviral, antibacterial, and antitumour properties with a large spectrum of antitumour activity. MTX (2) is used to treat breast cancer, acute leukaemia's, acute lymphomas, and multiple sclerosis in adults (Costa et al., 2013). At a chemical level, the main alteration of MTX (2) when compared to anthracyclines is the replacement of the amino sugar on the anthracyclines for an aminoalkylalcohol chain (Pratt et al., 1986). This compound was structurally designed to have little or no cardiotoxicity. Batra et al., confirmed the lower short and long term MTX (2) toxicity when compared to DOX (1) (Batra et al., 1986) in animal models; however, the clinical practice and other animal studies did not corroborate the data first gathered (Pratt et al., 1986, Rossato et al., 2014, Dores-Sousa et al., 2015).

MTX (2) has low absorption when administered orally and for this reason MTX (2) is administered via intramuscular or by intraperitoneal injection (Batra et al., 1986). The main MTX (2) metabolites (Scheme 3) were identified as the monocarboxylic acid (16) and dicarboxylic acid (17) resulting from the oxidation of the terminal hydroxyl groups of the side 
chains. These two metabolites are more polar than MTX (2) (Chiccarelli et al., 1986, Blanz et $a l .$, 1991). There are studies confirming that the glucuronide (18) is also an urinary metabolite of MTX (2) in humans (Batra et al., 1986), whereas the MTX glutathione (19) metabolite was only detected in in vitro models (Scheme 3) so far (Mewes et al., 1993, Rossato et al., 2013).

\section{Scheme 3}

In vitro models to study the metabolism of mitoxantrone. The metabolic profile of MTX (2) has been studied by using various methods, such as primary cultures of hepatocytes isolated from rats, rabbits, and humans (Richard et al., 1991), microsomes and hepatic S9 fractions (Rossato et al., 2013).

In a study with isolated perfused rat liver model, it was demonstrated that MTX (2) was extensively and rapidly metabolized and the mono- (16) and dicarboxylic (17) acid derivatives represented a very low percentage of the metabolites excreted in bile (Ehninger et al., 1984).

In another study, Wolf et al., identified the glutathione (19)- and glucurono (18)conjugates of MTX (2) as the main MTX (2) metabolites in rat liver microsomal fractions and in hepatocyte homogenates (Wolf et al., 1986). In the case of the cyclic naphtoquinoxaline (20) metabolite, it has been stated that it has anticancer properties (Panousis et al., 1997) but it seems a more cardiosafe metabolite (Shipp et al., 1993, Reis-Mendes et al., 2016a) when compared with MTX (2), at least in in vitro models, namely neonatal cardiomyocytes of cyclic naphtoquinoxaline (20) and in $\mathrm{H} 9 \mathrm{c} 2$ differentiated cells. Moreover, the other metabolites were not yet studied regarding their cardiotoxicity at this point.

In a recent study, Rossato et al. studied the metabolic profile of MTX (2) using phenobarbital-induced hepatic S9 fraction from adult rats and five metabolites were identified. Those metabolites were the naphtoquinoxaline metabolite (20), acetoxy ester metabolite (21), glutathione metabolites $(\mathbf{2 2}, \mathbf{2 3})$ and the monocarboxylic acid derivative (24) (Scheme 3) (Rossato et al., 2013). The metabolites 22 and 23 were previously found after incubation of MTX (2) with horseradish peroxidase and glutathione (Blanz et al., 1991). Cyclic naphthoquinoxaline 20, a product of biotransformation of MTX (2) in vivo in humans, pigs, and rats (Blanz et al., 1991, Rossato et al., 2013), is a product of metabolism of CYP P450 enzymes or peroxidases (Reis-Mendes et al., 2016b). The presence of metabolite cyclic naphthoquinoxaline $\mathbf{2 0}$ in the urine of different species proves for the first time the existence 
of intracellular enzymes capable of oxidizing mitoxantrone in vivo (Blanz et al., 1991) Moreover, Rossato et al, evaluated the metabolic profile in vivo in rats that received 7.5 $\mathrm{mg} / \mathrm{kg}$ of MTX (2) 24-h before. In the liver of the MTX-treated animals were identified 4 metabolites: cyclic naphtoquinoxaline (20), acetoxy ester metabolite (21), glutathione metabolite (22), and monocarboxylic acid derivative of MTX (24), whereas, in the heart the cyclic naphtoquinoxaline (20) was the only metabolite detected (Rossato et al., 2013).

In another study that aimed to explore the biotransformation of MTX (2), MTX (2) was incubated with rat, rabbit, and human hepatocytes. When MTX (2) was incubated with rat hepatocytes, it was rapidly taken up by the cells as observed by the distribution of the blue drug within the cells. Two metabolites were produced in rabbit and human hepatocytes but not in rat hepatocytes, the mono- (16) and dicarboxylic (17) acids. Moreover, the glutathione (22), cysteinylglycine (25), cysteine derivatives of MTX (26), and a thioether conjugate of MTX (27) (Scheme 3) were also identified (Mewes et al., 1993). In the same study, human HepG2 hepatoma cells were incubated with MTX (2) for $24 \mathrm{~h}$ and in the cell lysates of HepG2 cells, 2-(L-cysteine-5-yl)-MTX (26) was identified, while the glutathione metabolite (22) and cysteinylglycine (25) were not detected. Moreover, the cytotoxic effect of MTX (2) on rat hepatocytes revealed that these cells were less sensitive to parental compound and its metabolites: only at concentrations above $200 \mu \mathrm{M}$ a significant cytotoxic effect was observed, leading to about $20 \%$ cell death, during a 9-h incubation period, while in rat hepatocytes 400 $\mu \mathrm{M}$ of MTX (2) killed approximately $50 \%$ of the hepatocytes. An increasing number of hepatocytes were affected after $9 \mathrm{~h}$ of incubation, and $20 \%$ of hepatocytes were killed at 25 $\mu \mathrm{M}$ according to the leakage of LDH (Mewes et al., 1993).

\section{Cyclophosphamide (CTX)}

CTX (3) is an alkylating agent widely used as an antitumour agent in the clinical practice (Balis et al., 1983). CTX (3) is commonly used against several types of cancers like malignant lymphomas, leukaemia's, neuroblastoma, retinoblastoma, and carcinomas of the ovary, breast, endometrium, and lung, usually in combination with other chemotherapeutic agents (De Jonge et al., 2005). CTX (3) is a prodrug extensively metabolised to several active/toxic metabolites [4-hydroxycyclophosphamide (28), aldophosphamide (29),

phosphoramide mustard (30), and acrolein (31)] and inactive/nontoxic metabolites [4ketocyclophosphamide (32), carboxyphosphamide (33), dechloroethylcyclophosphamide (34), 
4-glutathionylcyclophosphamide (35), and diglutathionylphosphoramide mustard (36)] (Scheme 4), requiring enzymatic bioactivation to manifest its antitumour activity (De Jonge et al., 2005, Reis-Mendes et al., 2016b). The formation of the three inactive/nontoxic metabolites corresponds to the detoxification route of CTX (3). The main detoxification pathway leads to the formation of carboxyphosphamide (33) from aldophosphamide (29) (De Jonge et al., 2005). 4-Hydroxycyclophosphamide (28) and the phosphoramide mustard (30) are detoxified by GST to form 4-glutathionylcyclophosphamide (35) and diglutathionylphosphoramide mustard (36), respectively (Dirven et al., 1994). CTX (3) can be administered in a wide dosage range, either by oral or intravenous administration. After repeated administration, CTX (3) shows to cause auto induction (Crombag et al., 2016), in the other words, CTX (3) induces its own metabolism after repeated administration of several consecutives days. Auto induction results in an approximately 2 -fold decrease in the elimination half-life of CTX (3) and increased formation of its metabolites. This phenomena is detectable as soon as $24 \mathrm{~h}$ after the beginning of the treatment. The elimination half-life of CTX (3) is 5-9 h (De Jonge et al., 2005). After intravenous administration, CTX (3) is eliminated primarily by enzymatic oxidation to active and inactive metabolites as mentioned, which are mainly excreted in the urine, while 10\%-20\% of CTX (3) is excreted unchanged in the urine and $4 \%$ is excreted in the bile (Crombag et al., 2016).

CTX (3) is a prodrug with low protein binding (24\%), which is activated in the liver (Crombag et al., 2016) by hepatic microsomal mixed-function oxidases, predominantly by CYP P450. CYP P450 isoenzymes involved in the bioactivation of CTX (3) include CYP2A6, 2B6, 3A4, 3A5, 2C9, 2C18, and 2C19, with 2B6 displaying the highest 4-hydroxylase activity (De Jonge et al., 2005). The hydroxylation at the 4-position of the ring by hepatic mixed function oxidases yields the primary metabolite of CTX (3) (Scheme 4), 4hydroxycyclophosphamide (28), which subsequently originates aldophosphamide (29) [4hydroxycyclophosphamide (28) is in equilibrium with its ring-open tautomer aldophosphamide (29)]. Aldophosphamide (29) forms acrolein (31) nonenzymatically and the active alkylating moiety, phosphoramide mustard (30), which is formed by the spontaneous $\beta$ elimination of acrolein (31) from aldophosphamide (29) (Balis et al., 1983). In vivo, CTX (3) is converted to 4-hydroxycyclophosphamide (28) by hepatic microsomal enzymes but for in vitro experiments the use of 4-hydroperoxycyclophosphamide (37) (Scheme 4) is required (Levine et al., 1993) due to the in vitro fast conversion of the 4-hydroperoxyclophosphamide (37) to the metabolite 4-hydroxycyclophosphamide (28) and then its transformation to acrolein (31) (Dorr and Lagel, 1994). Acrolein (31) may be responsible for the cardiac and 
pulmonary toxicities and also for the renal damage observed after CTX (3) therapy (Monneret et al., 1993). Moreover, the primary metabolites [4-hydroxycyclophosphamide (28) and aldophosphamide (29)] can be enzymatically inactivated after oxidation giving 4ketocyclophosphamide (32) and carboxyphosphamide (33), the major urinary metabolites of CTX (3) (Balis et al., 1983).

\section{Scheme 4}

In vitro models to study the metabolism of cyclophosphamide. The metabolites like 4hydroxycyclophosphamide (28), and/or aldophosphamide (29) (Fenselau et al., 1977), phosphoramide mustard (30), acrolein (31), 4-ketocyclophosphamide (32), carboxyphosphamide (33), and dechloroethylcyclophosphamide (34) can be formed in human/rat liver microsomes with the appropriate co-factors, when incubated with CTX (3) (Connors et al., 1974, Ren et al., 1997). Ren et al., investigated the formation of 4hydroxycyclophosphamide (28) and dechloroethylcyclophosphamide (34) from CTX (3) in human liver microsomes. In incubations with CYP isoform-selective inhibitors, 4hydroxycyclophosphamide (28) was found to be formed primarily by CYP2C9 at lower concentration $(0.1 \mathrm{mM})$ and by CYP3A4/5 at high concentrations $(0.7$ and $5 \mathrm{mM})$, whereas dechloroethylcyclophosphamide (34) was found to be formed primarily by CYP3A4/5 at high concentrations (0.7 and $5 \mathrm{mM}$ ) (Ren et al., 1997). Connors et al., incubated CTX (3) with rat liver microsomes and two cytotoxic intermediates, 4-hydroxycyclophosphamide (28) and aldophosphamide (29), were formed and were then transformed into the known in vitro metabolite carboxyphosphamide (33). In addition, another metabolite not active in the bioassay system (thus, with low cytotoxicity), dechloroethylcyclophosphamide (34) was identified. Carboxyphosphamide (33) and 4-ketocyclophosphamide (32) are the principal urinary metabolites of CTX (3), but they were found to be non-toxic against Walker tumour cells in vitro. Still, in Walker tumour cells, another metabolite with low cytotoxicity, dechloroethylcyclophosphamide (34) was identified (Connors et al., 1974). The concentrations of carboxyphosphamide (33) and 4-ketocyclophosphamide (32) to kill $75 \%$ of the studied tumour cells were $>200 \mu \mathrm{g} / \mathrm{mL}$ and $800 \mu \mathrm{g} / \mathrm{ml}$, respectively. In contrast, phosphoramide mustard (30) is markedly toxic and the dose needed to kill $75 \%$ of tumour cells is low enough $(0-5 \mu \mathrm{g} / \mathrm{ml})$ for it to be considered a toxic metabolite. Acrolein (31) (3-5 $\mu \mathrm{g} / \mathrm{ml}$ ), which was detected following microsomal incubation of CTX (3), has been suggested 
as the antitumour metabolite, but it is not as toxic in the bioassay system involving Walker tumour cells as was phosphoramide mustard (30) in the concentrations tested $(0-5 \mu \mathrm{g} / \mathrm{ml})$ (Connors et al., 1974).

Acrolein (31) and 4-hydroperoxycyclophosphamide (37) are roughly equipotent as a cardiac cell toxins, in rat cardiac myocytes. The depletion of glutathione is involved in their toxic mechanisms. Therefore, to block the toxic effects of both 4hydroperoxycyclophosphamide (37) and acrolein (31) in rat myocytes, exogenous sulfhydryl containing compounds were used (Dorr and Lagel, 1994).

The cardiotoxicity of CTX (3) and acrolein (31) was studied in the H9c2 cell line and in isolated Langendorff-perfused rat hearts by Nakamura et al. They also investigated the cellular toxicity of DOX (1) in the same conditions and models, since DOX (1) is known to have cardiac toxicity. It has been found that CTX (3) by itself had no toxic effect, while the cytotoxicity of acrolein (31) was 1000 times higher than that of DOX (1) in this cell line. Regarding the isolated rat heart, acrolein (31) reduced the left ventricular pressure and heart rate and increased the left ventricular end diastolic pressure. No effects were found with CTX (3). These results suggest that the cardiac toxicity of CTX (3) may be largely caused by its metabolites, namely acrolein (31) (Nakamura et al., 2010).

\section{5-Fluorouracil (5-FU)}

5-FU (4) is widely used as an antitumour agent for the treatment of solid tumours. It is an antimetabolite that acts during the $S$ phase of the cell cycle and is an analogue of uracil with a fluorine atom at the C-5 position in place of the hydrogen (Heidelberger, 1975). 5-FU (4) is active against various types of cancer, including gastric (stomach), breast, pancreatic, colorectal, and head and neck carcinomas (Longley et al., 2003). 5-FU (4) is considered the second most frequent cause of cardiotoxicity by anticancer agents, after anthracyclines (ReisMendes et al., 2016b).

5-FU (4) is administered intravenously. After administration, 5-FU (4) binds weakly to proteins, shows a high apparent volume of distribution and is predominantly metabolized in the liver, where the DPD plays a crucial role in the deactivation of 5-FU (4) (Crombag et al., 2016). 5-FU (4) (as the free base) enters into the cells by passive diffusion and is distributed throughout the body, including the brain. Less 10 to $15 \%$ of the 5-FU (4) is excreted intact in the urine but its clearance occurs primarily through hepatic metabolism (Balis et al., 1983). 
5-FU (4) is metabolized via two routes in competition with each other (Scheme 5): the anabolic route, which gives rise to three main active metabolites, fluorodeoxyuridine monophosphate (5-FdUMP, 39), fluorouridine triphosphate (5-FUTP, 40), and fluorodeoxyuridine triphosphate (5-FdUTP, 41), and the catabolic route, which inactivates 5FU (4) and leads to elimination of the drug (Malet-Martino and Martino, 2002, Longley et al., 2003). The anabolic pathway of 5-FU (4) (Scheme 5) is rather complex, since various parallel reactions can occur. 5-FU (4) can react in the following three ways: the first leads in two steps to the formation of 5-FdUMP (39); the other two routes form 5-fluorouridine-5'monophosphate (5-FUMP, 42). This later molecule may undergo two successive phosphorylations to give rise to 5-fluorouridine-5'-diphosphate (5-FUDP, 43) and 5fluorouridine-5'-triphosphate (5-FUTP, 40). 5-FUTP (40) can be incorporated into the RNA instead of uridine-5'-triphosphate (UTP). 5-FUTP (40) can also form 5-FU-nucleotide sugars (5-FUDP-sugars, 44). 5-FdUMP (39) and 5-FUDP (43) can be transformed into 5-fluoro-2‘deoxyuridine-5'-diphosphate (5-FdUDP, 45). The latter may then be phosphorylated to 5FdUTP (41), which acts as a substrate for DNA polymerase and can thus be incorporated into the DNA (Malet-Martino and Martino, 2002). The catabolism (Scheme 5) involves three stages: the first stage of degradation occurs very fast under the action of DPD, which reduces 5-FU (4) to 5,6-dihydro-5-fluorouracil (5-FUH2, 46). DPD is the rate-limiting enzyme in 5FU (4) catabolism (Longley et al., 2003). The rate at which 5-FU (4) is available for anabolism is set effectively by this first stage. 5-FUH2 (46) is then cleaved to originate $\alpha$ fluoro- $\beta$-ureidopropionic acid (FUPA, 47) and in a third stage leads to the formation of $\alpha$ fluoro- $\beta$-alanine (FBAL, 48). FBAL (48) is the major catabolite of 5-FU (4) (Malet-Martino and Martino, 2002). An undesirable consequence of the catabolism of 5-FU (4) is the diversion into metabolic routes that lead to the formation of the highly myocardiotoxic fluoroacetate (49) by seission of the pyrimidine ring (Arellano et al., 1998). The high cardiotoxicity potential of fluoroacetate (49) is due to the fact that fluoroacetate (49) enters the Krebs cycle mimicking fluoroacetyl-coenzyme $\mathrm{A}$ and is then transformed into fluorocitrate (a potent inhibitor of the enzyme aconitase). The inhibition of aconitase by fluorocitrate inhibits the utilization of citric acid resulting in the accumulation of intracellular citrate (Matsubara et al., 1980). The build-up of citrate in heart leads to a severe impairment of cardiac ATP synthesis (Arellano et al., 1998).

\section{Scheme 5}


In vitro models to study the metabolism of 5-fluorouracil. The fluoroacetate (49) metabolite of 5-FU (4) was isolated in perfused rat liver and in the rats' urine. The levels of fluoroacetate (49) found in perfusates of rat livers and in rat urine were low. However, it is known that when 5-FU (4) is administrated in a therapeutic dose of $15 \mathrm{mg} / \mathrm{kg}$ for several days, fluoroacetate (49) accumulates in the body. Therefore, the cardio- and/or neurotoxic effects in patients treated with 5-FU (4) can be explained by the cumulative toxicity of fluoroacetate (49) that emerges from the catabolic pathway (Arellano et al., 1998). Moreover, it was found that the fluoroacetate (49) precursor, FBAL (48), has a prolonged half-life elimination time (Heggie et al., 1987) and it accumulates and is retained in various rat tissues up to 8 days, namely in liver, heart, and brain (Zhang et al., 1992).

The 5-FU (4) metabolism was studied in intact Yoshida sarcoma cells, where 5-FU (4) was mainly phosphorylated. In the same work but in liver slices, 5-FU (4) was mainly degraded and the degradation of 5-FU (4) was faster in the liver than in other tissues (kidney, bone marrow, spleen, heart, lung, thymus, brain, stomach, and muscle) and very slow in the tumour tissue (Ikenaka et al., 1979). This rapid/slow degradation depends on the polymorphism of the metabolic enzymes involved in 5-FU (4) catabolism.

\section{Tyrosine kinase inhibitors (TKIs)}

Tyrosine kinases are frequently mutated or amplified in cancer and therefore the development of therapeutic tyrosine kinase inhibitors (TKIs) has gained a recent interest since tyrosine kinase can be a potential therapeutic target. The current formation of TKIs is inherently non-selective and the design of multitargeted TKIs allows a single agent to be more effective. These unselective TKIs are used in several types of cancer. Their increase in use was accompanied with an increased risk of cardiotoxicity, since the inhibition of "bystander" targets that are involved in cardiomyocyte survival, causes cardiac damage (Force et al., 2007). Two general classes of target TKIs have been developed: humanized monoclonal antibodies directed against the tyrosine kinase receptor such as trastuzumab, pertuzumab, and bevacizumab and small-molecule TKIs including imatinib (5), sunitinib (6), and sorafenib (7).

Monoclonal antibodies have been found to cause cardiotoxicity, and this issue has been extensively reviewed (Force et al., 2007, Hudis, 2007, Perez et al., 2008, Nielsen et al., 2009, Maharsy, 2015). For instance, in a phase III clinical study of trastuzumab efficacy, the 
addition of trastuzumab to anthracyclines (DOX (1) or epirubicin) and CTX (3) improved survival in women with metastatic breast cancer; however, high cardiotoxicity was an unanticipated finding, since $27 \%$ of patients treated with the regimen of anthracyclines, CTX (3), and trastuzumab developed heart failure (Slamon et al., 2001).

After the milestone approval of imatinib (5), in 2001, 35 new small-molecule kinase inhibitors were approved. However, several cardiac adverse events are being described with TKIs (Lenihan and Kowey, 2013). Recently, the cardiotoxicity of 21 FDA-approved TKIs was screened and allowed to stablish a cardiac safety index for TKIs toxicity using human induced pluripotent stem cell-derived cardiomyocytes (Sharma et al., 2017). Endothelial cells and cardiac fibroblasts were also used in that work. Sorafenib (7), regorafenib (a close-related analogue of sorafenib), and ponatinib (withdrawn quickly for serious adverse vascular events) were the most cytotoxic TKIs found in this study, thus demonstrating that this approach can be important for screening the potential cardiotoxicity of new chemotherapeutic compounds. However, the role of their metabolites on the cardiotoxicity is not yet investigated thoroughly. Following, targeted therapy associated with cardiotoxicity, focusing on the first approved TKIs imatinib (5) and two commonly used vascular endothelial growth factor receptors (VEGFR) inhibitors sunitinib (6), and sorafenib (7) and their metabolites are presented.

\section{Imatinib}

Imatinib mesylate or STI571 (imatinib, 5) was the first TKIs anticancer drug of small molecules to be approved by the FDA after the International Randomized Study of Interferon versus STI571 clinical study that confirmed its potency in the treatment of chronic myelogenous leukaemia, while presenting minimal side effects (Force et al., 2007).

Imatinib (5) is rapidly and nearly completely absorbed in the gastrointestinal tract after oral administration. Maximum (peak) plasma concentration values (Cmax) after single and multiple doses are achieved within 1-2 h. The main phase I metabolic pathways (Scheme 6) identified for this compound were: CGP74588 (52, main metabolite, $N$-demethylation), AFN911 (53, benzylic hydroxylation), CGP72383 (54, pyridine $N$-oxidation), CGP71422 (55, piperazine- $N$-4-oxidation), M28.8 (56), M29.6 (57), APG050 (58), APG049 (59, piperazine ring oxidation with lactam formation), and M42.2 (60, oxidative deamination and rapid oxidation of the intermediate aldehyde to a carboxylic acid). Direct conjugation of imatinib 
(5) and of the $N$-demethyl metabolite CGP74588 (52) with glucuronic acid, most probably at the nitrogen atom, and glucuronidation of the oxidative metabolites CGP74588 (52), APG050 (58), M29.6 (57), and M28.8 (56) are pathways of phase II metabolism (Gschwind et al., 2005).

Imatinib (5) inhibits the tyrosine kinase activity of the BCR-ABL fusion protein resulting from a chromosomal translocation, known as the Philadelphia chromosome $(\mathrm{Ph})$. The BCR-ABL fusion protein dimerization phosphorylates the $A B L$ kinase domain leading to its constitutive activation. This constitutively active kinase triggers antiapoptotic pathways (RAS-ERK, PI3K-AKT, JAK-STAT), thus enhancing cell division and inhibiting DNA repair, therefore leading to chronic myelogenous leukaemia (Goldman and Melo 2003). In addition to the inhibition of BCR-ABL, the lack of specificity of the anticancer drug imatinib (5) enables it to be used for gastrointestinal stromal tumours, where its target is the c-kit kinase (Kerkelä et al., 2006).

Imatinib (5) blocks all BCR-ABL dependent phosphorylation and signalling events, which leads to reversal of the pro-survival effects and activation of apoptosis in chronic myeloid leukaemia progenitor cells. The BCR-ABL kinase is on plasma membrane or endoplasmic reticulum of cardiomyocytes and seems to be responsible to preserve endoplasmic reticulum homeostasis. The BCR-ABL kinase inhibitor, imatinib (5), causes endoplasmic reticulum stress, with activation of several noxious pathways that ultimately lead to BAX release followed by mitochondrial depolarization, ATP depletion, cytochrome $c$ release, and features of necrotic and apoptotic cell death in the heart (Force et al., 2007). Fernández and collaborators performed molecular modifications to imatinib (5) to achieve three objectives: guide to the primary impact on c-kit kinase, reduce the inhibitory impact on BCR-ABL kinase (which has been linked to the cardiovascular side effects of the drug), and promote inhibition of an additional target, JNK, to reinforce the prevention of cardiotoxicity. A new derivative named WBZ_4 (61) (Figure 2) caused a decrease of tumour volume and weight in a mouse model of gastrointestinal stromal tumours to a similar extent to that observed with imatinib (5). In contrast to imatinib (5), this new compound did not affect leftventricular cardiac function, contributing to that lack of cardiotoxicity the reduced activation of JNK in cardiomyocytes (Fernández et al., 2007).

It was recently demonstrated that the upregulation of Bcl-2, an anti-apoptotic protein, protects against imatinib (5)-induced cardiotoxicity and that this cardiotoxicity is agedependent. It is also important to point out that cardiac toxicity could be latent, as seen with 
anthracyclines, where cardiac dysfunction can occur years after the end of drug therapy (Maharsy et al., 2014).

\section{Scheme 6}

In plasma, urine, and faeces from four healthy male volunteers to whom were given a single 239-mg oral dose of imatinib mesylate, unchanged imatinib (5) and its $N$-demethyl metabolite CGP74588 (52) were the most prominent components in all of the investigated matrices (Gschwind et al., 2005). Imatinib (5) was metabolized to the active anticancer metabolite CGP74588 (52) (Scheme 6) by CYP3A4 and CYP3A5 and, to a lesser extent by CYP2D6 (van Erp et al., 2007). In a recent study, it was demonstrated that the demethyl metabolite, CGP74588 (52), was substantially less active than imatinib (5) in cell-based assays, both as an inhibitor of BCR-ABL and of c-kit kinases. Consequently, to improve the pharmacokinetic profile and hence efficacy of imatinib (5), the $N$-trideuteromethyl analogue (62) of imatinib (5) (Figure 2) was administrated in the rat via intravenous route. The $\mathrm{N}$ trideuteromethyl analogue (62) showed a similar potency to that of imatinib (5) as an inhibitor of the tyrosine kinase activity of BCR-ABL and of c-kit kinases, and this was translated into similar degrees of efficacy against cell proliferation. In the same work, Manley et al. demonstrated that the imatinib metabolite APG050 (58) was devoid of kinase activity at concentrations <3000 nM (Manley et al., 2013).

\section{Figure 2}

In vitro models to study the metabolism of imatinib. In vitro metabolism of imatinib (5) in rat and human liver microsomes showed that imatinib (5) formed two major metabolites in the presence of NADPH: $N$-demethyl imatinib metabolite CGP74588 (52) and the oxidative metabolite, CGP71422 (55), via $\mathrm{N}$-oxidation of the piperazine ring. This incubation also leads to the formation of other metabolites (Scheme 6), such as AFN911 (53), M28.8 (56) and M29.6 (57) (Ma et al., 2009). Still, in rat and human liver microsomes, three new conjugates (63-65) (Scheme 6) were detected that resulted from addition of 621 atomic mass units (amu), corresponding to adenine dinucleotide phosphate $\left(\mathrm{ADP}^{+}\right)$, to the $N$-demethyl metabolite CGP74588 (52), imatinib (5), and imatinib $N$-oxide (55) respectively, in the presence of NADPH. The major metabolite (64) was detected, which corresponds to adenine dinucleotide phosphate $\left(\mathrm{ADP}^{+}\right)$conjugate of imatinib $\left(\mathrm{ADP}^{+}\right.$adduct of imatinib). The conjugation 
occurred between the pyridine nitrogen of imatinib and the ribose ring of $\mathrm{ADP}^{+}$moiety. With the incubation with human liver microsomes, $\mathrm{ADP}^{+}$adducts of imatinib (64) was the major metabolite detected (Ma et al., 2008). However, the same authors in a later work and also using human liver microsomes, only detected two major metabolites CGP74588 (52) and CGP71422 (55) (Ma et al., 2009). These dissimilar outcomes can be the result of different human donors and therefore different enzymatic abilities of the microsomes.

Several imatinib metabolites were produced when imatinib (5) was incubated with insect-cell microsomes. Those metabolites were attributed to one demethylated and six $\mathrm{N}$ oxide- or hydroxy metabolites (Marull and Rochat, 2006). The metabolism of imatinib (5) was also investigated in rat and human liver microsomes, whose products were researched by atmospheric pressure chemical ionization (APCI) mass spectrometry (MS) to distinguish hydroxyl metabolites from $N$-oxides of imatinib because $N$-oxides are known to undergo deoxygenation during APCI. In rat liver microsomes, the formation of nine major metabolites was observed: four oxidative metabolites [AFN911 (53), CGP71422 (55), (66), and (67)], a $N$-desmethyl metabolite (CGP74588, 52), a $N$-demethylation followed by oxidation metabolite (68), and three novel conjugates $(\mathbf{6 3}, \mathbf{6 4}$, and 65$)$ resulting from 621 amu addition to $N$-desmethyl imatinib (CGP74588, 52), imatinib (5), and imatinib $N$-oxide (CGP71422, 55), respectively.

\section{Sunitinib}

Sunitinib (6), a multitargeted tyrosine kinase inhibitor, which was approved by both US and European Commission regulatory agencies for clinical use, extends survival of patients with metastatic renal-cell carcinoma and gastrointestinal stromal tumours, but concerns have been raised about its cardiac safety (Mellor et al., 2011).

Sunitinib (6) inhibits VEGFRs, platelet-derived growth factor receptors (PDGFR), the stem cell factor receptor, and c-kit. It causes cardiotoxicity in treated cancer patients (Maharsy, 2015). Its broad number of targets makes it hard to identify the exact mechanisms of sunitinib (6) toxicity when compared with other more selective kinase inhibitors; sunitinib (6) inhibits at least 50 kinase targets at therapeutically relevant concentrations in in vitro assays (Force and Kolaja, 2011).

After oral administration, sunitinib (6) is slowly absorbed in the gastrointestinal tract, reaching the Cmax in about $6-12 \mathrm{~h}$ in both healthy subjects and cancer patients. 
Approximately 95\% and 90\% of sunitinib (6) and SU12662 (69), its metabolite, (Scheme 7) are bound to plasma proteins, respectively (Di Gion et al., 2011). The terminal half-lives of sunitinib (6) and SU12662 (69) are approximately 40 to $60 \mathrm{~h}$ and 80 to $110 \mathrm{~h}$, respectively. Renal elimination plays a minor role in the clearance of sunitinib (6), therefore renal impairment will not have a significant effect on its pharmacokinetics (Khosravan et al., 2010). The metabolite SU12662 (69) is present in the urine of human, monkey, and rat subjects treated with sunitinib. The metabolite M3 (70) is a minor metabolite that was excreted in urine and faeces (Scheme 7). M4A, C, and D (71) are minor metabolites observed in faeces. Minor metabolites M5A and B (72) were excreted in both rat urine and faeces. M6 (73) was a minor metabolite detected in rat and monkey faeces. M8 (74) was a major metabolite in rat and monkey faeces. M9 (75) was a minor metabolite excreted in rat and monkey faeces. Metabolite M10 (76) was a minor metabolite only observed in monkey faeces (Speed et al., 2012).

Contradictory data regarding the cardiotoxicity of sunitinib exist. In one study, in patients that used the recommended therapeutic dose of $50 \mathrm{mg} /$ day, sunitinib (6) displayed a manageable toxicity and no cardiac adverse events were reported (Faivre et al., 2006). However, in another study, $15 \%$ of the patients treated with sunitinib (6) developed symptomatic grade 3/4 heart failure, with increased risk of cardiotoxicity among older patients and women, among patients with a prior history of coronary artery disease and congestive heart failure and in patients with a lower body mass index (Telli et al., 2008). It has been shown that sunitinib (6) increased blood pressure and almost half of the treated patients (47\%) developed hypertension (Chu et al., 2007). Sunitinib (6)-induced hypertension has an important role in its cardiotoxicity; however, additional mechanisms may be involved, since several patients who developed cardiotoxicity after sunitinib (6) did not had any sings of hypertension (Force and Kolaja, 2011). In treated patients, sunitinib (6)-induced cardiac dysfunction was associated with abnormal histopathological changes such as myocyte hypertrophy and changes in mitochondrial structure. Sunitinib (6) targets mitochondria in cultured rat cardiomyocytes, leading to cytochrome $c$ release into the cytosol. This release can activate the mitochondrial pathway for apoptosis. Sunitinib (6) induces cardiomyocyte apoptosis with activation of caspase-9, an initiator caspase of the mitochondrial apoptotic pathway (Chu et al., 2007). The gathered data is clear in the message that physicians treating patients with sunitinib (6) must be very careful, especially in patients with pre-existing cardiovascular risk factors, like hypertension, history of cardiac disease, or previous treatment with other cardiotoxic agents (Orphanos et al., 2009). 
Speed and colleagues studied $\left[{ }^{14} \mathrm{C}\right]$ sunitinib (6) metabolism in rats, monkeys, and humans (Scheme 7) and demonstrated that sunitinib (6) was extensively metabolized in the three species primarily via the oxidative metabolism pathways mediated by CYP P450s. Many metabolites were detected both in urine and faeces extracts but faecal excretion (61\%) was the major route of elimination of the dosed radioactivity in the three species. Several putative structures $(\mathbf{6 9 - 8 2})$ of sunitinib metabolites were proposed in this study (Scheme 7) (Speed et al., 2012). The main metabolic pathways were $N$-de-ethylation and hydroxylation of indolylidene/dimethylpyrrole. Radiochemical metabolite profiles of plasma samples from the three species showed two major radioactive peaks corresponding to sunitinib (6) and $\mathrm{N}$-deethyl-sunitinib (SU12662, 69) (Speed et al., 2012). SU12662 (69) was the major active metabolite. Pharmacokinetic/pharmacodynamic data from animal studies showed that target plasma concentrations of sunitinib (6) plus SU12662 (69) capable of inhibiting PDGFR- and VEGFR-2 phosphorylation were established in the range of 50 to $100 \mathrm{ng} / \mathrm{mL}$.

\section{Scheme 7}

CYP3A4 was demonstrated to be the major human CYP P450 isoform to catalyse the formation of SU12662 (69), which is then further metabolized to inactive compounds by the same enzyme (Di Gion et al., 2011, Speed et al., 2012).

In vitro models to study the metabolism of sunitinib. The identification of metabolites in vitro of sunitinib (6) was performed in liver microsomes from mice, rats, dogs, monkeys, and humans. SU12662 (69) was the major metabolite found in mice, monkeys, and human liver microsomes, while M2E (77) was the predominant metabolite in dog liver microsomes. The metabolite SU12662 (69) predominated at a higher substrate concentration (25 $\mu \mathrm{M})$, but M2E (77) was the major metabolite at a low concentration $(2 \mu \mathrm{M})$, in rat liver microsomes. Still, in vitro metabolism studies showed that the SU12662 (69) metabolite and sunitinib (6) were equipotent in biochemical tyrosine kinase inhibition and cellular proliferation assays, acting on VEGFR, PDGFR, and c-kit (Speed et al., 2008). 


\section{Sorafenib}

Sorafenib (7) is another multitargeted TKI against VEGFR 2 and 3, PDGFR b, c-kit, FMS-like tyrosine kinase-3 (Flt3 or CD135), RAF1 (or CRAF), and BRAF (Orphanos et al., 2009). It is approved for the treatment of hepatocellular carcinoma, advanced renal cell carcinoma, and differentiated thyroid carcinoma (Anon, 2015). The underlying pathways of sorafenib (7)-induced cardiotoxicity are not clear and several questions are still to be answered. Sorafenib (7) inhibits the RAF1 and BRAF kinase activity. These pathways are believed to have an important role in cell survival in the heart. Sorafenib (7) was hypothesized to disrupt the RAF1-MST2 protein-protein interaction, activating three proapoptotic mediators: Jun $\mathrm{N}$-terminal kinase (JNK), forkhead box $\mathrm{O}$ (FOXO) and large tumour suppressor, homologue 1 (LATS1). On the other hand, if sorafenib inhibits RAF1-ASK1 interaction, it will lead to activation of JNK, JNK-mediated phosphorylation of 14-3-3 proteins and release of BAX, which would lead to mitochondrial cytochrome $c$ release and cell death (Force et al., 2007). Recently, patient-specific human induced pluripotent stem cells-derived cardiomyocytes (hiPSC-CMs) were used to screen TKIs for cardiotoxicity by evaluating cardiomyocyte viability, contractility, electrophysiology, calcium handling, and intracellular signalling (Sharma et al., 2017). Sorafenib (7) induced the highest cell death in hiPSC-CMs, with median lethal dose $\left(\mathrm{LD}_{50}\right)$ value of $3.4 \mu \mathrm{M}$ and with safety indices comparable to those of DOX (1). Sorafenib (7) elicited a compensatory increase in cardioprotective insulin/IGF1 signalling (phosphorylation) in hiPSC-CMs. A twofold increase in the expression of neuropilin 2, a noncanonical VEGFR and an up-regulation of KDR (VEGFR2 receptor) and an up-regulation in the expression of VEGF ligands led the authors to hypothesize that hiPSC-CMs may compensate for VEGFR2 signalling loss by upregulating auxiliary VEGFR expression, thus facilitating VEGF signalling in the absence of VEGFR2 kinase activity (Sharma et al., 2017).

Sorafenib (7) is known to induce acute coronary symptoms including myocardial infarction in $2.9 \%$ of patients. Sorafenib (7) is often administrated after sunitinib (6) therapy (Orphanos et al., 2009). In phase I trials, was observed hypertension in 5-11\% of the treated patients (Strumberg et al., 2007) while in another study hypertension was reported in $17 \%$ of the patients (Escudier et al., 2007).

Sorafenib (7) is administered orally and it is rapidly absorbed resulting in Cmax in approximately $3 \mathrm{~h}$. Sorafenib (7) is mainly metabolized in the liver by CYP3A4, as well as by glucuronidation mediated UGT1A9. Sorafenib (7) conjugates may be cleaved in the 
gastrointestinal tract by the bacterial glucuronidase activity, allowing reabsorption of the unconjugated active substance. In vitro, $99.5 \%$ of sorafenib (7) is bound to human plasma proteins (Anon, 2015).

Eight metabolites (83-90) of sorafenib (7) (Scheme 8) have been identified, of which five were detected in plasma, M-2 (83), M-4 (84), M-3 (85), glucuronide of sorafenib (86), and carboxylic acid of sorafenib (87), three in the faeces, M-4 (84), M-3 (85), and carboxylic acid of sorafenib (87), and two in urine, glucuronide of sorafenib (86) and carboxylic acid of sorafenib (87). The main circulating metabolite of sorafenib (7) in plasma, the $N$-oxide (M-2, 83), has a similar in vitro potency to that of sorafenib (7). Sorafenib (7) has an elimination half-life of 25 - $48 \mathrm{~h}$. Following oral administration of sorafenib (7), 77\% of the dose was excreted in faeces and $19 \%$ of the dose was excreted in urine as glucuronidated metabolites. Unchanged sorafenib (7), accounting for $51 \%$ of the dose, was found in faeces but not in urine, indicating that biliary excretion of the unchanged active substance might contribute to the elimination of sorafenib (7) (Anon, 2015).

The metabolites M-2 (83), M-4 (84), and M-5 (88) of sorafenib (7) are potent inhibitors of several tyrosine kinase receptors, namely VEGFR-2, PDGFR- $\beta$, and Flt-3. Two of the metabolites, M-2 (83) and M-5 (88) were even more potent than sorafenib (7) at inhibiting PDGF-dependent human aortic smooth muscle cell proliferation. However, sorafenib (7) was more potent than M-2 (83) or M-5 (88) against RAF1. Sorafenib (7) was also significantly more potent against Flt-3 than M-5 (88). The three metabolites [M-2 (83), M-4 (84), and M-5 (88)] had similar in vitro pharmacological activity against VEGFR-2, PDGFR- $\beta$, and Flt-3 as sorafenib (7) but the metabolites have much lower plasma levels in vivo. The most predominant human metabolite, $\mathrm{M}-2$ (83), was also evaluated in vivo for its antitumour efficacy and data indicated that M-2 (83) was effective when administered orally at a dose level of $120 \mathrm{mg} / \mathrm{kg}$ against the MDA-MB-231 xenograft model, a model of human breast cancer (Anon, 2006). No assessment of the potential cardiotoxicity of metabolites was done so far, to the best of our knowledge.

\section{Scheme 8}

In vitro models to study the metabolism of sorafenib. Two major metabolites were identified using human liver microsomes: the metabolite M-2 (83), originated after oxidation of the pyridine nitrogen and metabolite M-3 (85) by oxidation of the terminal amido methyl group. 
In this system, the formation of M-4 (84) metabolite also occurred, with relative formation of the M-2 (83): M-3 (85): M-4 (84) metabolites being established in the ratio of $65: 34: 1$ (Ghassabian et al., 2012).

\section{Prodrugs}

The use of prodrugs is a strategy to overcome the undesirable properties of drugs and to enhance therapeutic efficacy (Han and Amidon, 2000). The use of the prodrug concept can allow increasing or decreasing the solubility of a drug, masking taste or odour problems, reduction of pain or irritation at injection sites, enhancement of chemical stability, enhancement of oral absorption, prolongation of drug action, reduction in toxicity, and achieving site-specific drug delivery. However, these advantages bring some disadvantages for prodrugs: among others, if a very water-soluble prodrug is not rapidly converted to the parent drug after administration, it may be significantly and rapidly eliminated in the urine, thereby reducing drug bioavailability. In addition, the possibility of prodrug accumulation in the body occurs, particularly in patients with impaired renal function (Stella et al., 1985).

There are many intrinsic and extrinsic factors that can influence the bioconversion of prodrugs. The activity of many enzymes responsible for the activation of the prodrugs may be decreased or increased due to genetic polymorphisms, age-related physiological changes, drug interactions, or interspecies variations leading to adverse pharmacokinetic, pharmacodynamic, and clinical effects. The genetic polymorphisms of prodrug activation contribute to the variability in prodrug activation and thus to the efficacy and safety of drugs. Nevertheless, in some cases, the development of a prodrug may be an attractive strategy for anticancer drug design, rather than searching for a new active agent with suitable ADMET properties (Huttunen et al., 2011). The reason for the pro-drug study in this review is to determine if this strategy had any success in decreasing cardiotoxicity or only in improved pharmacokinetics of anticancer drugs.

\section{Prodrugs of DOX (1)}

By using endogenous and exogenous enzymes and the prodrug design, it was possible to minimize the dose-related toxic side effects of DOX (1) and improve the delivery of the 
drug to the targeted tumour cells (Rollas and Küçükgüzel, 2008). Among DOX (1) prodrugs developed, the cephalosporanic acid based prodrugs (Hudyma et al., 1993), hydrazine and amide prodrugs, and carbamate prodrugs stand out (Rollas and Küçükgüzel, 2008). Two DOX(1)-HPMA ( $N$-(2-hydroxypropyl)methacrylamide) copolymer conjugates (PK1 and PK2) and an acid-sensitive albumin-binding prodrug (aldoxorubicin, 91) have been assessed clinically (Figure 3A). The first drug-polymer conjugate to enter clinical trials was PK1 (Figure 3A) (Kratz et al., 2007).

\section{Figure 3}

Aldoxorubicin (91) (Figure 3B) is conjugated to a linker (an acid-sensitive hydrazine moiety), a 6-carbon spacer, and a thiol-binding maleimide (6-maleimidocaproic acid hydrazide). Aldoxorubicin (91) also is derivatized at C-13-keto position (Mita et al., 2015). Aldoxorubicin (91) binds rapidly and covalently to the cysteine-34 amino acid of endogenous albumin, when it enters the bloodstream. This prodrug strategy has several advantages, among which stands out the cancer chemotherapy improvement. Aldoxorubicin (91) rapidly binds to the cysteine-34 position of endogenous albumin and the release of the albumin-bound drug in the acidic environment at the tumour site occurs. This is accomplished by the incorporation of an acid-sensitive bond between the drug and the carrier. Due to the enhanced vascular permeability and poor lymphatic drainage that are main characteristics of tumours, albuminbound DOX (1) accumulates in the tumour and is then released in the acidic environment of the tumour or inside tumour cells. This release occurs via cleavage of the acid-sensitive hydrazine bond between the drug and the linker (Kratz et al., 2002). Aldoxorubicin (91) shows a mean circulating half-life of about 20.1-21.1 h, a narrow mean volume of distribution and a slow mean clearance rate. These pharmacokinetic characteristics suggest that aldoxorubicin (91) is stable in circulation and does not accumulate to a substantial degree in body compartments outside of the bloodstream, even if it is or not bound to serum albumin. Almost all DOX (1) in circulation remains bound to albumin via the acid-sensitive linker and little free DOX (1) is released in the bloodstream. This is one major advantage of the covalent bond formed between aldoxorubicin (91) and serum albumin, since that the drug release only occurs upon transport to an acidic environment such as the one found at the tumour site. DOX (1) is excreted in the urine mostly as unmetabolized drug, reinforcing again the conclusion that after administration of aldoxorubicin (91), very little DOX (1) is released into the 
circulation (Mita et al., 2015). Toxicological studies performed in mice, rats, and dogs showed a 3- to 5-fold increase in the maximum tolerated dose, moderate and reversible myelosuppression, no liver toxicity and immunotoxicity, and no new toxicity when compared with DOX (1) (Kratz et al., 2007). In a rat model, aldoxorubicin (91) has shown to be significantly less cardiotoxic at equitoxic dose $[(1.1 \mathrm{mg} / \mathrm{kg})$ when compared with DOX (1) $(0.8 \mathrm{mg} / \mathrm{kg}$ weekly for 7 weeks)] (Lebrecht et al., 2007). In fact, the chronic mitochondrial and myocardial toxicity of aldoxorubicin (91) in rats is reduced, when compared with free DOX (1) (Kratz, 2007, Lebrecht et al., 2007). The lack of observed cardiotoxicity may be due to the fact that very little DOX (1) and its major metabolite DOXol (8) (which has been implicated in DOX (1) associated cardiotoxicity) are excreted in urine (Mita et al., 2015).

Because of all of the above, aldoxorubicin (91) was selected for clinical evaluation. In a phase I study, no patients had any clinical signs of congestive heart failure, even among patients treated at the higher dose levels and/or for extended periods (Unger et al., 2007). Aldoxorubicin (91) can be administered at doses several-fold higher than DOX (1) without associated acute cardiotoxicity (Mita et al., 2015). Aldoxorubicin (91) was able to induce tumour regression in tumour types known to be anthracycline-sensitive tumours, namely, breast cancer, small cell lung cancer, and sarcoma. However, in tumours like prostate and kidney cancer, tumours known to not being sensitive to anthracyclines (Unger et al., 2007), no significant tumour regression or tumour control was shown after aldoxorubicin (91) administration. Aldoxorubicin (91) is currently under investigation in larger clinical studies that involve patients with soft tissue sarcoma or other anthracycline-sensitive cancers (Chawla et al., 2015).

Prodrugs of 5-FU (4)

5-FU (4) shows nonspecific cytotoxicity for tumour cells, it loses efficiency because of its poor distribution to tumour sites, and its effectiveness is limited due to drug resistance (Malet-Martino and Martino, 2002). Therefore, new therapeutic strategies were needed. To improve the physicochemical, biopharmaceutical, and pharmacokinetic properties of 5-FU (4), several derivatives have been synthesized and some of these have found a place in the clinical practice. Their main benefit is the possibility of oral administration taking as example the capecitabine (CAP, 92) prodrug (Scheme 9) (Daumar et al., 2011). 
CAP (92) is a fluoropyrimidine and it was a developed antineoplastic prodrug of 5-FU (4) with enhanced tumour selectivity. When CAP (92) is orally administered, it crosses the gastrointestinal barrier intact and is rapidly and almost completely absorbed (Malet-Martino and Martino, 2002). Due to its efficacy, easier administration, and milder toxicity profile compared with 5-FU (4), CAP (92) has gained popularity (Ang et al., 2010). In the body, it is first metabolized in the liver by carboxylesterase to 5-deoxy-5-fluorocytidine (5-dFCyd, 93) and it is latter converted to 5-deoxy-5-fluorouridine (5-dFUrd, 94) by cytidine deaminase (Cyd deaminase) in the liver and tumour tissues (Scheme 9). This enzyme is mainly located in the liver and tumour tissues. 5-dFUrd (94) is converted to the active drug, 5-FU (4) by thymidine phosphorylase (dThdPase), which is present at higher concentrations in tumour tissues. Carboxylesterase, Cyd deaminase, and dThdPase are three enzymes essential for the clinical efficacy of CAP (92) (Miwa et al., 1998).

This prodrug was designed to limit plasma concentrations of 5-FU (4) by allowing it to be selectively bioactivated in the tumour, since the concentrations of 5-FU (4) in plasma do not reflect the exposure of the tumour tissues to 5-FU (4) because of the absent enzymatic activation in normal tissues (Gieschke et al., 2003). CAP (92) has two main advantages, which translate into an improved therapeutic index: increased concentration of the active principle at the tumour site, and decreased concentration of the drug in healthy tissues with a consequent reduction in systemic toxicity (Malet-Martino and Martino, 2002).

Cardiotoxicity of CAP (92) has been poorly reported, which may suggest that the incidence of cardiotoxicity of CAP (92) may be lower than the 1.5-2\% reported for 5-FU (4), but reach up to 35\% (Reis-Mendes et al., 2016b). In 2002, a patient, during treatment with CAP (92) developed a severe and prolonged acute coronary syndrome. This patient had developed similar symptoms during treatment with 5-FU (4) given by infusion (Frickhofen et al., 2002). In fact, CAP (92) should be considered an agent with cardiotoxic potential and the patients with symptoms suggestive of cardiotoxicity should not be treated with CAP (92). In another study, a patient experienced chest pain after $96 \mathrm{~h}$ following the initiation of CAP (92) therapy. They assumed that delayed cardiotoxicity may occur due to cumulative dose effect of 5-FU (4) or its metabolites after administration of CAP (92) (Senturk et al., 2009).

\section{Scheme 9}

CAP (92) was approved by the US FDA for use as a chemotherapy agent, when single-agent fluoropyrimidine therapy is preferred, namely in patients with metastatic 
colorectal cancer. The drug was also approved for use in metastatic breast cancer patients (Walko and Lindley, 2005). CAP (92) is also approved to be used to treat metastatic breast cancer that does not respond to other chemotherapy (NIH, 2013). However, safety data from clinical trials reveal that the toxic profile of CAP (92) is similar to its parent fluoropyrimidines (Wijesinghe et al., 2006).

\section{Prodrug of sunitinib}

There are many toxic side effects associated with sunitinib (6) that limit its therapeutic use despite patient's good response to the multi-targeted TKIs. So, to improve the therapeutic index of sunitinib (6), prodrugs that modify the pyrrole group and are able to mimic the tyrosine kinase receptor inhibition activity of sunitinib (6) were synthesized. Initially, Huang et al. synthesized the bioprecursor AST-001 (95, Figure 4), which showed good proprieties: inhibited cancer cell growth in vitro with a potency similar to that of sunitinib (6) and showed lower sunitinib (6) concentrations in multiple non-target organs when compared with sunitinib (6). However, AST-001 (95) was very unstable and rapidly hydrolysed. For this reason, synthesis of more stable compounds like AST-002 (96) and AST-003 (97) were generated (Figure 4). In vitro in plasma, AST-002 (96) and AST-003 (97) can be hydrolysed to sunitinib (6). The esterase inhibitor, paraoxon, can completely block that hydrolysis, suggesting that AST-002 (96) and AST-003 (97) can be efficiently hydrolysed by esterases in vivo. In the A549 cancer cell line, a decrease in the phosphorylation of STAT3 and AKT was observed after incubation with those metabolites, which revealed a similar effect to of sunitinib (6) (Huang et al., 2015). Moreover, AST-002 (96) and AST-003 (97) kill cancer cells more rapidly than sunitinib (6) leading to rapid changes in cell morphology after a 8-h incubation. The cells incubated with sunitinib (6) remained attached, elongated, and exhibited a normal healthy cell morphology, while the cells that were incubated with AST-002 (96) or AST-003 (97) appeared round and stressed. Moreover, in a xenograft mice, AST-003 (97) exhibited better efficacy due to its faster cell killing effect than sunitinib (6). Moreover, enzymes associated with cardiac, liver, and renal functions were less affected by AST-003 (97) suggesting overall decreased toxicity of AST-003 (97). This prodrug is rapidly hydrolysed in vivo into hydroxyl-methyl sunitinib (AST-004, 98) and then to sunitinib (6) (Scheme 10). The unique properties of AST-003 (97) suggest that it may have a better 
therapeutic index than sunitinib (6) in cancer therapy. The therapeutic effects of AST-003 (97) in humans have not yet been tested (Huang et al., 2015).

\section{Figure 4}

\section{Scheme 10}

\section{Synthesis of anticancer drug metabolites}

The models previously mentioned are used for the isolation of metabolites and these can be identified by several techniques such as nuclear magnetic resonance and mass spectrometry, usually by chromatographic techniques combined with on-line detection. The metabolites can be identified from biological fluids such as plasma, urine, or faeces. However, the metabolites are often present at low concentrations in biological fluids, and chemical synthesis emerges in this scenario as a valuable approach because metabolites are then obtained in amounts necessary for research activity/toxicity assays (Venn, 2008). The synthesis of metabolites may be done by classical synthesis using total or semi-synthesis or metabolic enzymes. The use of the enzymatic methods in the synthesis of drug metabolites allows in one step, by a biomimetic synthesis, to obtain the drug metabolites using the same biotransformation reaction that occurs in vivo. Similar to classical synthesis, the metabolite can be obtained with high purity and its identity can be confirmed in biological matrices. However, this biomimetic method for predicting metabolites is not always accurate; it is very specific for each metabolite and is also very time consuming.

The next section describes the synthetic procedures used to obtain metabolites of anticancer drugs DOX (1), MTX (2), CTX (3), 5-FU (4), imatinib (5), sunitinib (6), and sorafenib (7). The purpose of the syntheses of these metabolites is to further investigate if they have any antitumour activity and to evaluate their potential toxicity, namely cardiotoxicity. In most of the studies, the metabolites were chemically obtained and then isolated using diverse purification procedures. Nevertheless, in some cases, the crude product was used in biological studies without further purification. Most of the syntheses involved chemical reagents, but in conjugations, enzymes are more frequently applied. Table 2 highlight the synthetic methods and main products obtained applied to anticancer drugs 1-4, 
respectively. Only with pure metabolites are obtained can their pharmacological and toxicological aspects be accurately studied.

\section{Synthesis of DOX (1) metabolites}

In Table 2, methods applied in the synthesis of DOX (1) metabolites are firstly summarized. DOXol (8) was obtained by reducing the carbonyl group of DOX (1) and 7deoxydoxorubicinol aglycone (10) was formed from DOX (1) hydrochloride by catalytic hydrogenation. The metabolite 7-deoxydoxorubicin aglycone (11) was synthesized from reductive glycosidic cleavage of DOX (1) also by catalytic hydrogenation. Demethyldeoxydoxorubicinol aglycone 4- $O$-sulfate (12) and demethyldeoxydoxorubicinol aglycone 4-O- $\beta$-glucuronide (13) were obtained from DOX (1) by conjugation with sulfate or $\beta$-glucuronate, respectively, nearly equally in 4-O-position. The 7-hydroxydoxorubicinol aglycone (14) was obtained from 7-hydroxydoxorubicin aglycone (9) using the same procedures as described for DOXol (8) but with half quantities of all reactants. All metabolites of DOX (1) obtained were purified by thin-layer chromatography (Takanashi and Bachur, 1976).

Table 2

\section{Synthesis of MTX (2) metabolites}

In the synthesis of MTX (2) metabolites (Table 2, entries 8-11), the mono- (16) and di(17) carboxylic acid were synthesized from the 2,3-dihydro-1,4,5,8-tetrahydroxy-9,10anthracedione scaffold (Chiccarelli et al., 1986), while glutathione conjugate (19) and the cyclic naphthoquinoxaline (20) were formed starting from MTX (2) (Blanz et al., 1991). MTX (2) and related structures were found to be resistant to reductive enzymatic activation since the quinone functional group within its structure is known to be susceptible to enzymatic oxidation (Reszka et al., 1986). None of the metabolites were purified (Chiccarelli et al., 1986, Blanz et al., 1991) 


\section{Synthesis of CTX (3) metabolites}

In in vitro studies, 4-hydroperoxycyclophosphamide (37) is used as a more stable precursor of 4-hydroxycyclophosphamide (28), the biologically activated form of CTX (3) (Gamcsik et al., 1999). Table 2 (entries 12-18) highlights the synthesis of this analogue (37) as well as of CTX (3) metabolites. The 4-hydroperoxycyclophosphamide (37) is obtained by Fenton oxidation reaction of CTX (3) (Struck et al., 1974). The synthesis of metabolites 4hydroxycyclophosphamide (28) and aldophosphamide (29) started from 4hydroperoxycyclophosphamide (37). The reaction was maintained at $22^{\circ} \mathrm{C}$ for $90 \mathrm{~min}$ to reach equilibrium between 4-hydroxycyclophosphamide (28) and aldophosphamide (29) (Manthey and Sladek, 1988). The aldophosphamide (29) oxidation originates the inactive carboxyphosphamide (33) by ALDH (Ludeman, 1999). Conversion of 4hydroxycyclophosphamide (28) to acrolein (31) and phosphoramide mustard (30) proceeds via intermediate aldophosphamide (29) (Low et al., 1982). Fragmentation to phosphoramide mustard (30) is favourable in aldophosphamide (29) but not in carboxyphosphamide (33) because of differences in electronic factors related to enolization and/or resonance. The protons $\alpha$ to the carbonyl in an aldehyde are relatively acidic, when compared with those $\alpha$ to a carboxylate group, and therefore, aldophosphamide (29) is more susceptible to a basecatalysed $\alpha, \beta$-elimination reaction than is carboxyphosphamide (33) (Ludeman, 1999). The phosphoramide mustard (30) was prepared from phenylphosphorodichloridate (Struck et al., 1994). Acrolein (31) was obtained by the condensation of formaldehyde with acetaldehyde (Dumitriu et al., 1993). The 4-ketocyclophosphamide (32) was obtained from bis(2chloroethyl)amine (Hill et al., 1970). The metabolite 2-chloroacetaldehyde (38) was synthesized from 2-chloroacetic acid (Shaw et al., 1983).

\section{Synthesis of 5-FU (4) metabolites}

The methods applied in the synthesis of 5-FU (4) metabolites are included in Table 2 (entries 19-21). The 5-FdUMP (39) was synthesized from 5-FdUrd (51) (Abraham et al., 1996). 5-FUMP (42) was obtained from 5-FUrd (50) (Fujita et al., 1994). The synthetic route to 5-FUH2 (46) occurs from 1,3-bis-(4-methoxybenzyl)-5,6-dihydro-5-fluorouracil (LaFrate and Katzenellenbogen, 2007). 
The metabolite APG050 (58) was synthesized from compound (101) (Manley et al., 2013) and the metabolite CGP74588 (52) was formed from compound (103) (Kil et al., 2007) and their precursors (99-100). The total syntheses of metabolites (52 and 58) are represented in Scheme 11.

\section{Scheme 11}

\section{Synthesis of sunitinib (6) metabolites}

The metabolite SU12662 (69) was already synthetized (Elsinghorst and Gütschow, 2009). The metabolite M8 (74) was obtained from 5-hydroxy-2-oxindole (compound 104) (Caballero et al., 2012). The total syntheses of metabolite M8 (74) is represented in Scheme 12.

\section{Scheme 12}

\section{Synthesis of sorafenib (7) metabolites}

The metabolite M-2 (83) was already synthetized from sorafenib (7) and the metabolite M-3 (85) was synthesized from M-4 (84) (Pleiss et al., 2006). The metabolite M-4 (84) was prepared with 4-chloropyridine-2-carboxamide (105) (Ghassabian et al., 2012). The syntheses of metabolite M-4 (84) and M-3 (85) are represented in Scheme 13.

\section{Scheme 13}




\section{Conclusions}

This review sums up several aspects of the metabolism of frequently used anticancer drugs that cause cardiotoxicity. For that, the available data regarding toxicity and potential synthetic routes are discussed and summarized. It is of crucial importance to investigate drug metabolism and biotransformation, since the metabolites can be responsible for the pharmacological and therapeutic actions or, on the other hand, they can cause toxicity. Anthracyclines and other cytotoxic drugs and their metabolites cause cardiotoxicity, which can lead to cardiac death. Also the new added molecules to the anticancer therapy, TKIs used in various types of cancer have a great risk of cardiotoxicity. Contrarily to cytotoxic metabolites of anthracyclines and other drugs, which have been largely studied in the past decades, TKIs cardiotoxicity is still recent and of the evaluation of their metabolites putative cardiotoxicity is scarce.

To reduce some toxic side effects observed and improve drug delivery to tumour cells, the prodrug strategy has been applied to the DOX (1), 5-FU (4) and sunitinib (6) drugs. There are many intrinsic and extrinsic factors that can influence the bioconversion mechanisms of prodrugs. The activity of many enzymes responsible for the activation of the prodrugs may be decreased or increased due to genetic polymorphisms, age-related physiological changes, drug interactions, or interspecies variations leading to adverse pharmacokinetic, pharmacodynamic, and clinical effects. At present, systemic site-specific delivery by prodrugs is applicable to a small number of currently useful therapeutic agents; however, despite of these drawbacks, the prodrug development is still of great interest and has several advantages when considering the examples in this review.

The metabolites may be isolated from biological fluids such as plasma, urine and faeces. However, in these fluids, the metabolites are present at low amounts and it is necessary to call upon synthesis. This work also provides an overview of various methods that can be used to obtain and to study metabolites of various anticancer drugs. The use of different in vitro techniques for studying drug metabolism in humans is important in the early stages of development of new drugs. Among all the in vitro models, the model that is most widely disseminated is the microsomes.

This review also remits to the synthesis of major metabolites of the drugs mentioned to obtain the appropriate quantity for further pharmacological/toxicity studies. Most metabolites are obtained by total synthesis involving oxidation and reduction reactions and for that purpose similar chemical reagents are used. The synthesis of conjugated metabolites occurs, 
in most cases, by enzyme-mediated reactions. Large amounts of pure metabolites are required for the right assessment of their potential cardiotoxicity.

Decades after the use of the conventional anticancer drugs, such as DOX (1), MTX (2), CTX (3), and 5-FU (5) in the clinical practice, the effect of their metabolites on their cardiotoxicity are not fully recognized. With TKIs use emerging, we are still in the early stage of metabolism investigation, since studies have focused in pharmacological activity studies than in cardiotoxicity studies. Therefore, cardiotoxic effects of TKI metabolites remain to be fully elucidated by new research in the coming years.

\section{Acknowledgments}

This research was partially supported through national funds provided by FCT - Foundation for Science and Technology and European Regional Development Fund (ERDF) and COMPETE under the projects PTDC/DTP-FTO/1489/2014, PTDC/MAR-BIO/4694/2014 - QREN initiative with EU/FEDER financing through COMPETE - Operational Programme for Competitiveness Factors and INNOVMAR - Innovation and Sustainability in the Management and Exploitation of Marine Resources, reference NORTE-01-0145-FEDER-000035, Research Line NOVELMAR. V.M.C. (SFRH/BPD/110001/2015) acknowledges "Fundação para a Ciência e Tecnologia (FCT)" for her Post Doc grant. 


\section{References}

Abraham, T.W., Kalman, T.I., Mcintee, E.J. \& Wagner, C.R., 1996. Synthesis and biological activity of aromatic amino acid phosphoramidates of 5-fluoro-2'-deoxyuridine and 1- $\beta$ arabinofuranosylcytosine: evidence of phosphoramidase activity. J Med Chem, 39, 45694575 .

Aminkeng, F., Bhavsar, A.P., Visscher, H., Rassekh, S.R., Li, Y., Lee, J.W., Brunham, L.R., Caron, H.N., Van Dalen, E.C., Kremer, L.C., Van Der Pal, H.J., Amstutz, U., Rieder, M.J., Bernstein, D., Carleton, B.C., Hayden, M.R. \& Ross, C.J., 2015. A coding variant in RARG confers susceptibility to anthracycline-induced cardiotoxicity in childhood cancer. Nat Genet, 47, 1079-84.

Ang, C., Kornbluth, M., Thirlwell, M.P. \& Rajan, R.D., 2010. Capecitabine-induced cardiotoxicity: case report and review of the literature. Curr Oncol, 17, 59-63.

Anon, 2006. Nexavar: INN-Sorafenib. Accessed in 5 May 2016.

Anon, 2015. Nexavar. Summary of product characteristics. Accessed in 5 May 2016.

Arellano, M., Malet-Martino, M., Martino, R. \& Gires, P., 1998. The anti-cancer drug 5-fluorouracil is metabolized by the isolated perfused rat liver and in rats into highly toxic fluoroacetate. $\mathrm{Br} J$ Cancer 77, 79-86.

Asha, S. \& Vidyavathi, M., 2010. Role of human liver microsomes in in vitro metabolism of drugs-a review. Appl Biochem Biotechnol, 160, 1699-722.

Baillie, T.A., Cayen, M.N., Fouda, H., Gerson, R.J., Green, J.D., Grossman, S.J., Klunk, L.J., Leblanc, B., Perkins, D.G. \& Shipley, L.A., 2002. Drug metabolites in safety testing. Toxicol Appl Pharmacol, 182, 188-196.

Balis, F.M., Holcenberg, J.S. \& Bleyer, W.A., 1983. Clinical pharmacokinetics of commonly used anticancer drugs. Clin Pharmacokinet, 8, 202-32.

Batra, V.K., Morrison, J.A., Woodward, D.L., Siverd, N.S. \& Yacobi, A., 1986. Pharmacokinetics of mitoxantrone in man and laboratory animals. Drug Metab Rev, 17, 311-329.

Bjornsson, T.D., Callaghan, J.T., Einolf, H.J., Fischer, V., Gan, L., Grimm, S., Kao, J., King, S.P., Miwa, G., Ni, L., Kumar, G., Mcleod, J., Obach, R.S., Roberts, S., Roe, A., Shah, A., Snikeris, F., Sullivan, J.T., Tweedie, D., Vega, J.M., Walsh, J. \& Wrighton, S.A., 2003. The conduct of in vitro and in vivo drug-drug interaction studies: a pharmaceutical research and manufacturers of america (PhRMA) perspective. Drug Metab Dispos, 31, 815-32.

Blanz, J., Mewes, K., Ehninger, G., Proksch, B., Waidelich, D., Greger, B. \& Zeller, K.P., 1991. Evidence for oxidative activation of mitoxantrone in human, pig, and rat. Drug Metab Dispos, $19,871-80$.

Boucek Jr, R.J., Olson, R.D., Brenner, D.E., Ogunbunmi, E.M., Inui, M. \& Fleischer, S., 1987. The major metabolite of doxorubicin is a potent inhibitor of membrane-associated ion pumps: a correlative study of cardiac muscle with isolated membrane fractions. J Biol Chem, 262, 15851-15856.

Brandon, E.F.A., Raap, C.D., Meijerman, I., Beijnen, J.H. \& Schellens, J.H.M., 2003. An update on in vitro test methods in human hepatic drug biotransformation research: pros and cons. Toxicol Appl Pharmacol, 189, 233-246.

Burridge, P.W., Li, Y.F., Matsa, E., Wu, H., Ong, S.G., Sharma, A., Holmstrom, A., Chang, A.C., Coronado, M.J., Ebert, A.D., Knowles, J.W., Telli, M.L., Witteles, R.M., Blau, H.M., Bernstein, D., Altman, R.B. \& Wu, J.C., 2016. Human induced pluripotent stem cell-derived cardiomyocytes recapitulate the predilection of breast cancer patients to doxorubicin-induced cardiotoxicity. Nat Med, 22, 547-56.

Caballero, J., Muñoz, C., Alzate-Morales, J.H., Cunha, S., Gano, L., Bergmann, R., Steinbach, J. \& Kniess, T., 2012. Synthesis, in silico, in vitro, and in vivo investigation of 5-[11C]methoxysubstituted sunitinib, a tyrosine kinase inhibitor of VEGFR-2. Eur J Med Chem, 58, 272-280.

Chawla, S.P., Chua, V.S., Hendifar, A.F., Quon, D.V., Soman, N., Sankhala, K.K., Wieland, D.S. \& Levitt, D.J., 2015. A phase 1B/2 study of aldoxorubicin in patients with soft tissue sarcoma. Cancer, 121, 570-579. 
Chiccarelli, F.S., Morrison, J.A., Cosulich, D.B., Perkinson, N.A., Ridge, D.N., Sum, F.W., Murdock, K.C., Woodward, D.L. \& Arnold, E.T., 1986. Identification of human urinary mitoxantrone metabolites. Cancer Res, 46, 4858-61.

Chu, T.F., Rupnick, M.A., Kerkela, R., Dallabrida, S.M., Zurakowski, D., Nguyen, L., Woulfe, K., Pravda, E., Cassiola, F., Desai, J., George, S., Harris, D.M., Ismail, N.S., Chen, J.-H., Schoen, F.J., Van Den Abbeele, A.D., Demetri, G.D., Force, T., Chen, M.H. \& Morgan, J.A., 2007. Cardiotoxicity associated with tyrosine kinase inhibitor sunitinib. Lancet, 370, 2011-2019.

Connors, T.A., Cox, P.J., Farmer, P.B., Foster, A.B. \& Jarman, M., 1974. Some studies of the active intermediates formed in the microsomal metabolism of cyclophosphamide and isophosphamide. Biochem Pharmacol., 23, 115-129.

Costa, V.M., Carvalho, F., Duarte, J.A., Bastos Mde, L. \& Remiao, F., 2013. The heart as a target for xenobiotic toxicity: the cardiac susceptibility to oxidative stress. Chem Res Toxicol, 26, 1285311.

Crombag, M.R.B.S., Joerger, M., Thürlimann, B., Schellens, J.H.M., Beijnen, J.H. \& Huitema, A.D.R., 2016. Pharmacokinetics of selected anticancer drugs in elderly cancer patients: Focus on breast cancer. Cancers, 8, 1-22.

Daumar, P., Decombat, C., Chezal, J.-M., Debiton, E., Madesclaire, M., Coudert, P. \& Galmier, M.-J., 2011. Design, synthesis and in vitro drug release investigation of new potential 5-FU prodrugs. Eur J Med Chem, 46, 2867-2879.

De Jonge, M.E., Huitema, A.D.R., Rodenhuis, S. \& Beijnen, J.H., 2005. Clinical pharmacokinetics of cyclophosphamide. Clin Pharmacokinet, 44, 1135-1164.

Di Gion, P., Kanefendt, F., Lindauer, A., Scheffler, M., Doroshyenko, O., Fuhr, U., Wolf, J. \& Jaehde, U., 2011. Clinical pharmacokinetics of tyrosine kinase inhibitors: focus on pyrimidines, pyridines and pyrroles. Clin Pharmacokinet, 50, 551-603.

Dirven, H.A., Van Ommen, B. \& Van Bladeren, P.J., 1994. Involvement of human glutathione Stransferase isoenzymes in the conjugation of cyclophosphamide metabolites with glutathione. Cancer Res, 54, 6215-20.

Dores-Sousa, J.L., Duarte, J.A., Seabra, V., Bastos Mde, L., Carvalho, F. \& Costa, V.M., 2015. The age factor for mitoxantrone's cardiotoxicity: multiple doses render the adult mouse heart more susceptible to injury. Toxicology, 329, 106-19.

Dorr, R.T. \& Lagel, K., 1994. Effect of sulfhydryl compounds and glutathione depletion on rat heart myocyte toxicity induced by 4-hydroperoxycyclophosphamide and acrolein in vitro. Chem Biol Interact, 93, 117-28.

Dumitriu, E., Hulea, V., Bilba, N., Carja, G. \& Azzouz, A., 1993. Synthesis of acrolein by vapor phase condensation of formaldehyde and acetaldehyde over oxides loaded zeolites. J Mol Catal, 79, $175-185$.

Ehninger, G., Proksch, B., Hartmann, F., Gärtner, H.-V. \& Wilms, K., 1984. Mitoxantrone metabolism in the isolated perfused rat liver. Cancer Chemother Pharmacol., 12, 50-52.

Ehninger, G., Schuler, U., Proksch, B., Zeller, K.-P. \& Blanz, J., 1990. Pharmacokinetics and Metabolism of Mitoxantrone A Review. Clin Pharmacokinet., 18, 365-380.

Ekhart, C., Doodeman, V.D., Rodenhuis, S., Smits, P.H.M., Beijnen, J.H. \& Huitema, A.D.R., 2008. Influence of polymorphisms of drug metabolizing enzymes (CYP2B6, CYP2C9, CYP2C19, CYP3A4, CYP3A5, GSTA1, GSTP1, ALDH1A1 and ALDH3A1) on the pharmacokinetics of cyclophosphamide and 4-hydroxycyclophosphamide. Pharmacogenet Genomics, 18, 515-523.

Elsinghorst, P.W. \& Gütschow, M., 2009. Synthesis of $2 \mathrm{H}$ - and 13C-labelled sunitinib and its primary metabolite. J Labelled Comp Radiopharm, 52, 360-365.

Escudier, B., Eisen, T., Stadler, W.M., Szczylik, C., Oudard, S., Siebels, M., Negrier, S., Chevreau, C., Solska, E., Desai, A.A., Rolland, F., Demkow, T., Hutson, T.E., Gore, M., Freeman, S., Schwartz, B., Shan, M., Simantov, R. \& Bukowski, R.M., 2007. Sorafenib in advanced clearcell renal-cell carcinoma. $N$ Engl J Med, 356, 125-34.

Faivre, S., Delbaldo, C., Vera, K., Robert, C., Lozahic, S., Lassau, N., Bello, C., Deprimo, S., Brega, N., Massimini, G., Armand, J.P., Scigalla, P. \& Raymond, E., 2006. Safety, pharmacokinetic, and antitumor activity of SU11248, a novel oral multitarget tyrosine kinase inhibitor, in patients with cancer. J Clin Oncol, 24, 25-35. 
Fenselau, C., Kan, M.N., Rao, S.S., Myles, A., Friedman, O.M. \& Colvin, M., 1977. Identification of aldophosphamide as a metabolite of cyclophosphamide in vitro and in vivo in humans. Cancer Res, 37, 2538-43.

Fernández, A., Sanguino, A., Peng, Z., Ozturk, E., Chen, J., Crespo, A., Wulf, S., Shavrin, A., Qin, C., Ma, J., Trent, J., Lin, Y., Han, H.-D., Mangala, L.S., Bankson, J.A., Gelovani, J., Samarel, A., Bornmann, W., Sood, A.K. \& Lopez-Berestein, G., 2007. An anticancer C-Kit kinase inhibitor is reengineered to make it more active and less cardiotoxic. J Clin Invest, 117, 4044-4054.

Force, T. \& Kolaja, K.L., 2011. Cardiotoxicity of kinase inhibitors: the prediction and translation of preclinical models to clinical outcomes. Nat Rev Drug Discov, 10, 111-126.

Force, T., Krause, D.S. \& Van Etten, R.A., 2007. Molecular mechanisms of cardiotoxicity of tyrosine kinase inhibition. Nat Rev Cancer, 7, 332-344.

Frickhofen, N., Beck, F.J., Jung, B., Fuhr, H.G., Andrasch, H. \& Sigmund, M., 2002. Capecitabine can induce acute coronary syndrome similar to 5-fluorouracil. Ann Oncol, 13, 797-801.

Fujita, K.-I., Matsukawa, A., Shibata, K., Tanaka, T., Taniguchi, M. \& Oi, S., 1994. Synthesis of 5fluorouridine 5'-diphosphate galactose from 5-fluorouridine by chemical phosphorylation and microbial uridylyl transfer. Carbohydr Res, 265, 299-302.

Fura, A., Shu, Y.-Z., Zhu, M., Hanson, R.L., Roongta, V. \& Humphreys, W.G., 2004. Discovering drugs through biological transformation: role of pharmacologically active metabolites in drug discovery. J Med Chem, 47, 4339-4351.

Gamcsik, M.P., Dolan, M.E., Andersson, B.S. \& Murray, D., 1999. Mechanisms of resistance to the toxicity of cyclophosphamide. Curr Pharm Des, 5, 587-605.

Gardner, E.R., Burger, H., Van Schaik, R.H., Van Oosterom, A.T., De Bruijn, E.A., Guetens, G., Prenen, H., De Jong, F.A., Baker, S.D., Bates, S.E., Figg, W.D., Verweij, J., Sparreboom, A. $\&$ Nooter, K., 2006. Association of enzyme and transporter genotypes with the pharmacokinetics of imatinib. Clin Pharmacol Ther, 80, 192-201.

Gasser, R., Funk, C., Matzinger, P., Klemisch, W. \& Viger-Chougnet, A., 1999. Use of transgenic cell lines in mechanistic studies of drug metabolism. Toxicol In Vitro, 13, 625-632.

Ghassabian, S., Rawling, T., Zhou, F., Doddareddy, M.R., Tattam, B.N., Hibbs, D.E., Edwards, R.J., Cui, P.H. \& Murray, M., 2012. Role of human CYP3A4 in the biotransformation of sorafenib to its major oxidized metabolites. Biochem Pharmacol, 84, 215-223.

Gibson, G.G. \& Skett, P., 2001. Introduction to drug metabolism: Nelson Thornes.

Gieschke, R., Burger, H.U., Reigner, B., Blesch, K.S. \& Steimer, J.L., 2003. Population pharmacokinetics and concentration-effect relationships of capecitabine metabolites in colorectal cancer patients. Br J Clin Pharmacol, 55, 252-63.

Goldman , J.M. \& Melo , J.V., 2003. Chronic myeloid leukemia - advances in biology and new approaches to treatment. $N$ Engl J Med, 349, 1451-1464.

Gross, E., Busse, B., Riemenschneider, M., Neubauer, S., Seck, K., Klein, H.-G., Kiechle, M., Lordick, F. \& Meindl, A., 2008. Strong Association of a Common Dihydropyrimidine Dehydrogenase Gene Polymorphism with Fluoropyrimidine-Related Toxicity in Cancer Patients. PLOS ONE, 3, e4003.

Gschwind, H.P., Pfaar, U., Waldmeier, F., Zollinger, M., Sayer, C., Zbinden, P., Hayes, M., Pokorny, R., Seiberling, M., Ben-Am, M., Peng, B. \& Gross, G., 2005. Metabolism and disposition of imatinib mesylate in healthy volunteers. Drug Metab Dispos, 33, 1503-12.

Gunaratna, C., 2000. Drug metabolism and pharmacokinetcs in drug discovery: a primer for bioanalytical chemists, part I. Bioanalyt Inc, 17-23.

Han, H.-K. \& Amidon, G.L., 2000. Targeted prodrug design to optimize drug delivery. AAPS PharmSci, 2, 48-58.

Heggie, G.D., Sommadossi, J.P., Cross, D.S., Huster, W.J. \& Diasio, R.B., 1987. Clinical pharmacokinetics of 5-fluorouracil and its metabolites in plasma, urine, and bile. Cancer Res, 47, 2203-6.

Heidelberger, C., 1975. Fluorinated pyrimidines and their nucleosides. In A.C. Sartorelli \& D.G. Johns (eds.) Antineoplastic and Immunosuppressive Agents: Part II. Berlin, Heidelberg: Springer Berlin Heidelberg, 193-231.

Hill, D.L., Kirk, M.C. \& Struck, R.F., 1970. Isolation and identification of 4-ketocyclophosphamide, a possible active form of the antitumor agent cyclophosphamide. J Am Chem Soc, 92, 3207-8. 
Huang, Q., Zhou, C., Chen, X., Dong, B., Chen, S., Zhang, N., Liu, Y., Li, A., Yao, M. \& Miao, J., 2015. Prodrug AST-003 improves the therapeutic index of the multi-targeted tyrosine kinase inhibitor sunitinib. PloS one, 10, e0141395.

Hudis, C.A., 2007. Trastuzumab--mechanism of action and use in clinical practice. N Engl J Med, 357, $39-51$.

Hudyma, T.W., Bush, K., Colson, K.L., Firestone, R.A. \& King, H.D., 1993. Synthesis and release of doxorubicin from a cephalosporin based prodrug by a $\beta$-lactamase-immunoconjugate. Bioorg Med Chem Lett, 3, 323-328.

Huttunen, K.M., Raunio, H. \& Rautio, J., 2011. Prodrugs--from serendipity to rational design. Pharmacol Rev, 63, 750-71.

Ikenaka, K., Shirasaka, T., Kitano, S. \& Fujii, S., 1979. Effect of uracil on metabolism of 5fluorouracil in vitro. Gan, 70, 353-9.

Industry, G.F., 2005. Safety testing of drug metabolites. Pharmacol and Toxicol, 1-11.

Industry, G.F., 2006. Drug interaction studies - study design, data analysis, and implications for dosing and labeling. Clin Pharmacol, 1-51.

Jamieson, D., Lee, J., Cresti, N., Jackson, R., Griffin, M., Sludden, J., Verrill, M. \& Boddy, A.V., 2014. Pharmacogenetics of adjuvant breast cancer treatment with cyclophosphamide, epirubicin and 5-fluorouracil. Cancer Chemother Pharmacol, 74, 667-674.

Jia, L. \& Liu, X., 2007. The conduct of drug metabolism studies considered good practice (II): in vitro experiments. Curr Drug Metab, 8, 822-9.

Joerger, M., Huitema, A.D.R., Meenhorst, P.L., Schellens, J.H.M. \& Beijnen, J.H., 2005. Pharmacokinetics of low-dose doxorubicin and metabolites in patients with AIDS-related kaposi sarcoma. Cancer Chemother Pharmacol, 55, 488-496.

Kerkelä, R., Grazette, L., Yacobi, R., Iliescu, C., Patten, R., Beahm, C., Walters, B., Shevtsov, S., Pesant, S. \& Clubb, F.J., 2006. Cardiotoxicity of the cancer therapeutic agent imatinib mesylate. Nat Med, 12, 908-916.

Khosravan, R., Toh, M., Garrett, M., La Fargue, J., Ni, G., Marbury, T.C., Swan, S.K., Lunde, N.M. \& Bello, C.L., 2010. Pharmacokinetics and safety of sunitinib malate in subjects with impaired renal function. J Clin Pharmacol, 50, 472-481.

Kil, K.-E., Ding, Y.-S., Lin, K.-S., Alexoff, D., Kim, S.W., Shea, C., Xu, Y., Muench, L. \& Fowler, J.S., 2007. Synthesis and positron emission tomography studies of carbon-11-labeled imatinib (Gleevec). Nucl Med Biol, 34, 153-163.

Kratz, F., 2007. DOXO-EMCH (INNO-206): the first albumin-binding prodrug of doxorubicin to enter clinical trials. Expert Opin Investig Drugs, 16, 855-66.

Kratz, F., Abu Ajaj, K. \& Warnecke, A., 2007. Anticancer carrier-linked prodrugs in clinical trials. Expert Opin Investig Drugs, 16, 1037-58.

Kratz, F., Warnecke, A., Scheuermann, K., Stockmar, C., Schwab, J., Lazar, P., Drückes, P., Esser, N., Drevs, J., Rognan, D., Bissantz, C., Hinderling, C., Folkers, G., Fichtner, I. \& Unger, C., 2002. Probing the cysteine-34 position of endogenous serum albumin with thiol-binding doxorubicin derivatives. Improved efficacy of an acid-sensitive doxorubicin derivative with specific albumin-binding properties compared to that of the parent compound. J Med Chem, $45,5523-5533$.

Lafrate, A.L. \& Katzenellenbogen, J.A., 2007. Improved chemical syntheses of 5,6-dihydro-5fluorouracil. J Org Chem, 72, 8573-8576.

Lathia, C., Lettieri, J., Cihon, F., Gallentine, M., Radtke, M. \& Sundaresan, P., 2006. Lack of effect of ketoconazole-mediated CYP3A inhibition on sorafenib clinical pharmacokinetics. Cancer Chemother Pharmacol, 57, 685-92.

Lebrecht, D., Geist, A., Ketelsen, U.P., Haberstroh, J., Setzer, B., Kratz, F. \& Walker, U.A., 2007. The 6-maleimidocaproyl hydrazone derivative of doxorubicin (DOXO-EMCH) is superior to free doxorubicin with respect to cardiotoxicity and mitochondrial damage. Int J Cancer, 120, 92734.

Lenihan, D.J. \& Kowey, P.R., 2013. Overview and management of cardiac adverse events associated with tyrosine kinase inhibitors. Oncologist, 18, 900-8. 
Levine, E.S., Friedman, H.S., Griffith, O.W., Colvin, O.M., Raynor, J.H. \& Lieberman, M., 1993. Cardiac cell toxicity induced by 4-hydroperoxycyclophosphamide is modulated by glutathione. Cardiovasc Res, 27, 1248-53.

Licata, S., Saponiero, A., Mordente, A. \& Minotti, G., 2000. Doxorubicin metabolism and toxicity in human myocardium: role of cytoplasmic deglycosidation and carbonyl reduction. Chem Res Toxicol, 13, 414-20.

Lin, J.H. \& Lu, A.Y., 1997. Role of pharmacokinetics and metabolism in drug discovery and development. Pharmacol Rev, 49, 403-49.

Lipshultz, S.E., Cochran, T.R., Franco, V.I. \& Miller, T.L., 2013. Treatment-related cardiotoxicity in survivors of childhood cancer. Nat Rev Clin Oncol, 10, 697-710.

Liu, X. \& Jia, L., 2007. The conduct of drug metabolism studies considered good practice (I): analytical systems and in vivo studies. Curr Drug Metab, 8, 815-821.

Longley, D.B., Harkin, D.P. \& Johnston, P.G., 2003. 5-fluorouracil: mechanisms of action and clinical strategies. Nat Rev Cancer, 3, 330-8.

Low, J.E., Borch, R.F. \& Sladek, N.E., 1982. Conversion of 4-hydroperoxycyclophosphamide and 4hydroxycyclophosphamide to phosphoramide mustard and acrolein mediated by bifunctional catalysis. Cancer Res, 42, 830-7.

Ludeman, S.M., 1999. The chemistry of the metabolites of cyclophosphamide. Curr Pharm Des, 5, 627-644.

Luffer-Atlas, D., 2008. Unique/Major human metabolites: why, how, and when to test for safety in animals. Drug Metab Rev, 40, 447-463.

Ma, S., Subramanian, R., Xu, Y., Schrag, M. \& Shou, M., 2008. Structural characterization of novel adenine dinucleotide phosphate conjugates of imatinib in incubations with rat and human liver microsomes. Drug Metab Dispos, 36, 2414-8.

Ma, S., Xu, Y. \& Shou, M., 2009. Characterization of imatinib metabolites in rat and human liver microsomes: differentiation of hydroxylation from $\mathrm{N}$-oxidation by liquid chromatography/atmospheric pressure chemical ionization mass spectrometry. Rapid Commun Mass Spectrom, 23, 1446-50.

Maddin, N., Husin, A., Gan, S.H., Aziz, B.A. \& Ankathil, R., 2016. Impact of CYP3A4*18 and CYP3A5*3 Polymorphisms on Imatinib Mesylate Response Among Chronic Myeloid Leukemia Patients in Malaysia. Oncol Ther, 4, 303-314.

Maharsy, W., 2015. Chemotherapy induced cardiotoxicity: facts, breakthroughs, and challenges. $J$ Med, 5, 51-56.

Maharsy, W., Aries, A., Mansour, O., Komati, H. \& Nemer, M., 2014. Ageing is a risk factor in imatinib mesylate cardiotoxicity. Eur J Heart Fail, 16, 367-376.

Malet-Martino, M. \& Martino, R., 2002. Clinical studies of three oral prodrugs of 5-fluorouracil (capecitabine, UFT, S-1): a review. Oncologist, 7, 288-323.

Manley, P.W., Blasco, F., Mestan, J. \& Aichholz, R., 2013. The kinetic deuterium isotope effect as applied to metabolic deactivation of imatinib to the des-methyl metabolite, CGP74588. Bioorg Med Chem, 21, 3231-3239.

Manthey, C.L. \& Sladek, N.E., 1988. Kinetic characterization of the catalysis of "activated" cyclophosphamide (4-hydroxycyclophosphamide/aldophosphamide) oxidation to carboxyphosphamide by mouse hepatic aldehyde dehydrogenases. Biochem Pharmacol, 37, 2781-2790.

Marull, M. \& Rochat, B., 2006. Fragmentation study of imatinib and characterization of new imatinib metabolites by liquid chromatography-triple-quadrupole and linear ion trap mass spectrometers. J Mass Spectrom, 41, 390-404.

Matsubara, I., Kamiya, J. \& Imai, S., 1980. Cardiotoxic effects of 5-fluorouracil in the guinea pig. Jpn J Pharmacol, 30, 871-9.

Mellor, H.R., Bell, A.R., Valentin, J.P. \& Roberts, R.R., 2011. Cardiotoxicity associated with targeting kinase pathways in cancer. Toxicol Sci, 120, 14-32.

Menna, P., Gonzalez Paz, O., Chello, M., Covino, E., Salvatorelli, E. \& Minotti, G., 2012. Anthracycline cardiotoxicity. Expert Opin Drug Saf, 11, S21-S36.

Mewes, K., Blanz, J., Ehninger, G., Gebhardt, R. \& Zeller, K.P., 1993. Cytochrome P-450-induced cytotoxicity of mitoxantrone by formation of electrophilic intermediates. Cancer Res, 53. 
Minotti, G., Cavaliere, A.F., Mordente, A., Rossi, M., Schiavello, R., Zamparelli, R. \& Possati, G., 1995. Secondary alcohol metabolites mediate iron delocalization in cytosolic fractions of myocardial biopsies exposed to anticancer anthracyclines. Novel linkage between anthracycline metabolism and iron-induced cardiotoxicity. J Clin Invest., 95, 1595-1605.

Minotti, G., Licata, S., Saponiero, A., Menna, P., Calafiore, A.M., Di Giammarco, G., Liberi, G., Animati, F., Cipollone, A., Manzini, S. \& Maggi, C.A., 2000. Anthracycline metabolism and toxicity in human myocardium: comparisons between doxorubicin, epirubicin, and a novel disaccharide analogue with a reduced level of formation and [4Fe-4S] reactivity of its secondary alcohol metabolite. Chem Res Toxicol, 13, 1336-41.

Mita, M.M., Natale, R.B., Wolin, E.M., Laabs, B., Dinh, H., Wieland, S., Levitt, D.J. \& Mita, A.C., 2015. Pharmacokinetic study of aldoxorubicin in patients with solid tumors. Invest New Drugs, 33, 341-348.

Miwa, M., Ura, M., Nishida, M., Sawada, N., Ishikawa, T., Mori, K., Shimma, N., Umeda, I. \& Ishitsuka, H., 1998. Design of a novel oral fluoropyrimidine carbamate, capecitabine, which generates 5-fluorouracil selectively in tumours by enzymes concentrated in human liver and cancer tissue. Eur J Cancer, 34, 1274-81.

Monneret, C., Gagnet, R. \& Florent, J.-C., 1993. Synthesis of cyclophosphamide analogs from aminotrideoxy sugars. Carbohydr Res, 240, 313-322.

Moore, M.J., 1991. Clinical Pharmacokinetics of Cyclophosphamide. Clin Pharmacokinet, 20, 194208.

Nakajima, M., Komagata, S., Fujiki, Y., Kanada, Y., Ebi, H., Itoh, K., Mukai, H,, Yokoi, T. \& Minami, H., 2007. Genetic polymorphisms of CYP2B6 affect the pharmacokinetics/pharmacodynamics of cyclophosphamide in Japanese cancer patients. Pharmacogenet Genomics, 17, 431-445.

Nakamura, S., Aoki, M., Mori, A., Nakahara, T., Sakamoto, K. \& Ishii, K., 2010. [Analysis of cardiac toxicity caused by cyclophosphamide in the $\mathrm{H} 9 \mathrm{c} 2$ cell line and isolated and perfused rat hearts]. Gan To Kagaku Ryoho, 37, 677-80.

Nielsen, D.L., Andersson, M. \& Kamby, C., 2009. HER2-targeted therapy in breast cancer. Monoclonal antibodies and tyrosine kinase inhibitors. Cancer Treat Rev, 35, 121-36.

Nih, 2013. Capecitabine. https://www.cancer.gov/about-cancer/treatment/drugs/capecitabine. Accessed in 22 March 2017.

Obach, R.S., 2013. Pharmacologically active drug metabolites: impact on drug discovery and pharmacotherapy. Pharmacol Rev, 65, 578-640.

Olson, R.D., Mushlin, P.S., Brenner, D.E., Fleischer, S., Cusack, B.J., Chang, B.K. \& Boucek Jr, R.J., 1988. Doxorubicin cardiotoxicity may be caused by its metabolite, doxorubicinol. Proc Natl Acad Sci U S A, 85, 3585-3589.

Orphanos, G.S., Ioannidis, G.N. \& Ardayanis, A.G., 2009. Cardiotoxicity induced by tyrosine kinase inhibitors. Acta Oncol, 48, 964-970.

Panousis, C., Kettle, A.J. \& Phillips, D.R., 1997. Neutrophil-mediated activation of mitoxantrone to metabolites which form adducts with DNA. Cancer Lett, 113, 173-178.

Peer, C.J., Sissung, T.M., Kim, A., Jain, L., Woo, S., Gardner, E.R., Kirkland, C.T., Troutman, S.M., English, B.C., Richardson, E.D., Federspiel, J., Venzon, D., Dahut, W., Kohn, E., Kummar, S., Yarchoan, R, Giaccone, G., Widemann, B. \& Figg, W.D., 2012. Sorafenib is an inhibitor of UGT1A1 but is metabolized by UGT1A9: implications of genetic variants on pharmacokinetics and hyperbilirubinemia. Clin Cancer Res, 18, 2099-107.

Perez, E.A., Koehler, M., Byrne, J., Preston, A.J., Rappold, E. \& Ewer, M.S., 2008. Cardiac safety of lapatinib: pooled analysis of 3689 patients enrolled in clinical trials. Mayo Clin Proc, 83, 67986.

Petros, W.P., Hopkins, P.J., Spruill, S., Broadwater, G., Vredenburgh, J.J., Colvin, O.M., Peters, W.P., Jones, R.B., Hall, J. \& Marks, J.R., 2005. Associations Between Drug Metabolism Genotype, Chemotherapy Pharmacokinetics, and Overall Survival in Patients With Breast Cancer. J Clin Oncol, 23, 6117-6125.

Pleiss, U., Gerisch, M. \& Seidel, D., 2006. Syntheses of [2H3, 15N], [14C]Nexavar ${ }^{\mathrm{TM}}$ and its labeled metabolites. J Labelled Comp Radiopharm, 49, 603-613. 
Pratt, C.B., Vietti, T.J., Etcubanas, E., Sexauer, C., Krance, R.A., Mahoney, D.H. \& Patterson, R.B., 1986. Novantrone for childhood malignant solid tumors. A pediatric oncology group phase II study. Invest New Drugs, 4, 43-8.

Raj, S., Franco, V.I. \& Lipshultz, S.E., 2014. Anthracycline-induced cardiotoxicity: a review of pathophysiology, diagnosis, and treatment. Curr Treat Options Cardiovasc Med, 16.

Rautio, J., Kumpulainen, H., Heimbach, T., Oliyai, R., Oh, D., Jarvinen, T. \& Savolainen, J., 2008. Prodrugs: design and clinical applications. Nat Rev Drug Discov, 7, 255-270.

Reis-Mendes, A., Gomes, A.S., Carvalho, R.A., Carvalho, F., Remiao, F., Pinto, M., Bastos, M.L., Sousa, E. \& Costa, V.M., 2016a. Naphthoquinoxaline metabolite of mitoxantrone is less cardiotoxic than the parent compound and it can be a more cardiosafe drug in anticancer therapy. Arch Toxicol.

Reis-Mendes, A.F., Sousa, E., De Lourdes Bastos, M. \& Costa, V.M., 2016b. The role of the metabolism of anticancer drugs in their induced-cardiotoxicity. Curr Drug Metab, 17, 75-90.

Ren, S., Yang, J.S., Kalhorn, T.F. \& Slattery, J.T., 1997. Oxidation of cyclophosphamide to 4hydroxycyclophosphamide and deschloroethylcyclophosphamide in human liver microsomes. Cancer Res, 57, 4229-35.

Reszka, K., Kolodziejczyk, P. \& William Lown, J., 1986. Horseradish peroxidase-catalyzed oxidation of mitoxantrone: spectrophotometric and electron paramagnetic resonance studies. $J$ Free Radic Biol Med, 2, 25-32.

Richard, B., Fabre, G., De Sousa, G., Fabre, I., Rahmani, R. \& Cano, J.P., 1991. Interspecies variability in mitoxantrone metabolism using primary cultures of hepatocytes isolated from rat, rabbit and humans. Biochem Pharmacol, 41, 255-262.

Rochat, B., 2005. Role of cytochrome P450 activity in the fate of anticancer agents and in drug resistance: focus on tamoxifen, paclitaxel and imatinib metabolism. Clin Pharmacokinet, 44, 349-66.

Rollas, S. \& Küçükgüzel, Ş.G., 2008. Hydrazone, amide, carbamate, macromolecular and other prodrugs of doxorubicin. Open Drug Deliv J, 2, 77-85.

Rooseboom, M., Commandeur, J.N.M. \& Vermeulen, N.P.E., 2004. Enzyme-catalyzed activation of anticancer prodrugs. Pharmacol Rev, 56, 53-102.

Rossato, L.G., Costa, V.M., Dallegrave, E., Arbo, M., Silya, R., Ferreira, R., Amado, F., DinisOliveira, R.J., Duarte, J.A., De Lourdes Bastos, M., Palmeira, C. \& Remiao, F., 2014. Mitochondrial cumulative damage induced by mitoxantrone: late onset cardiac energetic impairment. Cardiovasc Toxicol, 14, 30-40.

Rossato, L.G., Costa, V.M., De Pinho, P.G., Arbo, M.D., De Freitas, V., Vilain, L., De Lourdes Bastos, M., Palmeira, C. \& Remião, F., 2013. The metabolic profile of mitoxantrone and its relation with mitoxantrone-induced cardiotoxicity. Arch Toxicol, 87, 1809-1820.

Salvatorelli, E., Menna, P. \& Minotti, G., 2015. Managing anthracycline-induced cardiotoxicity: beginning with the end in mind. Future Cardiol, 11, 363-366.

Sawyer, D.B., 2013. Anthracyclines and Heart Failure. N Engl J Med, 368, 1154-1156.

Senturk, T., Kanat, O., Evrensel, T. \& Aydinlar, A., 2009. Capecitabine-induced cardiotoxicity mimicking myocardial infarction. Neth Heart J, 17, 277-80.

Seong, S.J., Lim, M., Sohn, S.K., Moon, J.H., Oh, S.J., Kim, B.S., Ryoo, H.M., Chung, J.S., Joo, Y.D., Bang, S.M., Jung, C.W., Kim, D.H., Park, S.Y., Yoon, S.S., Kim, I., Lee, H.G., Won, J.H., Min, Y.H., Cheong, J.W., Park, J.S., Eom, K.S., Hyun, M.S., Kim, M.K., Kim, H., Park, M.R., Park, J., Kim, C.S., Kim, H.J., Kim, Y.K., Park, E.K., Zang, D.Y., Jo, D.Y., Lee, H.W. \& Yoon, Y.R., 2013. Influence of enzyme and transporter polymorphisms on trough imatinib concentration and clinical response in chronic myeloid leukemia patients. Ann Oncol, 24, 75660 .

Sharma, A., Burridge, P.W., Mckeithan, W.L., Serrano, R., Shukla, P., Sayed, N., Churko, J.M., Kitani, T., Wu, H., Holmstrom, A., Matsa, E., Zhang, Y., Kumar, A., Fan, A.C., Del Alamo, J.C., Wu, S.M., Moslehi, J.J., Mercola, M. \& Wu, J.C., 2017. High-throughput screening of tyrosine kinase inhibitor cardiotoxicity with human induced pluripotent stem cells. Sci Transl Med, 9.

Shaw, I.C., Graham, M.I. \& Mclean, A.E.M., 1983. 2-Chloroacetaldehyde, a metabolite of cyclophosphamide in the rat. Xenobiotica, 13, 433-437. 
Shipp, N.G., Dorr, R.T., Alberts, D.S., Dawson, B.V. \& Hendrix, M., 1993. Characterization of experimental mitoxantrone cardiotoxicity and its partial inhibition by ICRF-187 in cultured neonatal rat heart cells. Cancer Res, 53, 550-6.

Skarka, A., Skarydova, L., Stambergova, H. \& Wsol, V., 2011. Anthracyclines and their metabolism in human liver microsomes and the participation of the new microsomal carbonyl reductase. Chem Biol Interact, 191, 66-74.

Slamon , D.J., Leyland-Jones , B., Shak , S., Fuchs , H., Paton , V., Bajamonde , A., Fleming , T., Eiermann , W., Wolter , J., Pegram , M., Baselga , J. \& Norton , L., 2001. Use of chemotherapy plus a monoclonal antibody against HER2 for metastatic breast cancer that overexpresses HER2. N Engl J Med, 344, 783-792.

Smith, L.A., Cornelius, V.R., Plummer, C.J., Levitt, G., Verrill, M., Canney, P. \& Jones, A., 2010. Cardiotoxicity of anthracycline agents for the treatment of cancer: systematic review and meta-analysis of randomised controlled trials. BMC Cancer, 10, 337.

Speed, B., Bu, H.Z., Pool, W.F., Peng, G.W., Wu, E.Y., Patyna, S., Bello, C. \& Kang, P., 2012. Pharmacokinetics, distribution, and metabolism of [14C]sunitinib in rats, monkeys, and humans. Drug Metab Dispos, 40, 539-55.

Speed, W., Bello, C., Peng, G., Patyna, S. \& Wu, E., 2008. In vitro and in vivo metabolism of sunitinib in nonclinical species and humans. Cancer Research, 68, 1285-1285.

Stella, V.J., Charman, W.N.A. \& Naringrekar, V.H., 1985. Prodrugs. Drugs, 29, 455-473.

Struck, R.F., Schmid, S.M. \& Waud, W.R., 1994. Antitumor activity of halogen analogs of phosphoramide, isophosphoramide, and triphosphoramide mustards, the cytotoxic metabolites of cyclophosphamide, ifosfamide, and trofosfamide. Cancer Chemother Pharmacol, 34, 1916.

Struck, R.F., Thorpe, M.C., Coburn, W.C. \& Laster, W.R., 1974. Cyclophosphamide. Complete inhibition of murine leukemia L1210 in vivo by a fenton oxidation product. J Am Chem Soc, 96, 313-315.

Strumberg, D., Clark, J.W., Awada, A., Moore, M.J., Richly, H., Hendlisz, A., Hirte, H.W., Eder, J.P., Lenz, H.-J. \& Schwartz, B., 2007. Safety, pharmacokinetics, and preliminary antitumor activity of sorafenib: a review of four phase I trials in patients with advanced refractory solid tumors. Oncologist, 12, 426-437.

Takanashi, S. \& Bachur, N.R., 1976. Adriamycin metabolism in man. Evidence from urinary metabolites. Drug Metab Dispos, 4, 79-87.

Telli, M.L., Witteles, R.M., Fisher, G.A. \& Srinivas, S., 2008. Cardiotoxicity associated with the cancer therapeutic agent sunitinib malate. Ann Oncol, 19, 1613-8.

Unger, C., Haring, B., Medinger, M., Dreys, J., Steinbild, S., Kratz, F. \& Mross, K., 2007. Phase I and pharmacokinetic study of the (6-maleimidocaproyl)hydrazone derivative of doxorubicin. Clin Cancer Res, 13, 4858-66.

Van Erp, N.P., Gelderblom, H. \& Guchelaar, H.J., 2009. Clinical pharmacokinetics of tyrosine kinase inhibitors. Cancer Treat Rev, 35, 692-706.

Van Erp, N.P., Gelderblom, H., Karlsson, M.O., Li, J., Zhao, M., Ouwerkerk, J., Nortier, J.W., Guchelaar, H.J., Baker, S.D. \& Sparreboom, A., 2007. Influence of CYP3A4 inhibition on the steady-state pharmacokinetics of imatinib. Clin Cancer Res, 13, 7394-400.

Veal, G.J., Cole, M., Chinnaswamy, G., Sludden, J., Jamieson, D., Errington, J., Malik, G., Hill, C.R., Chamberlain, T. \& Boddy, A.V., 2016. Cyclophosphamide pharmacokinetics and pharmacogenetics in children with B-cell non-Hodgkin's lymphoma. Eur J Cancer, 55, 56-64.

Vejpongsa, P. \& Yeh, E.T.H., 2014. Prevention of anthracycline-induced cardiotoxicity: challenges and opportunities. J Am Coll Cardiol, 64, 938-945.

Venn, R.F., 2008. Principles and practice of bioanalysis: CRC Press.

Voon, P.J., Yap, H.L., Ma, C.Y.T., Lu, F., Wong, A.L., Sapari, N.S., Soong, R., Soh, T.I., Goh, B.C. \& Lee, H.S., 2013. Correlation of aldo- ketoreductase (AKR) 1C3 genetic variant with doxorubicin pharmacodynamics in Asian breast cancer patients. Br J Clin Pharmacol, 75, 1497-1505.

Walko, C.M. \& Lindley, C., 2005. Capecitabine: a review. Clin Ther, 27, 23-44. 
Weenen, H., Van Maanen, J.M.S., De Planque, M.M., Mcvie, J.G. \& Pinedo, H.M., 1984. Metabolism of 4'-modified analogs of doxorubicin. Unique glucuronidation pathway for 4'-epidoxorubicin. Eur J Cancer Clin Oncol, 20, 919-926.

Wijesinghe, N., Thompson, P.I. \& Mcalister, H., 2006. Acute coronary syndrome induced by capecitabine therapy. Heart Lung Circ, 15, 337-339.

Wolf, C.R., Macpherson, J.S. \& Smyth, J.F., 1986. Evidence for the metabolism of mitozantrone by microsomal glutathione transferases and 3-methylcholanthrene-inducible glucuronosyl transferases. Biochem Pharmacol, 35, 1577-81.

Yule, S.M., Price, L., Mcmahon, A.D., Pearson, A.D.J. \& Boddy, A.V., 2004. Cyclophosphamide Metabolism in Children with Non-Hodgkin's Lymphoma. Clin Cancer Res, 10, 455.

Zhang, R.W., Soong, S.J., Liu, T.P., Barnes, S. \& Diasio, S.B., 1992. Pharmacokinetics and tissue distribution of 2-fluoro-beta-alanine in rats. Potential relevance to toxicity pattern of 5fluorouracil. Drug Metab Dispos, 20, 113-9.

Zhang, S., Liu, X., Bawa-Khalfe, T., Lu, L.-S., Lyu, Y.L., Liu, L.F. \& Yeh, E.T.H., 2012. Identification of the molecular basis of doxorubicin-induced cardiotoxicity. Nat Med, 18, 1639-1642.

\section{List of Figures Captions:}

Figure 1 - Anticancer drugs approached in this work: DOX (1), MTX (2), CTX (3), 5-FU (4), imatinib (5), sunitinib (6), and sorafenib (7).

Figure 2 - Compound WBZ_4 (60) (Fernández et al., 2007) and N-deuteromethyl analogue (61) (Manley et al., 2013).

Figure 3 - A - Prodrugs of DOX (1) that have been assessed clinically. PK1 and PK2 compounds incorporate galactosamine as a targeting ligand (Kratz et al., 2007). B Aldoxorubicin (90) prodrug of DOX (1) conjugated to a linker hydrazine, a 6-carbon spacer, and a thiol-binding maleimide (Chawla et al., 2015).

Figure 4 - Prodrugs of sunitinib (6) (Huang et al., 2015).

Scheme 1 - Biotransformation of drugs and its consequences (Gunaratna, 2000).

Scheme 2 - Metabolites resulting from DOX (1). AKR - aldo/ketoreductase; CBR - carbonyl reductase; a) deglycosylation; b) $O$-dealkylation; c) sulfation; d) glucuronidation (Takanashi and Bachur, 1976, Voon et al., 2013).

Scheme 3 - Metabolites resulting from MTX (2) ( Mewes et al., 1993, Rossato et al., 2013, Reis-Mendes et al., 2016b).

Scheme 4 - The main metabolites resulting from CTX (3). CTX (3) is extensively metabolized in the liver by CYP450 enzymes to active/toxic metabolites [(4- 
hydroxycyclophosphamide (28), aldophosphamide (29), phosphoramide mustard (30), and acrolein (31)], and inactive metabolites [4-ketocyclophosphamide (32), carboxyphosphamide (33), dechloroethylcyclophosphamide (34), 4-glutathionylcyclophosphamide (35), and diglutathionylphosphoramide mustard (36)]. Other enzymes are involved and several nonenzymatic catalysed reactions occur. CYP - cytochrome P450; GST - glutathione Stransferase; ALDH - aldehyde dehydrogenase ( Dirven et al., 1994, De Jonge et al., 2005, Ekhart et al., 2008, Jamieson et al., 2014).

Scheme 5 - Intracellular anabolism and catabolism of 5-FU (4). DPD - dihydropyrimidine dehydrogenase (Malet-Martino and Martino, 2002, Gross et al., 2008, Jamieson et al., 2014). Scheme 6 - Metabolites of imatinib (5) and identified metabolic processes: a) $\mathrm{N}$ demethylation; b) hydroxylation; c) $N$-oxidation; d) $N$-demethylation and oxidation; e) oxidation; f) deamination and oxidation. CYP - cytochrome P450 (Gschwind et al., 2005, Ma et al., 2008, van Erp et al., 2009).

Scheme 7 - Proposed pathways for metabolism of sunitinib (6) in rat, monkey, and human. Metabolite M11 (82) was a major radioactive component in monkey urine and faeces. Glu glucuronide; CYP - cytochrome P450 (van Erp et al., 2009, Speed et al., 2012).

Scheme 8 - Metabolites of sorafenib (7). UGT - uridine glucuronosyl transferase; CYP cytochrome P450 (Lathia et al., 2006, Ghassabian et al., 2012, Peer et al., 2012).

Scheme 9 - Metabolic pathway of CAP (92). a) Carboxylesterase (liver); b) Cyd deaminase (liver, tumours); c) dThdPase (tumours) (Málet-Martino and Martino, 2002).

Scheme 10 - Model proposed for AST-003 (97) bioactivation. a) Esterase (Huang et al., 2015).

Scheme 11 - Total syntheses of metabolite CGP74588 (52) and APG050 (58) (Kil et al., 2007, Manley et al., 2013). $\mathrm{Et}_{3} \mathrm{~N}$ - triethylamine.

Scheme 12 - Total synthesis of metabolite M8 (74) (Caballero et al., 2012). PIFA phenyliodine(III)bis(trifluoroacatate).

Scheme 13 - Synthesis of metabolite M-2 (83) (Pleiss et al., 2006). DMF dimethylformamide. 

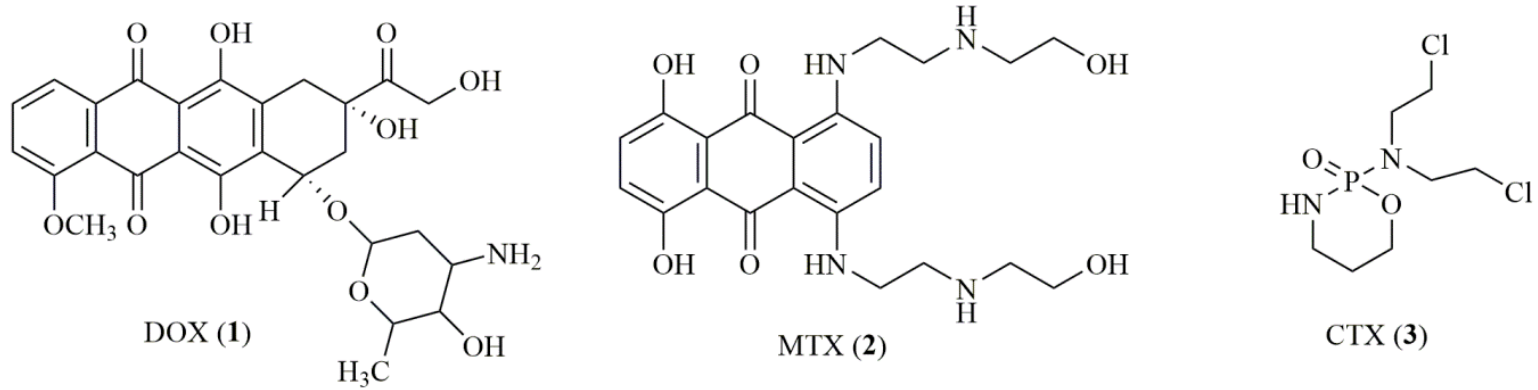<smiles>O=c1[nH]cc(F)c(=O)[nH]1</smiles>

5-FU (4)<smiles>Cc1ccc(NC(=O)c2ccc(CN3CCN(C)CC3)cc2)cc1Nc1nccc(-c2cccnc2)n1</smiles>

Imatinib (5)<smiles>CNC(=O)c1cc(Oc2ccc(NC(=O)Nc3ccc(Cl)c(C(F)(F)F)c3)cc2)ccn1</smiles>

Sorafenib (7)<smiles>C1CCCCC1</smiles><smiles>CCC</smiles><smiles>C/C=N\CC</smiles><smiles>Cc1ccc(-c2ccnc(Nc3cc(NC(=O)c4ccc(CN5CCN(C)CC5)cc4)ccc3C)n2)cc1</smiles> 
A

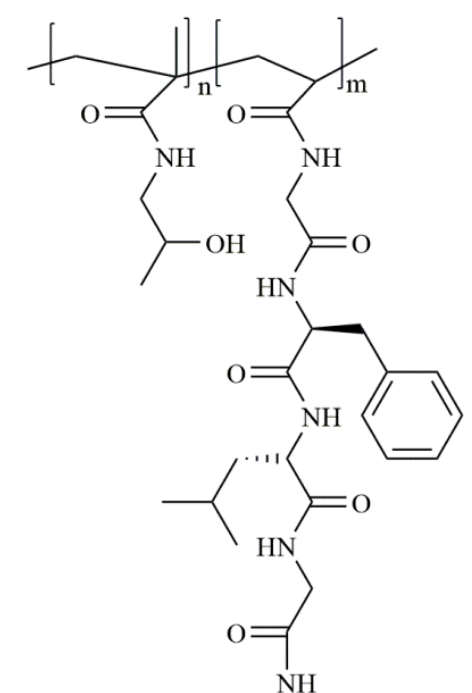

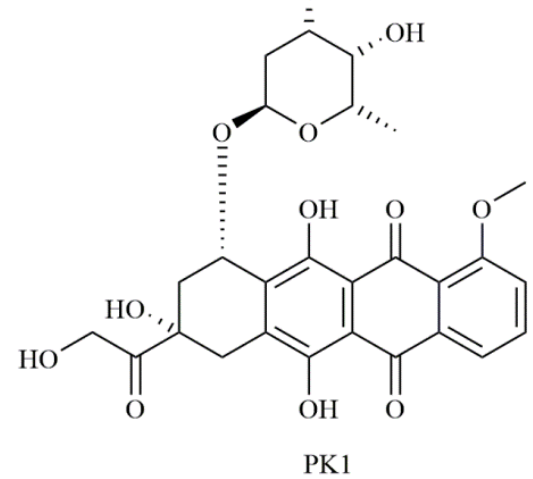
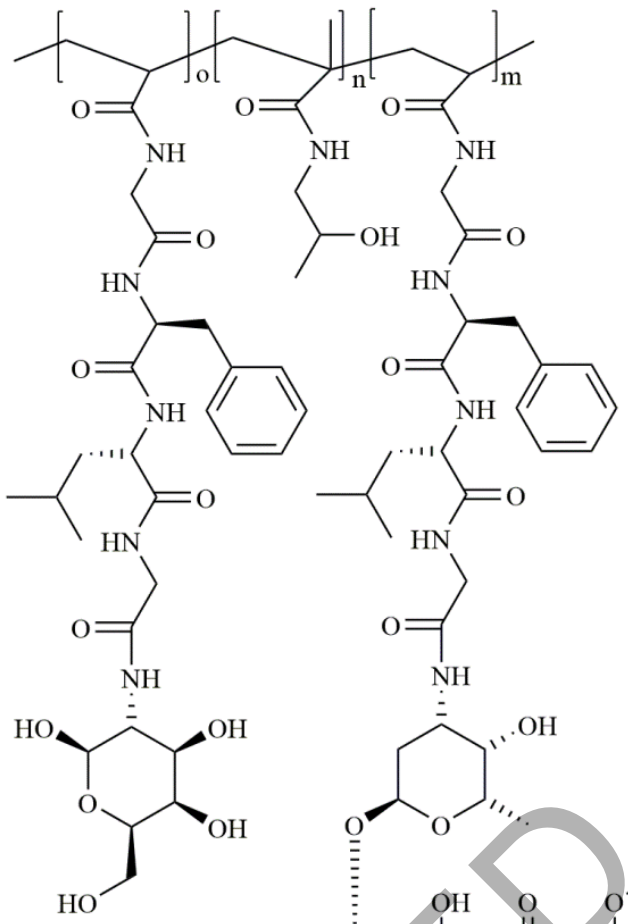

Galactosamine

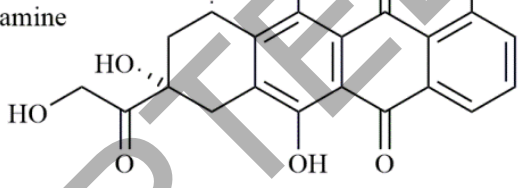

PK2

B

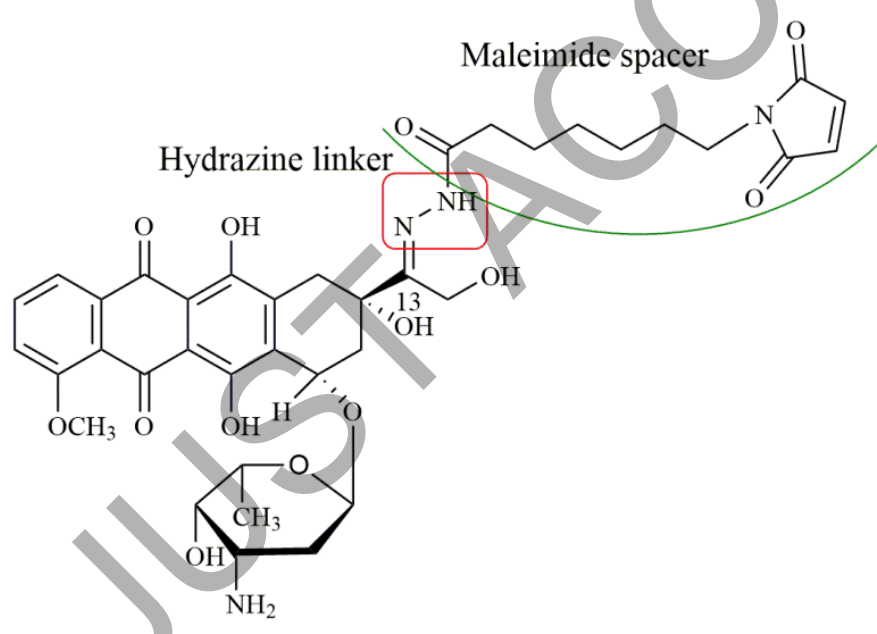

Aldoxorubicin (91) 


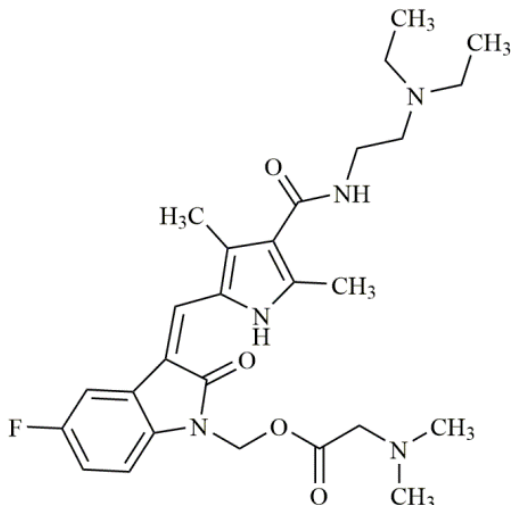

AST-001 (95)

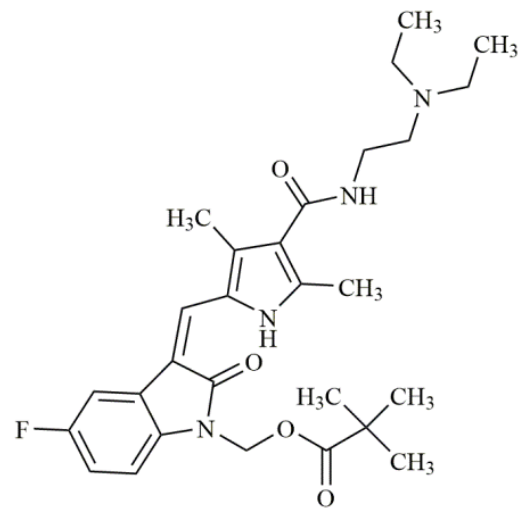

AST-002 (96)

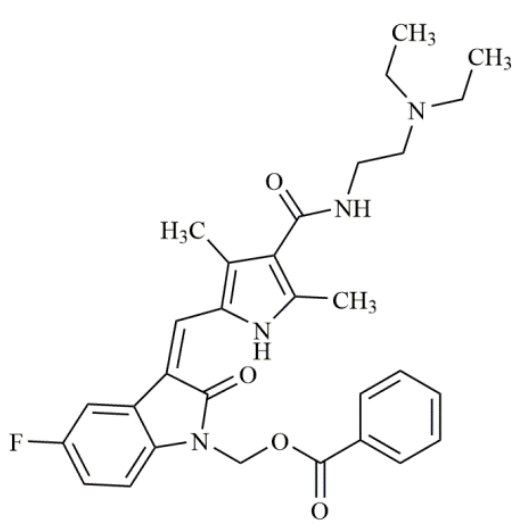

AST-003 (97)

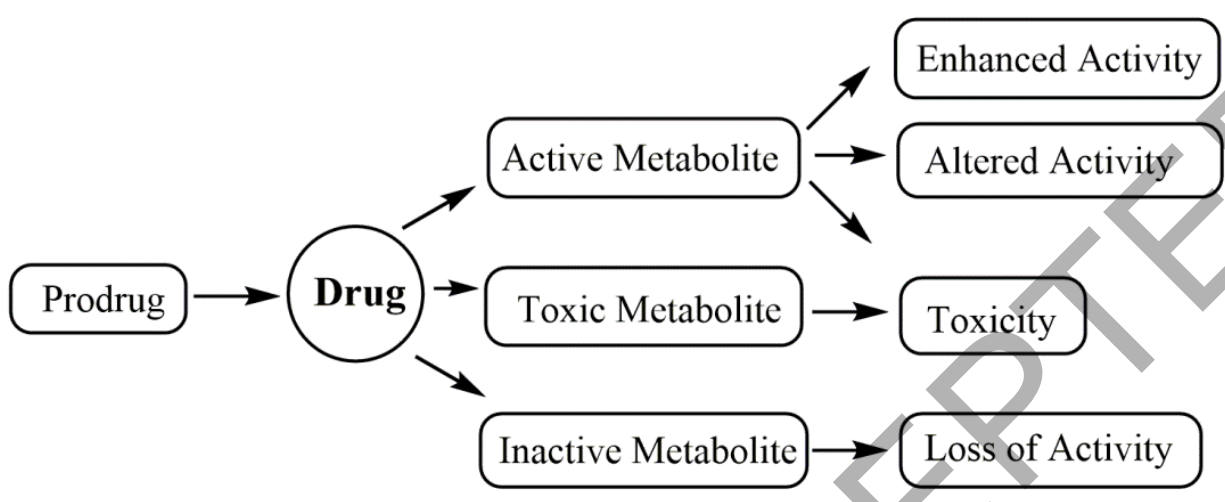


<smiles>CCOc1cccc2c1C(=O)c1c(O)c3c(c(O)c1C2=O)CC[C@](CC)(C(=O)CO)C3</smiles>

7-Deoxydoxorubicin aglycone (11)

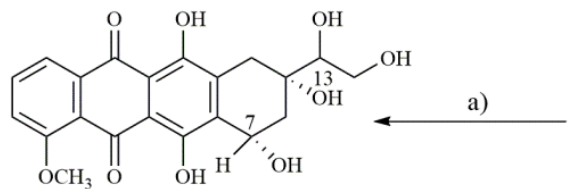

7-Hydroxydoxorubicinol aglycone (14)

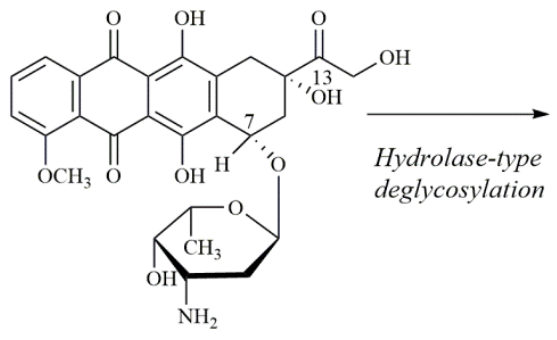<smiles>COc1cccc2c1C(=O)c1c(O)c3c(c(O)c1C2=O)CC(C[C@H](O)CO)(C(=O)CO)CC3</smiles>

7-Hydroxydoxorubicin aglycone (9)

$\operatorname{DOX}(\mathbf{1})$

NADPH-dependent cytoplasmatic aldo/keto - AKR or carbonyl-reductases - CBR

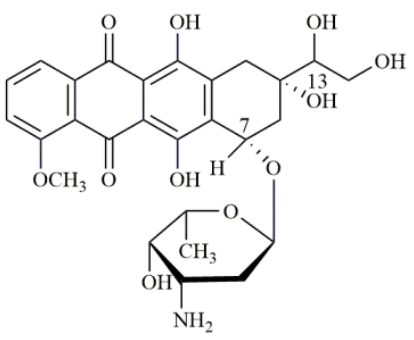

DOXol (8) $\mid \begin{aligned} & \text { Reductase-type } \\ & \text { deglycosylation }\end{aligned}$

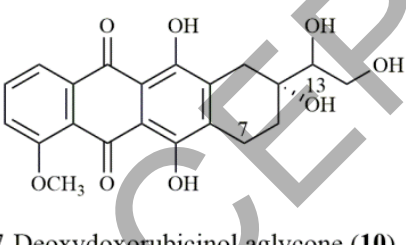

7-Deoxydoxorubicinol aglycone (10)<smiles>[CH]1C=C1</smiles>

b)

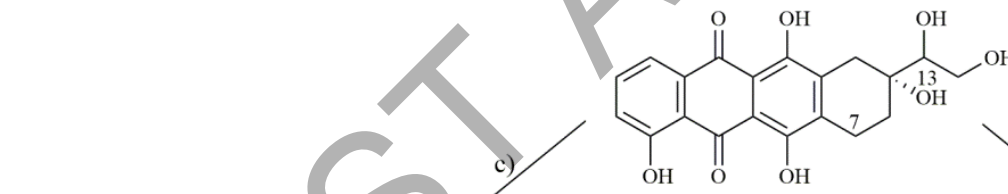

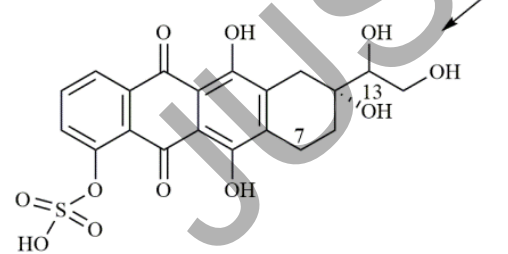

Demethyldeoxydoxorubicinol aglycone (15)

Demethyldeoxydoxorubicinol aglycone 4- $O$-sulfate (12)

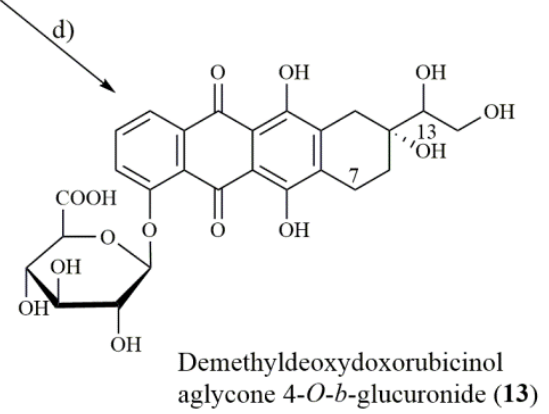




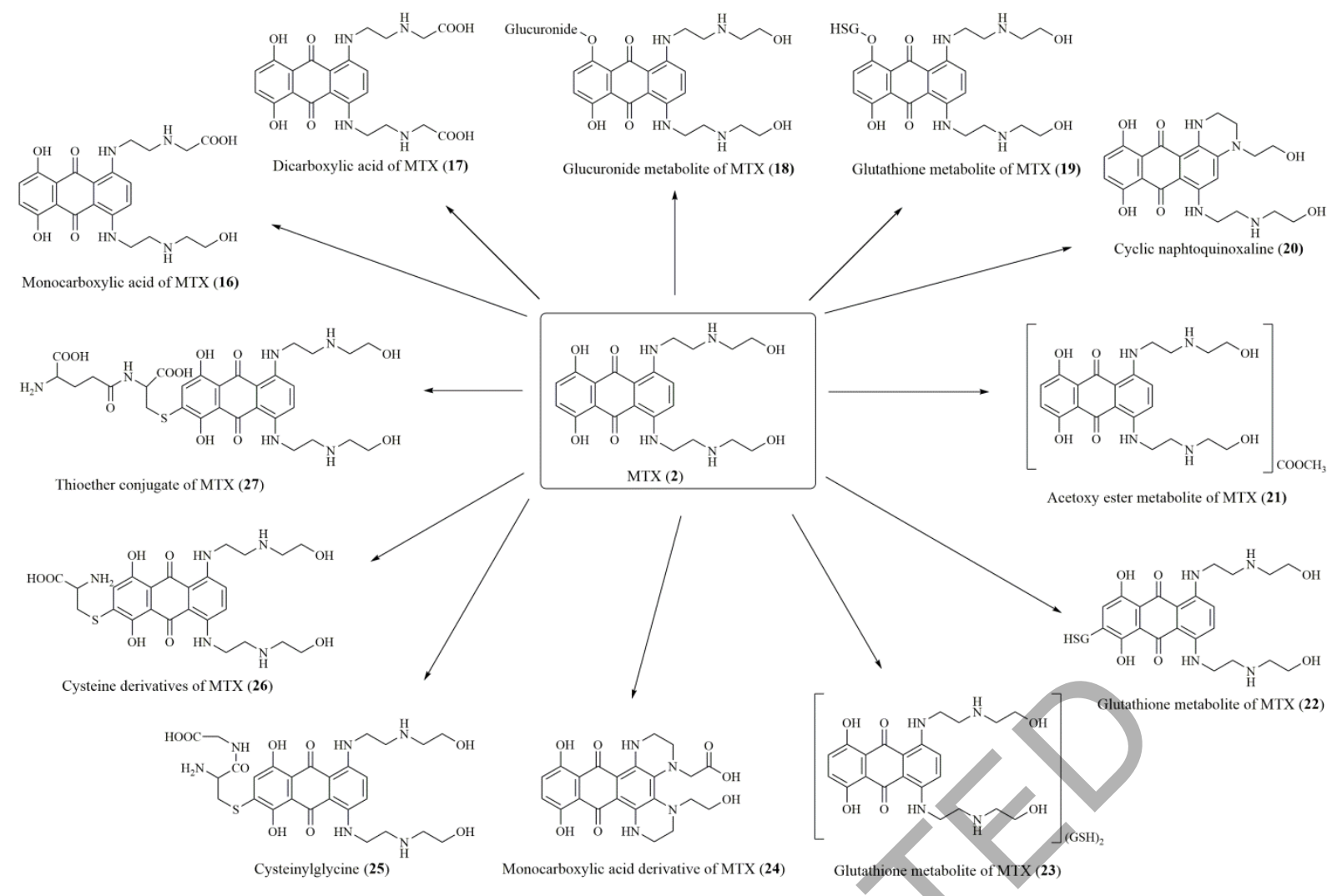


<smiles>O=P1(NCCCl)NCCCO1</smiles>

Dechloroethylcyclophosphamide (34)

$$
\mathrm{Cl} \longrightarrow \mathrm{O}
$$

Chloroacetaldeyde (38)
CYP3A4

CYP3A5

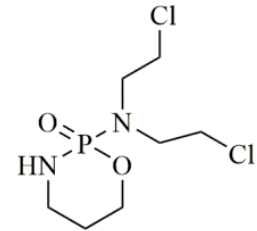

CTX (3)

CYP2B6

CYP2C9

CYP2C19

CYP3A4

CYP3A5<smiles>O=P1(N(CCCl)CCCl)NC([Si])CCO1</smiles>

4-Glutathionylcyclophosphamide (35)
GSTA1

GSTP1<smiles>O=P1(NCCCl)NC(O)CCO1</smiles>

4-Hydroxycyclophosphamide (28)

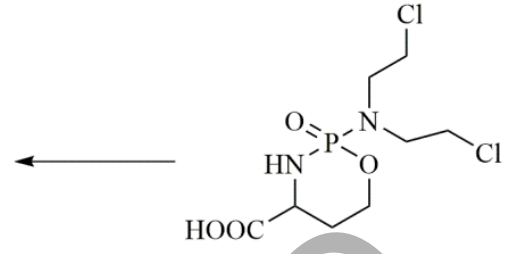

4-Hydroperoxycyclophosphamide (37)
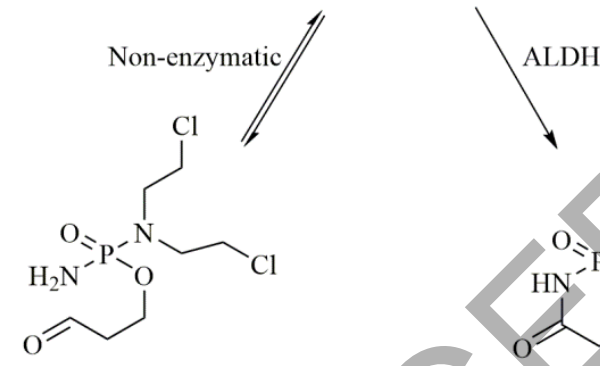

$\mathrm{Cl}$

Aldophosphamide (29)

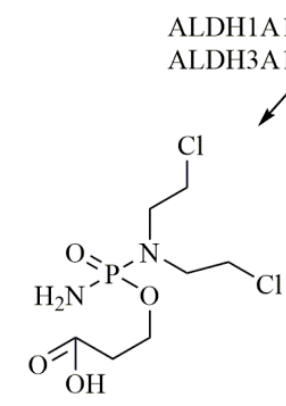

Carboxyphosphamide (33)

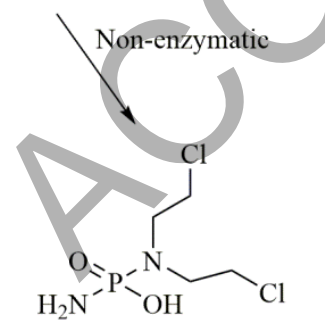

Phosphoramide mustard (30) GSTA1

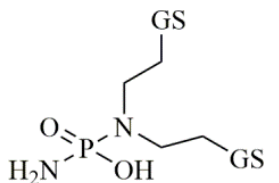

Diglutathionylphosphoramide mustard (36) 


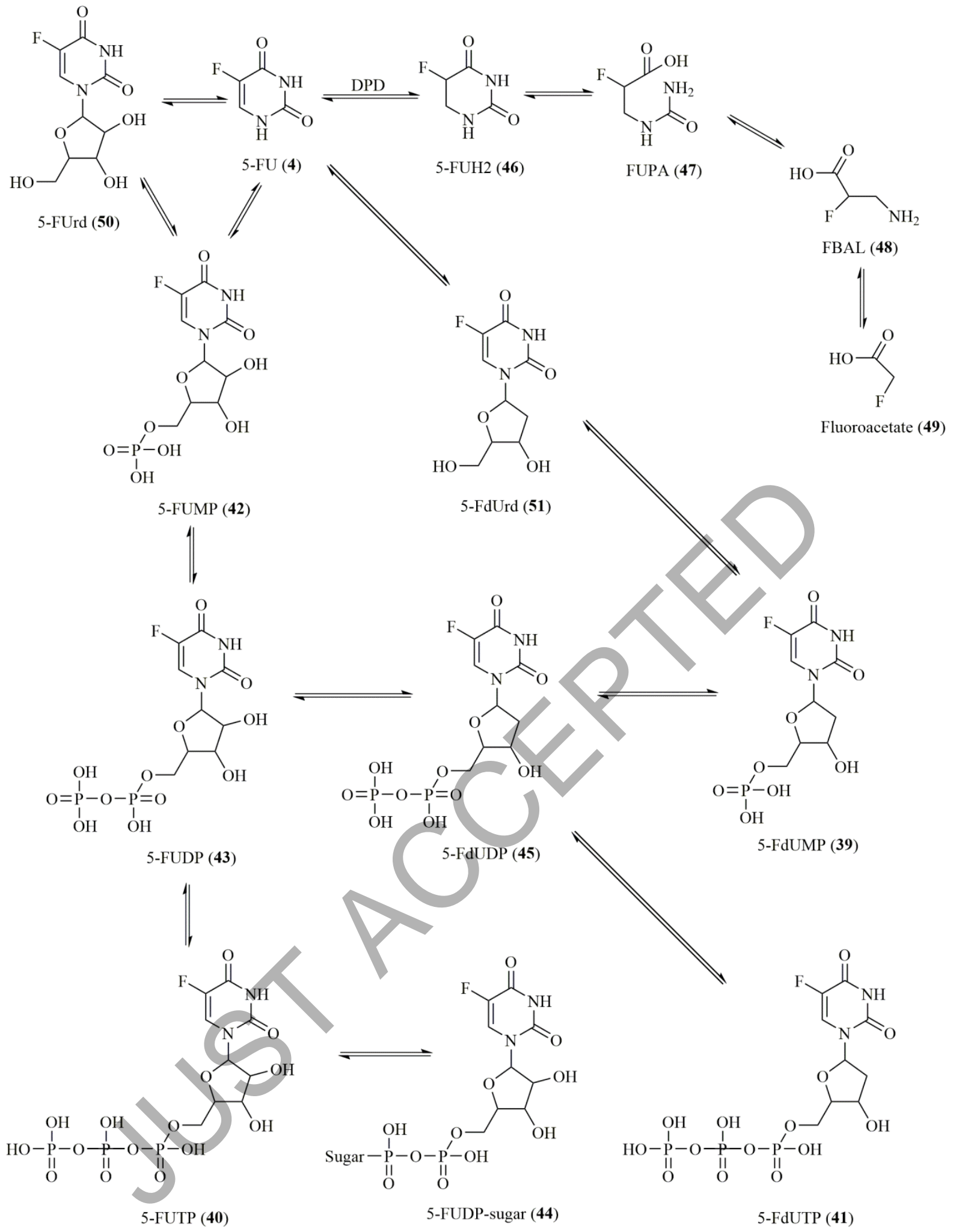




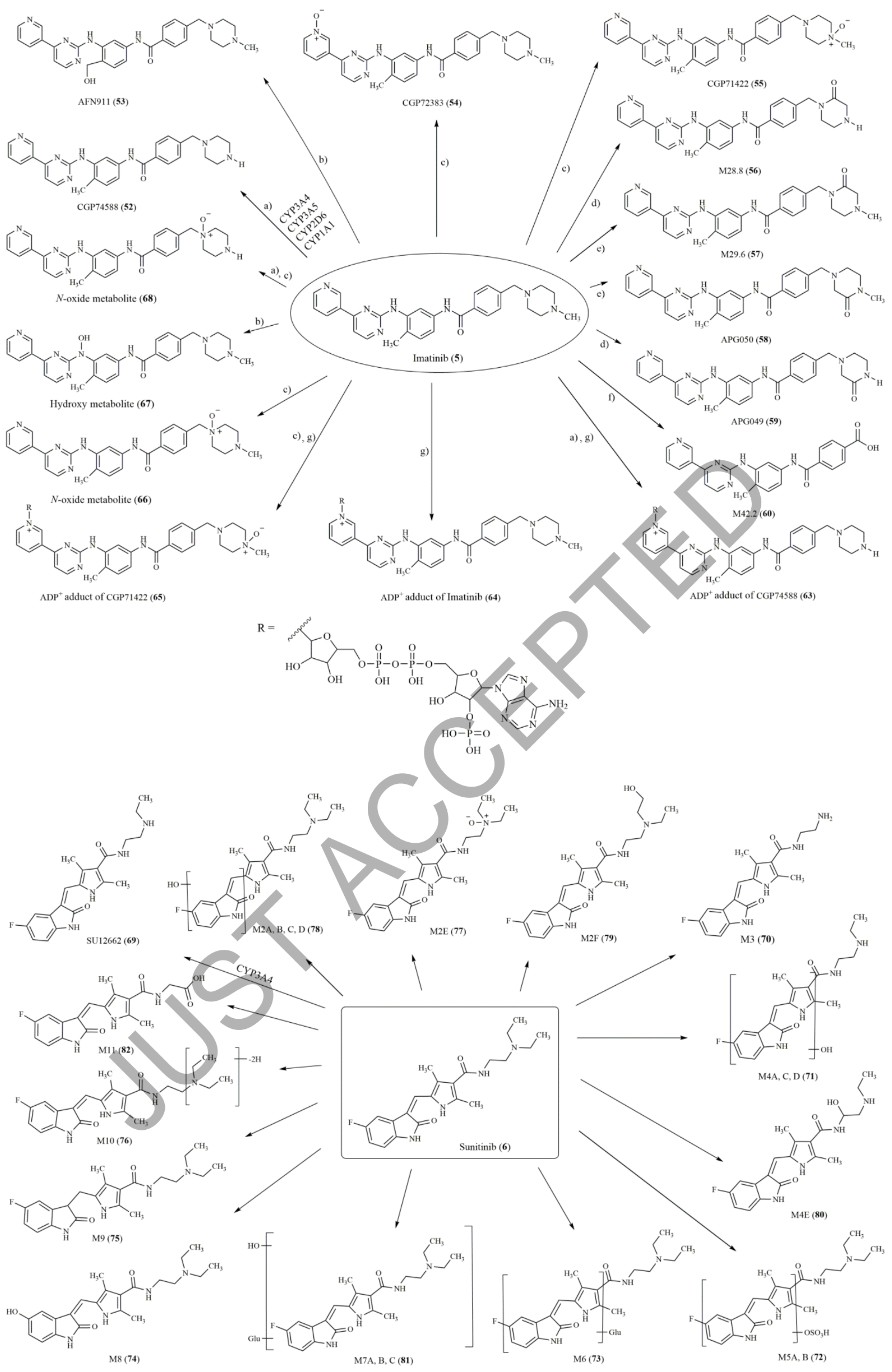




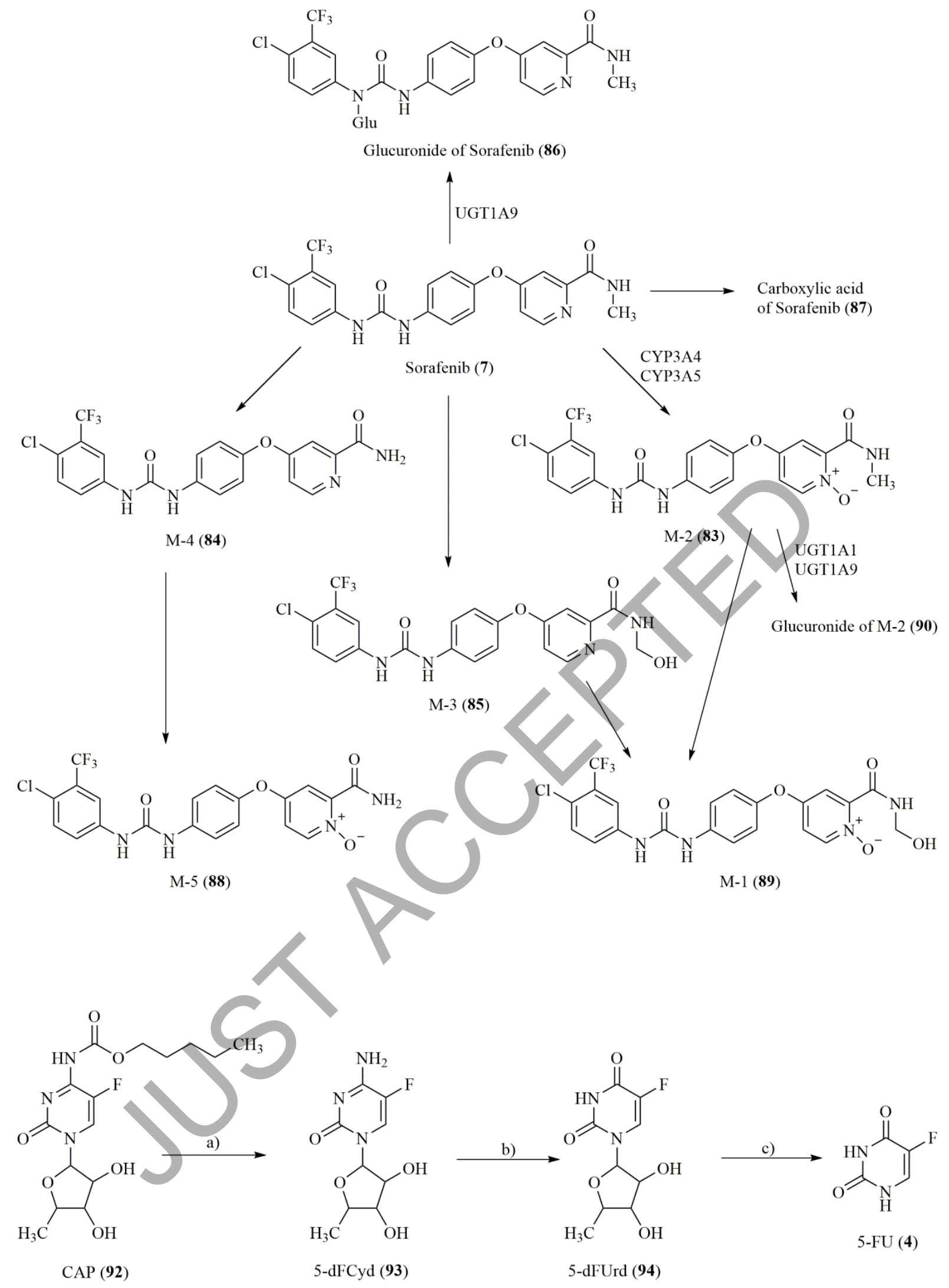


<smiles>CCN(CC)CCNC(=O)c1c(C)[nH]c(/C=c2/c(=C/c3c(/C=C4\C(=O)Nc5ccc(F)cc54)[nH]c(C)c3C(=O)NCCN(CC)CC)c(=O)n(COC(=O)c3ccccc3)c3ccc(F)cc23)c1C</smiles>

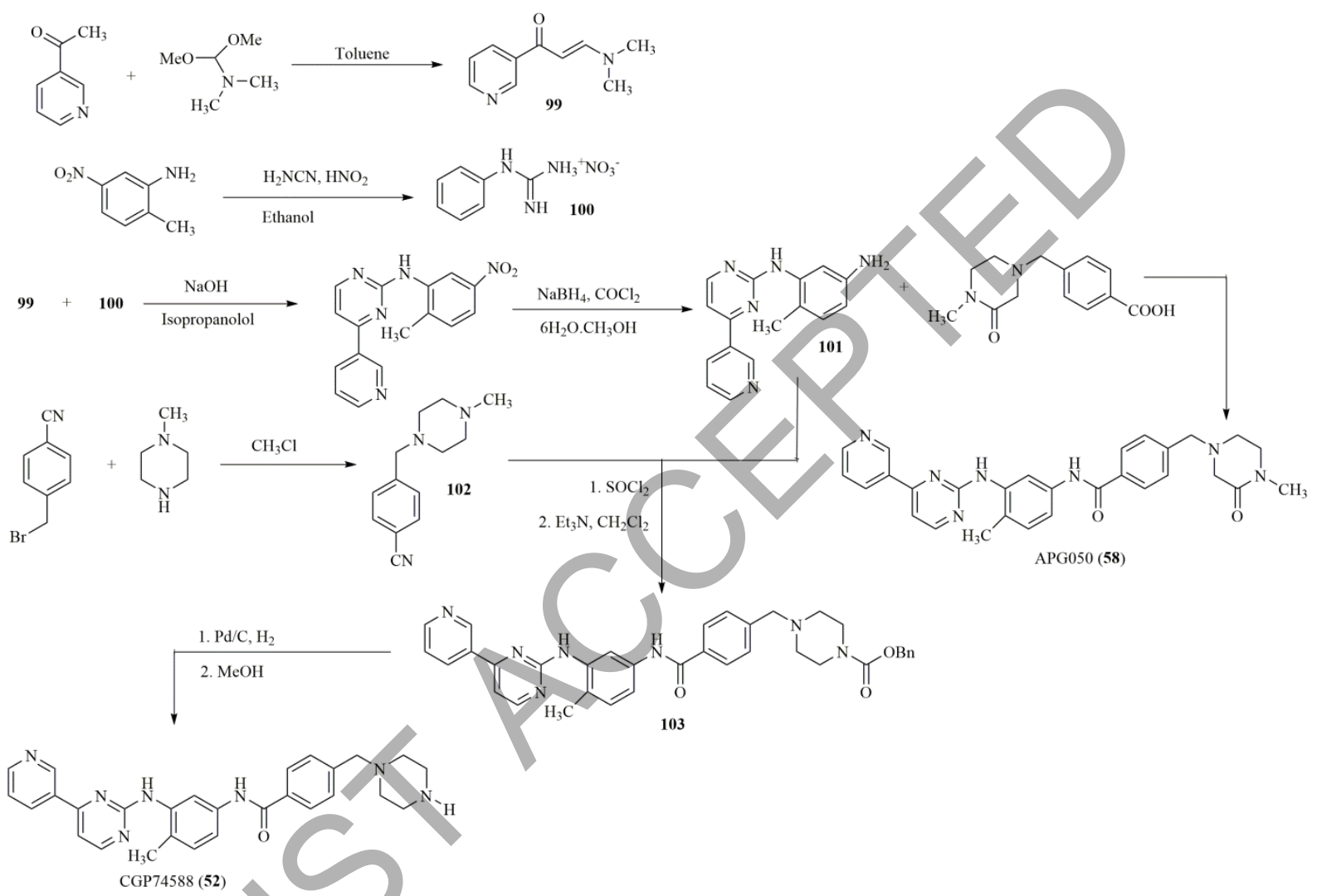

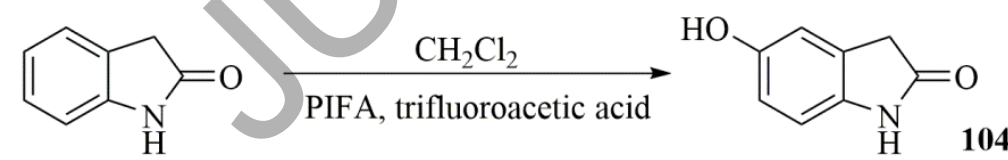<smiles>CCC(CC)CCNC(=O)c1c(C)[nH]c(C=O)c1C=CCOCCOCCO</smiles> 
<smiles>CC(C)(C)[13C](C)(C)C</smiles><smiles>NC(=O)c1cc(Oc2ccc(NC(=O)Nc3ccc(Cl)c(C(F)(F)F)c3)cc2)ccn1</smiles>

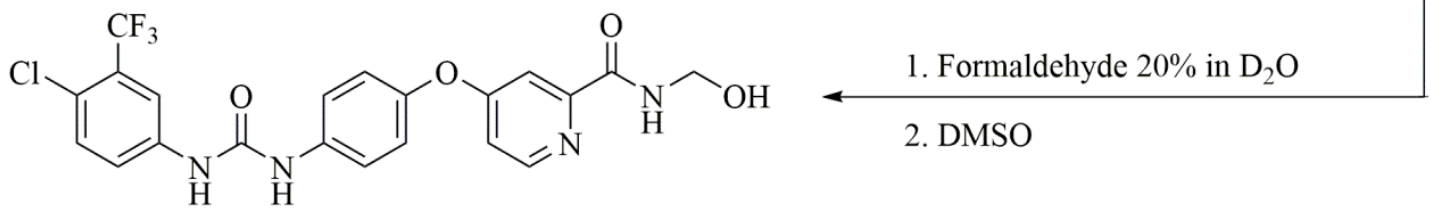

M-3 (85) 
Table 1. Commonly used in vitro models of drug metabolism.

\begin{tabular}{|c|c|c|c|c|}
\hline In vitro model & Advantages & Disadvantages & Requirements & References \\
\hline $\begin{array}{l}\text { Microsomes } \\
\text { Vesicles of the } \\
\text { endoplasmic } \\
\text { reticulum; usually } \\
\text { obtained from the } \\
\text { liver and they } \\
\text { contain CYP and } \\
\text { UGT. }\end{array}$ & $\begin{array}{l}\text { Can be obtained } \\
\text { from every organ or } \\
\text { animal source; easy } \\
\text { preparation and use; } \\
\text { good long-term } \\
\text { stability at }-80{ }^{\circ} \mathrm{C} \text {; } \\
\text { low cost; they can be } \\
\text { obtained from frozen } \\
\text { or portions of } \\
\text { organs; fully } \\
\text { characterized human } \\
\text { microsomes are } \\
\text { commercially } \\
\text { available; inter- } \\
\text { individual variation } \\
\text { can also be studied; } \\
\text { one of the best } \\
\text { characterized in vitro } \\
\text { model for research in } \\
\text { drug metabolism; it } \\
\text { allows gathering } \\
\text { information } \\
\text { regarding metabolic } \\
\text { profile, stability, } \\
\text { metabolite } \\
\text { identification, and } \\
\text { kinetics. }\end{array}$ & $\begin{array}{l}\text { Non-microsomal metabolism is } \\
\text { not studied, since other enzymes } \\
\text { namely GST, NAT, and ST, and } \\
\text { cytosolic cofactors are absent. } \\
\text { Therefore, some metabolites are } \\
\text { not detected that would have been } \\
\text { formed in intact cells; } \\
\text { unsuitability for quantitative } \\
\text { estimations of in vivo human } \\
\text { biotransformation because of the } \\
\text { presence of high level CYPs and } \\
\text { UGTs and no competition with } \\
\text { other enzymes; the in vitro } \\
\text { incubation conditions, such as the } \\
\text { ionic strength, pH value of the } \\
\text { incubation medium, and the } \\
\text { organic solvents, can affect the } \\
\text { outcomes of the studies. }\end{array}$ & $\begin{array}{l}\text { NADPH- } \\
\text { regenerating system, } \\
\text { when CYP-mediated } \\
\text { metabolism is } \\
\text { studied. UDP- } \\
\text { glucuronic acid is } \\
\text { required in the } \\
\text { reaction media, when } \\
\text { the glucuronidation- } \\
\text { mediated metabolism } \\
\text { is to be studied. }\end{array}$ & $\begin{array}{c}\text { (Gunaratna, } \\
\text { 2000), (Asha } \\
\text { and } \\
\text { Vidyavathi, } \\
\text { 2010) }\end{array}$ \\
\hline $\begin{array}{l}\text { Supersomes } \\
\text { Microsomes and } \\
\text { baculo virus (they } \\
\text { are also called } \\
\text { baculosomes) are } \\
\text { placed in insect } \\
\text { cells. }\end{array}$ & $\begin{array}{l}\text { Allow the unique } \\
\text { specification } \\
\text { expressing enzyme } \\
\text { activity of one single } \\
\text { CYP isoform. }\end{array}$ & $\begin{array}{l}\text { In UGT supersomes, the UGT } \\
\text { active site is shielded behind a } \\
\text { hydrophobic barrier, resulting in } \\
\text { latent glucuronidations, but this } \\
\text { can be overcome using a pore- } \\
\text { forming agent like alamethicin; } \\
\text { non-microsomal metabolism is } \\
\text { not studied. }\end{array}$ & $\begin{array}{l}\text { Same requirements } \\
\text { as microsomes. }\end{array}$ & $\begin{array}{c}\text { (Asha and } \\
\text { Vidyavathi, } \\
\text { 2010), } \\
\text { (Brandon } e t\end{array}$ \\
\hline $\begin{array}{l}\text { Cytosolic liver } \\
\text { fractions } \\
\text { Contain phase II } \\
\text { enzymes such as } \\
\text { GST, NAT, and } \\
\text { ST; obtained by a } \\
\text { differential } \\
\text { centrifugation of } \\
\text { whole-liver } \\
\text { homogenate. }\end{array}$ & $\begin{array}{l}\text { Allow the } \\
\text { biotransformation by } \\
\text { NAT, ST, and GST } \\
\text { to be studied either } \\
\text { separately or in } \\
\text { combination } \\
\text { depending of the } \\
\text { cofactors added. }\end{array}$ & $\begin{array}{l}\text { Only the soluble phase II } \\
\text { enzymes present in the liver } \\
\text { cytosol fractions can be } \\
\text { investigated. The metabolic } \\
\text { pathways of UGT or CYPs, } \\
\text { which are located on the } \\
\text { endoplasmic reticulum, cannot be } \\
\text { investigated with this model. }\end{array}$ & $\begin{array}{l}\text { The factors to be } \\
\text { added depend on the } \\
\text { cytosolic enzyme to } \\
\text { be studied. E.g. } \\
\text { glutathione is } \\
\text { required for GST } \\
\text { catalysis. }\end{array}$ & $a l ., 2003)$ \\
\hline
\end{tabular}




\begin{tabular}{|c|c|c|c|c|}
\hline $\begin{array}{l}\text { S9 fractions } \\
\text { Correspond to the } \\
\text { post- } \\
\text { mitochondrial } \\
\text { supernatant } \\
\text { fraction from } \\
\text { homogenized } \\
\text { liver. They are a } \\
\text { mixture of } \\
\text { microsomes and } \\
\text { cytosol content of } \\
\text { a tissue. }\end{array}$ & $\begin{array}{l}\text { Contain a wide } \\
\text { variety of phase I } \\
\text { and phase II } \\
\text { enzymes including } \\
\text { CYPs, flavin- } \\
\text { monooxygenases, } \\
\text { carboxylesterases, } \\
\text { epoxide hydrolases, } \\
\text { UGT, ST, } \\
\text { methyltransferases, } \\
\text { acetyltransferases, } \\
\text { GST and other drug } \\
\text { metabolizing } \\
\text { enzymes. } \\
\text { As in microsomes, } \\
\text { S9 fractions can be } \\
\text { prepared from } \\
\text { various tissues, } \\
\text { although the most } \\
\text { commonly used is } \\
\text { the hepatic tissue. }\end{array}$ & $\begin{array}{l}\text { CYP activity in the } S 9 \text { fractions is } \\
\text { approximately } 20-25 \% \text { of those } \\
\text { in the corresponding microsomal } \\
\text { fraction. }\end{array}$ & $\begin{array}{l}\text { The factors to be } \\
\text { added depend on the } \\
\text { enzymes or group of } \\
\text { enzymes to be } \\
\text { studied. }\end{array}$ & \\
\hline $\begin{array}{l}\text { Cell lines } \\
\text { Human liver cell } \\
\text { lines include Hep } \\
\text { G2 (from } \\
\text { hepatocellular } \\
\text { carcinoma), BC2 } \\
\text { (hepatoma), Hep } \\
\text { 3B } \\
\text { (hepatocellular } \\
\text { carcinoma), C3A } \\
\text { (hepatoblastoma), } \\
\text { PLC/PRF/5 } \\
\text { (hepatoma), } \\
\text { HepaGR (from a } \\
\text { human hepatic } \\
\text { progenitor) and } \\
\text { others. }\end{array}$ & $\begin{array}{l}\text { Can be isolated from } \\
\text { primary tumours of } \\
\text { the liver } \\
\text { parenchyma; they } \\
\text { are easy to culture } \\
\text { and usually present a } \\
\text { stable enzyme } \\
\text { concentration. Cell } \\
\text { lines are often used } \\
\text { for drug metabolism } \\
\text { studies when } \\
\text { enzymes are induced } \\
\text { and in cytotoxicity } \\
\text { studies with the } \\
\text { parental drug or its } \\
\text { metabolites. }\end{array}$ & $\begin{array}{l}\text { Less popular for metabolic } \\
\text { studies. Cell lines often go } \\
\text { dedifferentiation of their cellular } \\
\text { characteristics and they also have } \\
\text { incomplete expression of all } \\
\text { families of metabolic enzymes, } \\
\text { when compared to other in vitro } \\
\text { models. Since they have low } \\
\text { expression or even null } \\
\text { expression of some important } \\
\text { phase I and phase II drug- } \\
\text { metabolizing enzymes, it is } \\
\text { difficult to investigate the } \\
\text { individual CYPs or other } \\
\text { enzymes metabolites in this } \\
\text { model. }\end{array}$ & $\begin{array}{l}\text { They should } \\
\text { resemble the normal } \\
\text { physiology of human } \\
\text { hepatocytes in vivo } \\
\text { and usually no } \\
\text { addition of } \\
\text { enzymatic cofactors } \\
\text { is required. }\end{array}$ & $\begin{array}{l}\text { (Asha and } \\
\text { Vidyavathi, } \\
\text { 2010), } \\
\text { (Brandon et } \\
\text { al., 2003) }\end{array}$ \\
\hline $\begin{array}{l}\text { Transgenic cell } \\
\text { lines } \\
\text { A cell line } \\
\text { expressing phase } \\
\text { I and/or phase II } \\
\text { enzymes through } \\
\text { recombinant }\end{array}$ & $\begin{array}{l}\text { Are most useful for } \\
\text { the characterization } \\
\text { and identification of } \\
\text { specific metabolic } \\
\text { pathways, to } \\
\text { generate metabolites } \\
\text { for structure }\end{array}$ & $\begin{array}{l}\text { Higher price when compared to } \\
\text { other in vitro models and this } \\
\text { model does not reflect a complete } \\
\text { in vivo situation as they express } \\
\text { only the isozymes transfected. }\end{array}$ & $\begin{array}{l}\text { Usually no addition } \\
\text { of enzymatic } \\
\text { cofactors is required. }\end{array}$ & $\begin{array}{l}\text { (Asha and } \\
\text { Vidyavathi, } \\
\text { 2010), } \\
\text { (Gasser et } \\
\text { al., 1999) }\end{array}$ \\
\hline
\end{tabular}




\begin{tabular}{|c|c|c|c|c|}
\hline $\begin{array}{l}\text { expression of } \\
\text { human enzymes } \\
\text { in a cell line. }\end{array}$ & $\begin{array}{l}\text { elucidation and } \\
\text { pharmacological } \\
\text { characterization, to } \\
\text { assess the potential } \\
\text { drug-drug } \\
\text { interactions at the } \\
\text { metabolic level and } \\
\text { to detect reactive } \\
\text { products. They are } \\
\text { easy to maintain in } \\
\text { culture and allow the } \\
\text { possibility of } \\
\text { studying the } \\
\text { enzymatic reactions } \\
\text { of a single enzyme } \\
\text { enabling even to } \\
\text { detect residual } \\
\text { metabolites. }\end{array}$ & & & \\
\hline $\begin{array}{l}\text { Isolated } \\
\text { hepatocytes } \\
\text { Primary cells are } \\
\text { isolated from } \\
\text { fresh liver tissue } \\
\text { and can be used } \\
\text { immediately after } \\
\text { isolation or in } \\
\text { culture for long- } \\
\text { term studies. }\end{array}$ & $\begin{array}{l}\text { Are used to study } \\
\text { both phase I and } \\
\text { phase II reactions } \\
\text { since they contain } \\
\text { both the enzymes } \\
\text { and cofactors that a } \\
\text { drug is likely to find } \\
\text { in vivo in the liver. } \\
\text { Moreover, } \\
\text { cryopreserved } \\
\text { hepatocytes are } \\
\text { available } \\
\text { commercially. }\end{array}$ & $\begin{array}{l}\text { Cultured or cryopreserved cells } \\
\text { lose the CYP activity rapidly with } \\
\text { increasing incubation time after } \\
\text { seeding. Also, hepatocytes cannot } \\
\text { be frozen and thawed or be } \\
\text { prepared from previously frozen } \\
\text { liver. As mentioned, cultured } \\
\text { hepatocytes undergo gradually a } \\
\text { loss of liver-specific functions } \\
\text { with time, namely a decrease in } \\
\text { CYP expression while } \\
\text { cryopreserved hepatocytes retain } \\
\text { the activity of most of phase I and } \\
\text { phase II enzymes. There may be } \\
\text { inter-individual variations } \\
\text { between batches, which can be } \\
\text { overcome by using mixtures of } \\
\text { hepatocytes from multiple donors. }\end{array}$ & $\begin{array}{l}\text { Usually no addition } \\
\text { of enzymatic } \\
\text { cofactors is required. }\end{array}$ & $\begin{array}{l}\text { (Gunaratna, } \\
\text { 2000), (Asha } \\
\text { and } \\
\text { Vidyavathi, } \\
\text { 2010), (Jia } \\
\text { and Liu, } \\
\text { 2007) }\end{array}$ \\
\hline $\begin{array}{l}\text { Tissue slices } \\
\text { The incubation of } \\
\text { liver slices in } \\
\text { nutrient-rich } \\
\text { media. }\end{array}$ & $\begin{array}{l}\text { Liver slices can be } \\
\text { easily and rapidly } \\
\text { produced. } \\
\text { addition, liver slices } \\
\text { are not exposed to } \\
\text { proteolytic enzymes, } \\
\text { which can destroy } \\
\text { important membrane } \\
\text { receptors of the cell. } \\
\text { They contain all the } \\
\text { drug metabolizing }\end{array}$ & $\begin{array}{l}\text { Inadequate penetration of the } \\
\text { perfusion medium can occur; } \\
\text { liver slices cannot be } \\
\text { cryopreserved and they have to be } \\
\text { immediately used since they have } \\
\text { a limited useful experimental } \\
\text { period. }\end{array}$ & $\begin{array}{l}\text { Usually no addition } \\
\text { of } \\
\text { cofactors is required. }\end{array}$ & $\begin{array}{l}\text { (Gunaratna, } \\
\text { 2000), (Asha } \\
\text { and } \\
\text { Vidyavathi, } \\
\text { 2010) }\end{array}$ \\
\hline
\end{tabular}




\begin{tabular}{|c|c|c|c|c|}
\hline & $\begin{array}{l}\text { enzymes with all the } \\
\text { cofactors present at } \\
\text { relevant } \\
\text { concentrations. }\end{array}$ & & & \\
\hline $\begin{array}{l}\text { Isolated perfused } \\
\text { liver } \\
\text { Perfused animal } \\
\text { liver is useful in } \\
\text { cases where bile } \\
\text { secretion is } \\
\text { important or } \\
\text { when validation } \\
\text { of other in vitro } \\
\text { methods } \\
\text { required. }\end{array}$ & $\begin{array}{l}\text { Animal liver is used } \\
\text { for } \\
\text { biotransformation } \\
\text { studies. This is } \\
\text { regarded as correct } \\
\text { model for human } \\
\text { drug } \\
\text { biotransformation. }\end{array}$ & $\begin{array}{l}\text { Poor reproducibility, labour- } \\
\text { intensive, and its functional } \\
\text { integrity is limited to } 3 \mathrm{~h} \text {. }\end{array}$ & $\begin{array}{l}\text { The choice of the } \\
\text { animal species } \\
\text { requires some } \\
\text { previous knowledge } \\
\text { whether that animal } \\
\text { species shares } \\
\text { metabolic } \\
\text { resemblance to } \\
\text { human in that } \\
\text { particular drug. }\end{array}$ & $\begin{array}{l}\text { (Asha and } \\
\text { Vidyavathi, } \\
\text { 2010) }\end{array}$ \\
\hline
\end{tabular}

CYP - cytochrome P450; GST - glutathione S-transferases; NADPH - nicotinamide adenine dinucleotide phosphate; NAT - N-acetyl transferases; ST - sulfotransferases; UGTs - glucuronosyl transferases. 
Table 2. Synthesis of anticancer drug conventional metabolites.

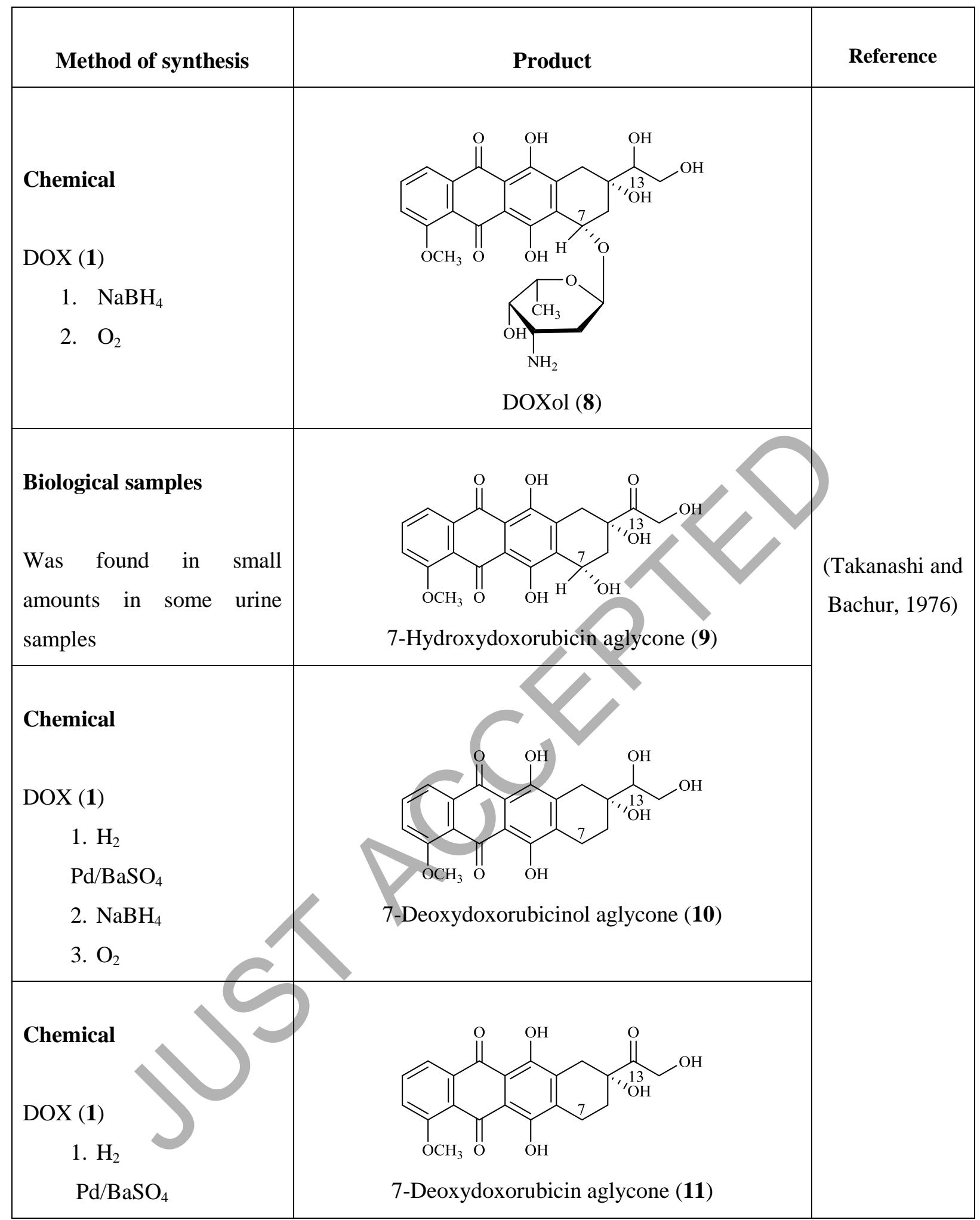




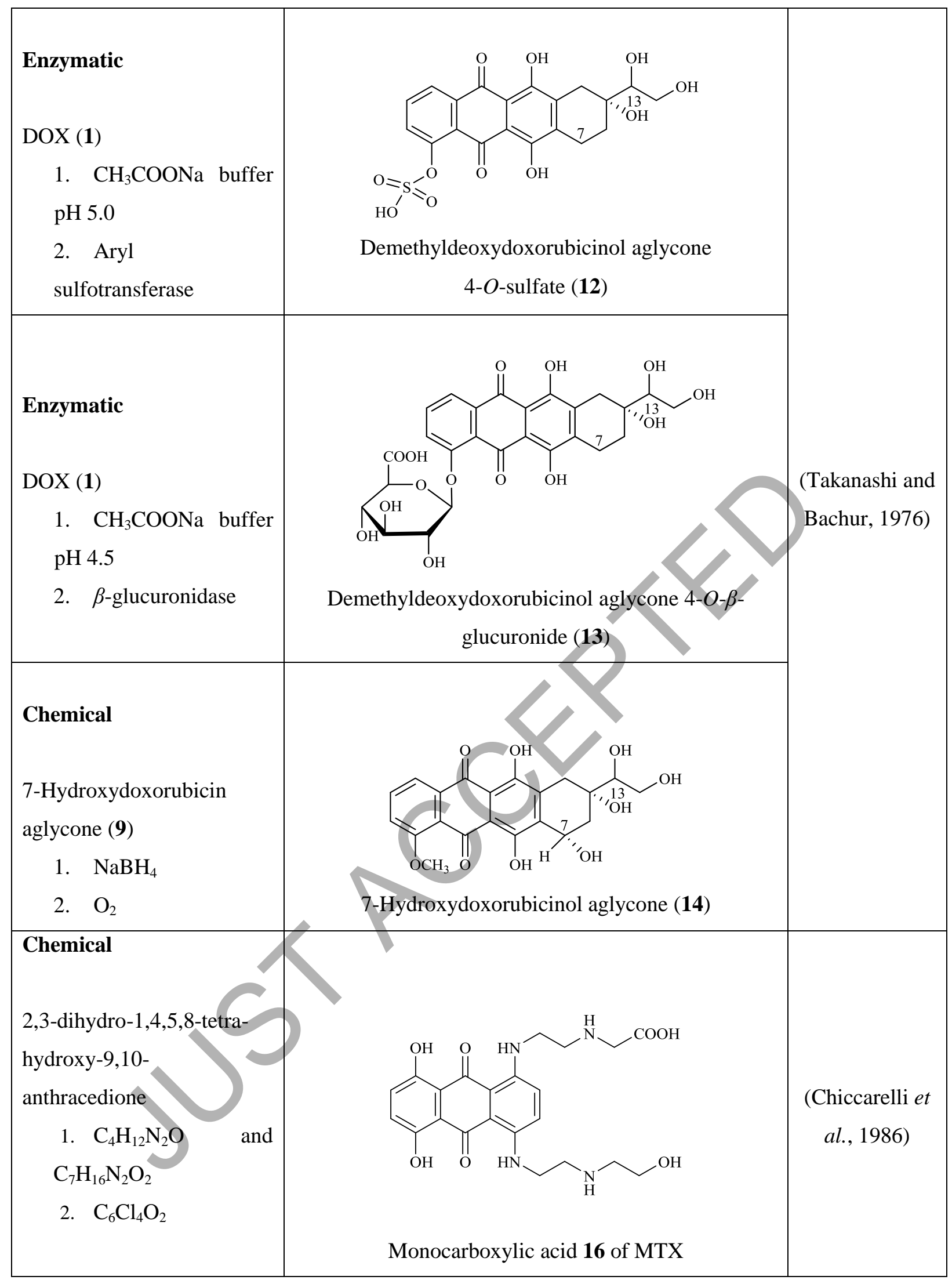




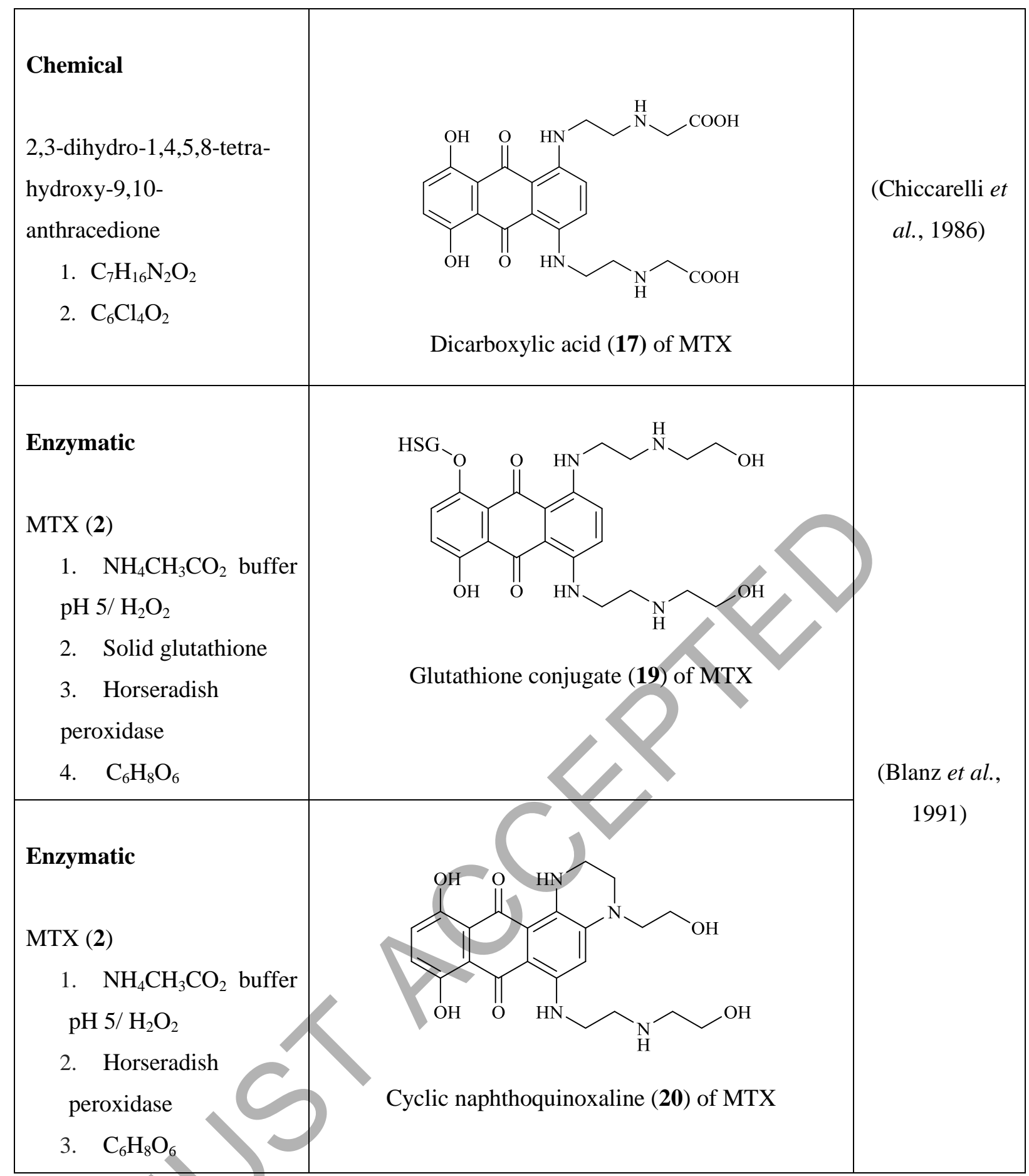




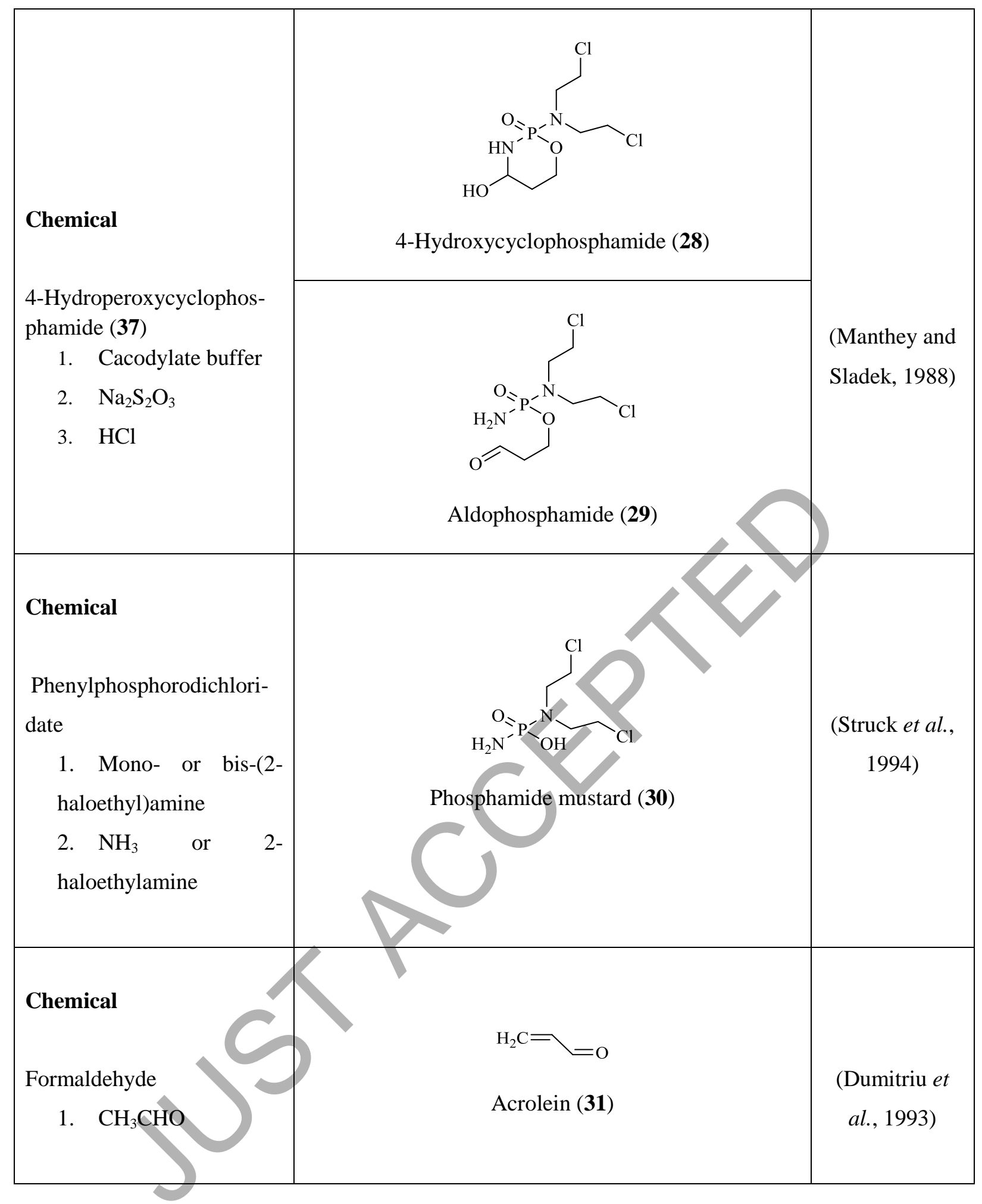




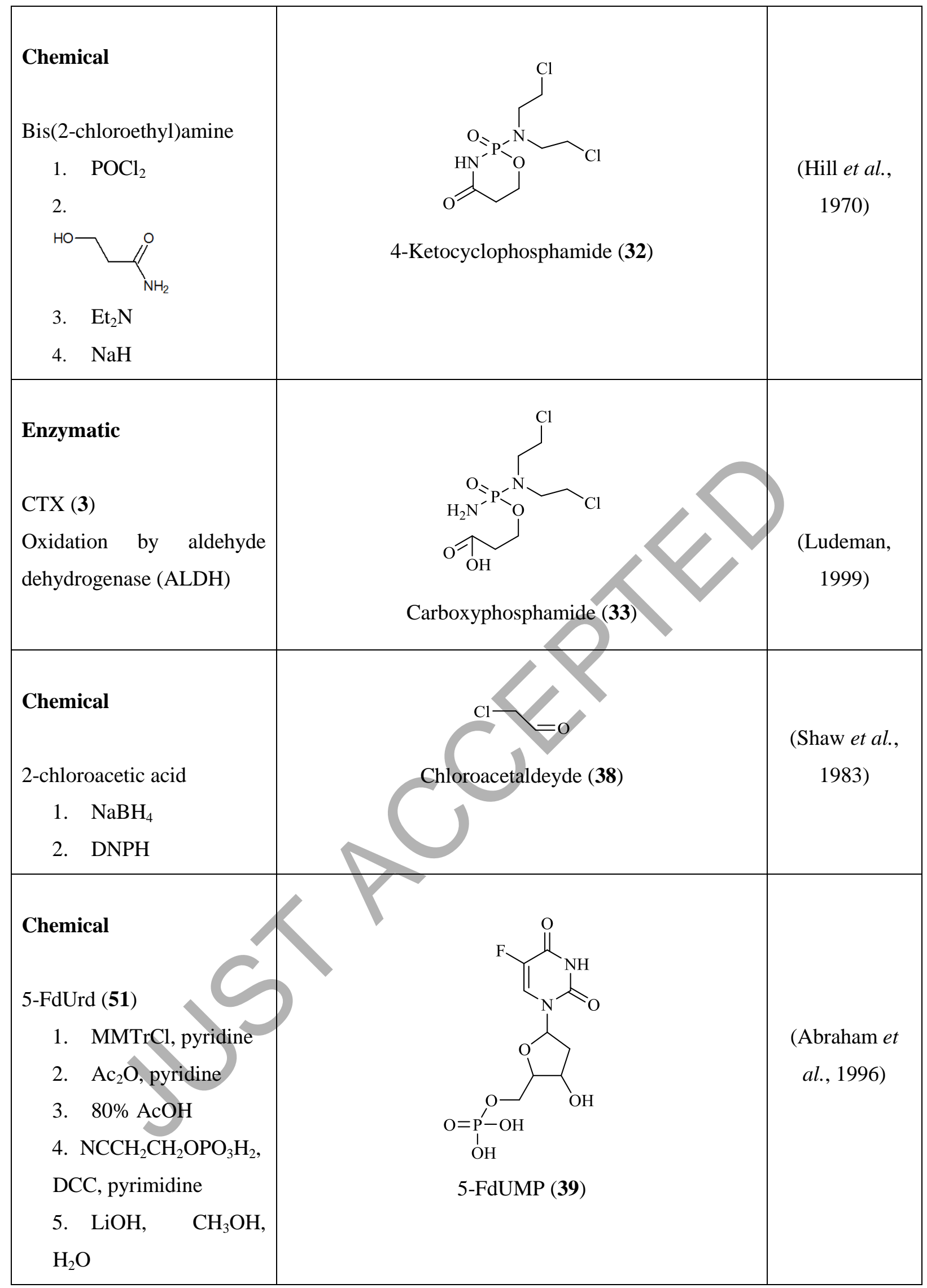




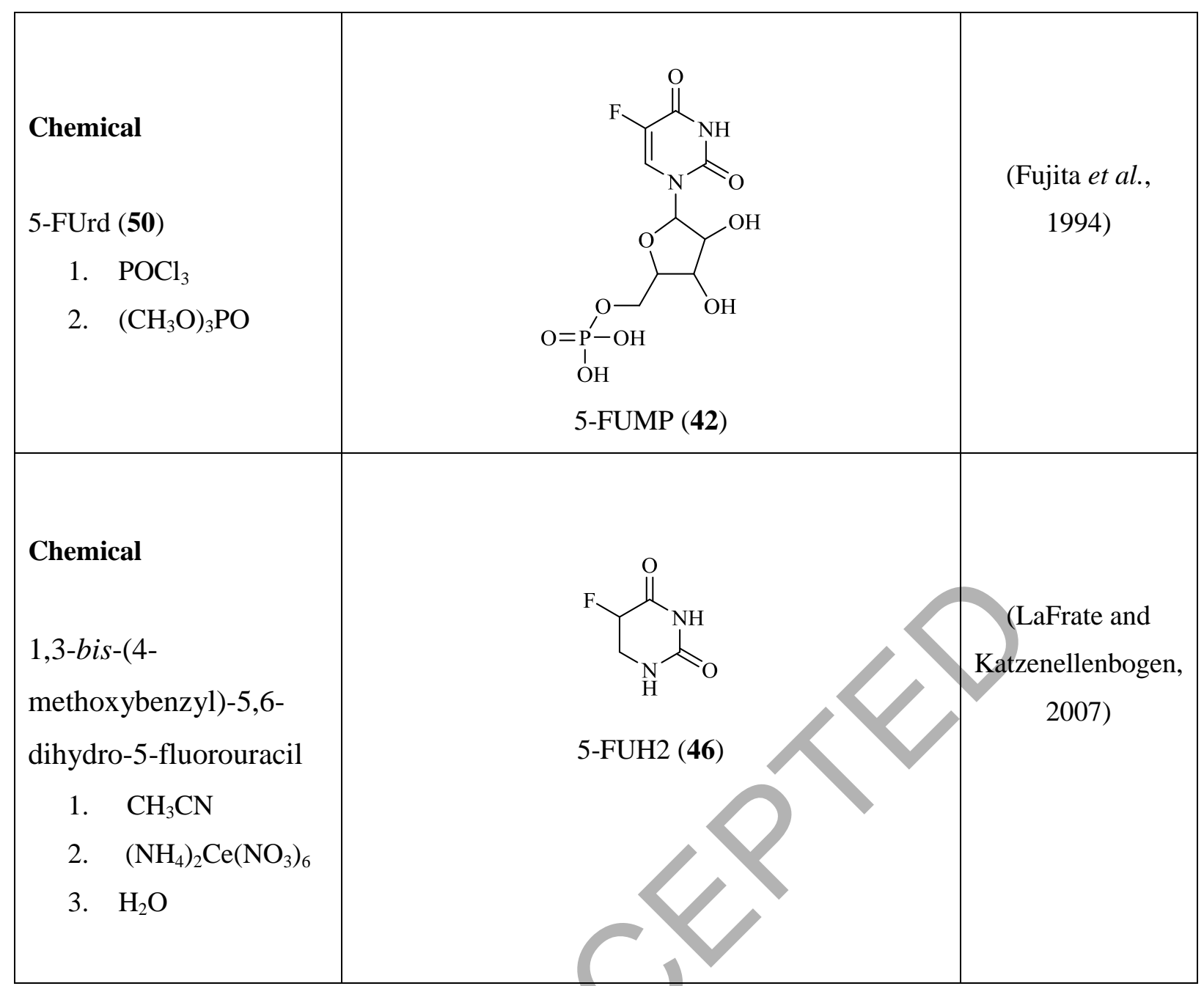

$\mathrm{ALDH}$ - aldehyde dehydrogenase; $\mathrm{Ac}_{2} \mathrm{O}$ - acetic anhydride; $\mathrm{AcOH}$ - acetic acid; $\mathrm{BaSO}_{4}$ - barium sulfate; $\mathrm{C}_{6} \mathrm{H}_{8} \mathrm{O}_{6}$ - ascorbic acid; $\mathrm{CH}_{3} \mathrm{CHO}$ - acetaldehyde; $\mathrm{C}_{6} \mathrm{Cl}_{4} \mathrm{O}_{2}$ - chloranil; $\mathrm{C}_{4} \mathrm{H}_{12} \mathrm{~N}_{2} \mathrm{O}$ - 2-(2Aminoethyl-amino)ethanol; $\quad \mathrm{C}_{7} \mathrm{H}_{16} \mathrm{~N}_{2} \mathrm{O}_{2}$ tert-butyl-2-aminoethyl-aminoacetate; $\mathrm{CH}_{3} \mathrm{COONa}$ Sodium acetate; $\mathrm{CH}_{3} \mathrm{OH}$ - methanol; $\left(\mathrm{CH}_{3} \mathrm{O}\right)_{3} \mathrm{PO}$ - trimethyl phosphate; $\mathrm{CH}_{3} \mathrm{CN}$ - acetonitrile; DCC - N,N'-dicyclohexylcarbodiimide; DNPH - 2,4-dinitrophenylhydrazine; $\mathrm{Et}_{2} \mathrm{~N}$ - diethylamine; $\mathrm{H}_{2}-$ hydrogen; $\mathrm{NH}_{3}$ - ammonia; $\mathrm{HCl}$ - hydrochloric acid; $\mathrm{LiOH}$ - lithium hydroxide; $\mathrm{MMTrCl}-4$ methoxytriphenylchloromethane; $\mathrm{NaBH}_{4}$ - sodium borohydride; $\mathrm{NaH}$ - sodium hydride; $\mathrm{Na}_{2} \mathrm{~S}_{2} \mathrm{O}_{3}$ sodium thiosulfate; $\mathrm{NH}_{4} \mathrm{CH}_{3} \mathrm{CO}_{2}$ - ammonium acetate; $\left(\mathrm{NH}_{4}\right)_{2} \mathrm{Ce}\left(\mathrm{NO}_{3}\right)_{6}$ - ammonium cerium (IV) nitrate; $\mathrm{O}_{2}$ - oxygen; $\mathrm{Pd}$ - palladium: $\mathrm{POCl}_{2}$ - phenylphosphonic dichloride; $\mathrm{POCl}_{3}$ - phosphoryl chloride. 